\author{
by \\ Dipak Patel \\ Bachelor of Engineering, Gujarat University, 1998 \\ A project \\ presented to Ryerson University \\ in partial fulfillment of the \\ requirements for the degree of \\ Master of Engineering \\ in the program of \\ Electrical and Computer Engineering \\ Toronto, Ontario, Canada, 2017 \\ C) Dipak Patel, 2017
}




\section{Author's decla ration}

I hereby declare that I am the sole author of this project.

I authorize Ryerson University to lend this project report to other institutions or individuals for the purpose of Scholarly research.

I further authorize Ryerson University to reproduce this project report by photocopying or by other means, in total or in part, at the request of other institutions or individuals for the purpose of scholarly research.

I understand that my project report may be made electronically available to the public. 
DESIGN AND IMPLEMENTATION OF INTELLIGENT BUILDING /SMART BUILDING

Master of Engineering, 2017

Dipak Patel

Electrical and Computer Engineering

Ryerson University

\begin{abstract}
The intelligent building is supposed to provide the environment and means for an optimal utilization of the building, according to its designation. This extended function of a building can be achieved only by means of an extensive use of building service systems, such as HVAC, electric power, communication, safety and security, transportation, sanitation, etc. Building intelligence is not related to the sophistication of service systems in a building, but rather to the integration among the various service systems, and between the systems and the building structure. Systems' integration can be accomplished through teamwork planning of the building, starting at the initial design stages of the building. This paper examines some existing buildings claimed to be "intelligent", according to their level of systems' integration. Intelligent buildings respond to the needs of occupants and society, promoting the well-being of those living and working in them and providing value through increasing staff productivity and reducing operational costs. Intelligent Buildings considers cultural changes affecting the way people live and work, the importance of an integrated approach to design and management and the benefits technological developments can bring in developing sustainable buildings that meet users' needs.
\end{abstract}




\section{Acknowledge ments}

This project could not have been completed without the help of many extraordinary individuals and organizations.

I want to express my gratitude to Dr. Vadim L. Guerkov, my graduate supervisor and

mentor, for your dedicated support and guidance throughout my academic career at Ryerson thus far, and for giving me the opportunity to work on a topic so close to my heart. 


\section{Table of Contents}

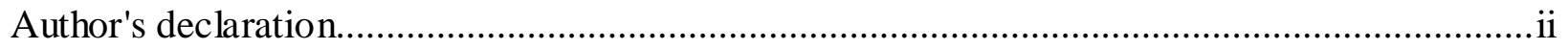

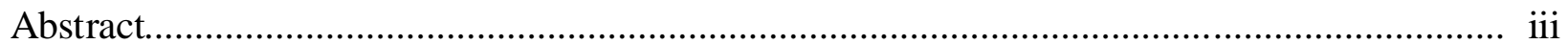

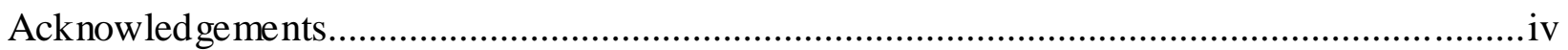

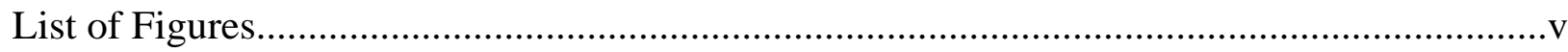

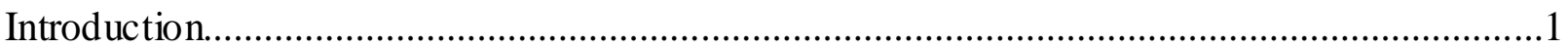

Motivation and Objectives and Contribution................................................................

1. His tory and Technological Evolution of Intelligent Building..............................................5

1.1Typical Building Vs Integrated Building................................................................. 7

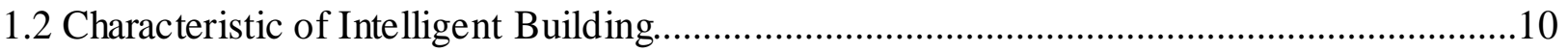

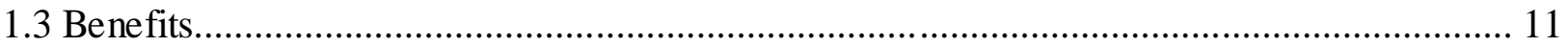

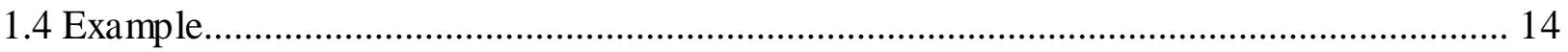

2.Practical Design for Building Automation................................................................. 15

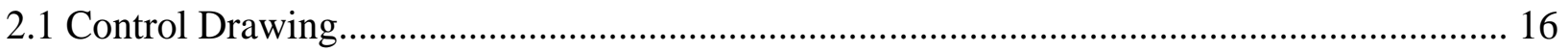

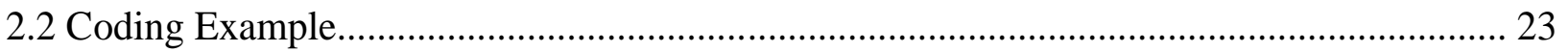

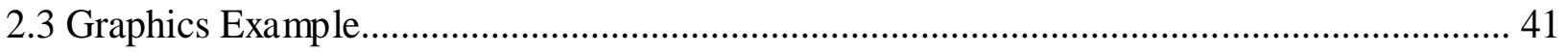

2.4Live presentation of Intelligent Building Project .................................................. 45

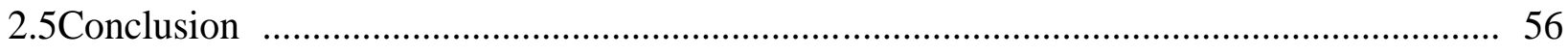

Appendix I Wiring Diagram with Layout............................................................... 52

Appendix II Technical Documentation on Hardware Selection and Its Specification............58

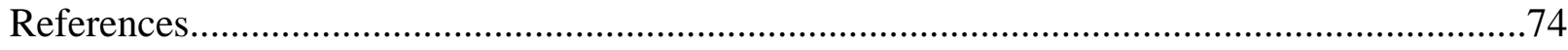




\section{List of Figures}

Figure $\quad$ Page

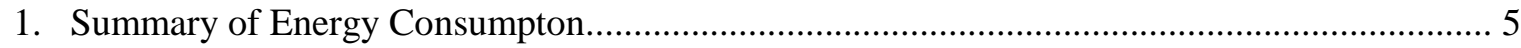

2. Technological Evolution of Building Automation System................................................... 6

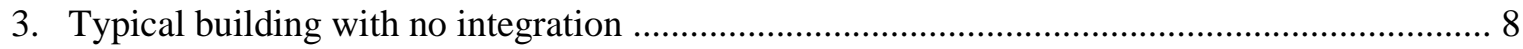

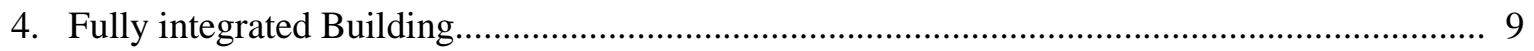

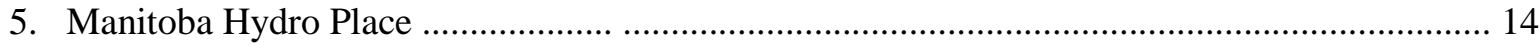

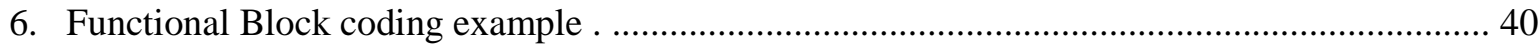

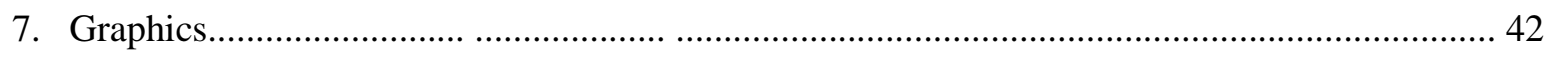

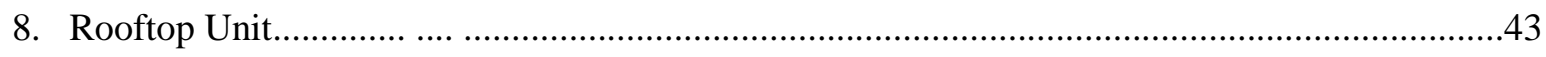

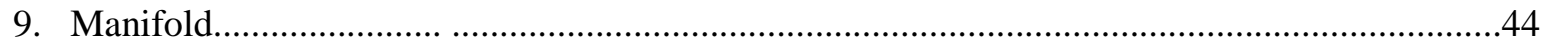

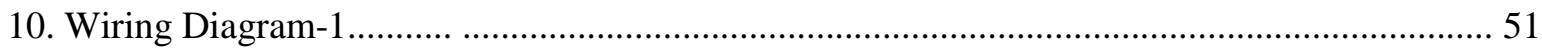

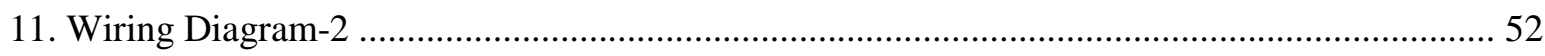

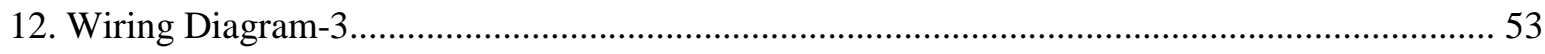

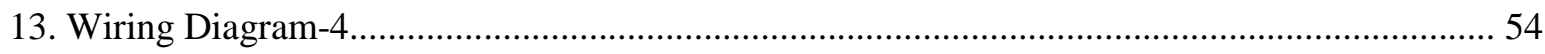

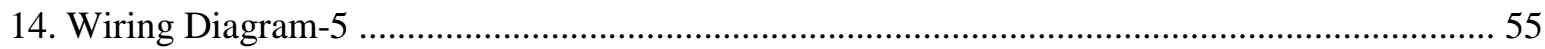




\section{Introduction}

Intelligent buildings apply technologies to improve the building environment and functionality for occupants/tenants while controlling costs, improving security, comfort and accessibility.

Intelligent buildings respond to the needs of occupants and society, promoting the well-being of those living and working in them and providing value through increasing staff productivity and reducing operational costs. Written by authors from practice and academia, Intelligent Buildings considers cultural changes affecting the way people live and work, the importance of an integrated approach to design and management and the benefits technological developments can bring in developing sustainable buildings that meet users' needs. (17)

As building owners, facility managers and tenants fully understand the impact modern technology will have on their business operations now and into the future, they will also realize the benefits of network integration of these various systems, devices and applications within their buildings or campuses. Through this network approach, they are able to share the value generated by the knowledge worker to be more efficient and productive, and also information generated by existing and future 'Intelligent Building' systems, devices and applications to contain operational costs and maximize ROI(Return on Investment) .(5) Rapid advances in technology and the emergence of enterprise distributed computing platforms created the need to integrate IT systems. This integration of applications required a single, low voltage cable distribution infrastructure. The rapid deployment of integrated voice and data systems based on digital transmission and IP based protocols, set the stage for the next step in the technology evolution process. The advent of integrated voice and data digital transmission techniques, coupled with ever increasing data transmission speeds and customer demand for additional 
information, led to the proliferation of the Local Area Network (LAN) industry. LAN systems and networked devices provided an economical method to connect and distribute information within organizational work groups. The evolution of the integrated IT systems and markets has dramatically effected and guided the development of structured cabling systems. A "total end-toend connectivity solution" offers customers low voltage connectivity that is critically important as the bandwidth, data transfer speeds and mission critical information from various devices attached to the network is transmitted within a building or campus. Information technology in buildings does not refer only to PCs and telephones, but also Building Automation Systems (BAS), such as security ( surveillance and access control), Heating Ventilation Air Conditioning (HVAC), and Fire/Life/Safety (FLS) as they transition from electro/ mechanical and pneumatic technology to microprocessor based software driven systems. Leading building automation providers already have state of the art computer based software controlled systems for building management. Most manufacturers of major building automation systems offer computer based, software driven systems, based on distributed processing architectures. These systems are required to interface with other building automation systems and devices, and also to interface with voice, data, LAN and video systems located within a building or campus.(14).(16)

Here, based on requirement I contribute my skills to design the building automation project. This consist hardware design, hardware selection, program controller with designed sequence of operation, commissioning controllers for its proper operation and create graphics for end user operation. Details are described in later part of the project. 


\section{Motivation}

A big Hindu Temple is built in 2007 called BAPS. This temple add the community hall and residence for priests in 2012. They have 2 floors concrete structure with various mechanical equipment and under floor heating system implemented for heating and cooling purpose. It was a big challenge to bring all equipment under one umbrella and control using centralized control system. To operate this different equipment locally, there must be an operator work 24/7. Also, these equipment needs to have alarm system to notify the operator in case of failure of any mechanical equipment. Also, there is no system which can analyze the performance of the system and give suggestion to improve the system. Also, there is no graphics interface to view the detail performance of the system. So, in nutshell, there are quite a few challenges to control these mechanical equipment.

Challenges :

- Control multiple mechanical equipment using centralized control.

- Required alarm system to notify the fault in the system.

- Required performance analysis using trends to improve the system.

- Required graphics interface to watch the system with real time data and control over it

- Required design and implementation of automation system to perform the system auto matically.

\section{Objectives and Contribution}

These challenges brought to my attention. To overcome all challenges, the only solution can implemented would be centralized building automation system or intelligent building automation system. 
The new add on building has 7 Rooftop units, 8 manifolds to control the under floor heating system. These building needs control system design which includes detail study of mechanical equipment and needs layout to control it. First of all, I design a sequence of operation for each mechanical equipment. Based upon that, next step is to choose controller and peripheral devices to accommodate the sequence of operation. Once hardware is selected, need wiring diagram to do wiring between controller and equipment. This results in detail wiring diagram for each equipment. To perform centralized control system, there is a need for network between controllers and communicate them to one another over common protocol language.

Once the hardware design is completed, there is a need to run wires for peripheral devices like space sensors, duct sensors, relay wiring to control the equipment and under floor sensors, control valves etc. All field wires comes back to controller which controls the equipment using control algorithm.

Contribution :

- Design and implementation of building automation system

- Hardware selection based upon the application of the unit

- Design the sequence of operation, control algorithm, control drawing- wiring diagram

- Hardware installation, programming controller and commissioning

- Verify sequence of operation and functional test of the system

- Graphics design and implementation to monitor and control the system locally and remotely

Below are the details about control drawing which explains the entire control system design. 


\section{History and Technological Evolution of Intelligent Building}

As the Figure- 1 below, Buildings uses $39 \%$ of the total energy consumption as highest of all energy consumption. This building portion is total of residential and commercial building consumption. So, there is huge opportunities of making this building intelligent to control it better and interact it with end users.(1).(3)

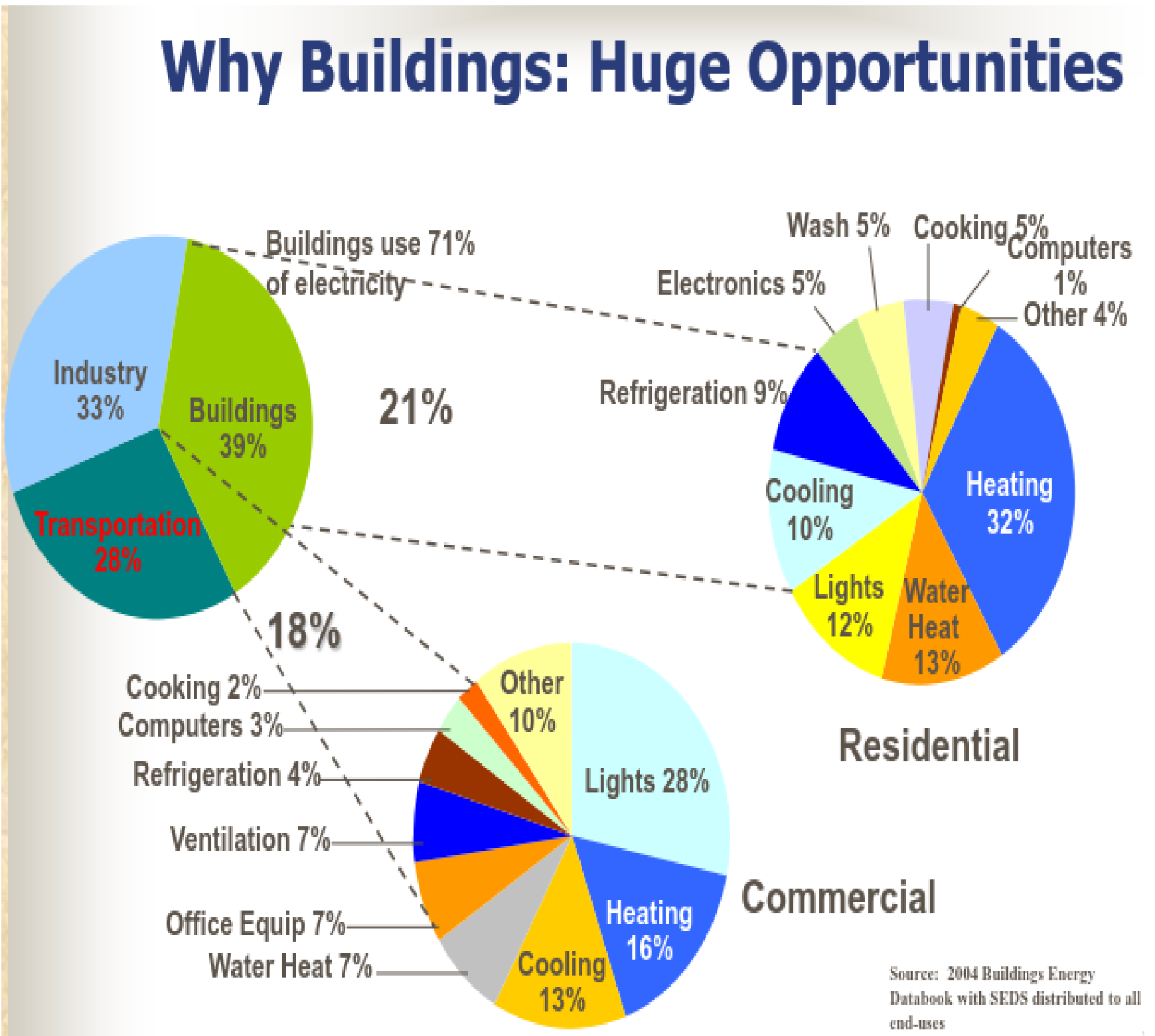

Figure -1. Summary of Energy Consumption 


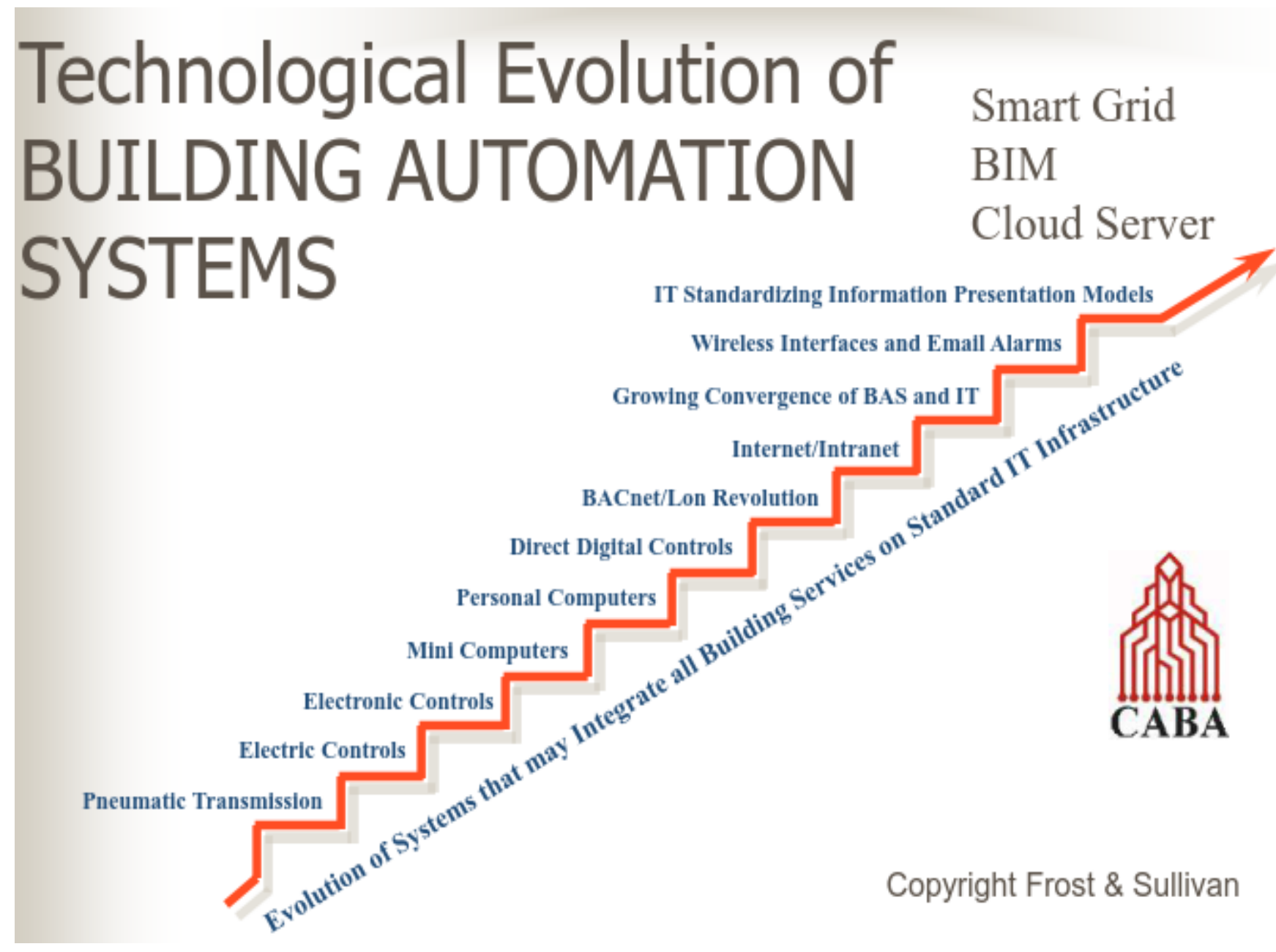

Figure - 2 Technological Evolution of Building Automation Systems

In early 60s', the Pneumatic Controls control the major HVAC system in the buildings. It uses large air compressors to compress the air to control the major component of the HVAC systems. It was expensive and local control over the equipment. Later on, Electrical controls took place to control the HVAC system. In 70s', the Electronics controls change the electrical controls into Electronics. In 80s', BACnet and LON protocol made big revolution in the ind ustry. This protocol unified the platform to bring different devices together first time. Later on, internet with IT concepts made the building automation control remote and wireless. Now, IT becomes the standard for building automation with industry standard protocols. (3)(7). 


\section{$\underline{\text { 1.1. Typical building Vs Integrated Buildings }}$}

As we seen in the Figure -3, typical building with no integration has five different segments to control the entire building. All five segments which is Fire Management System, Door Access and Intrusion Detection, Lighting Control System, HVAC Control System and Main Electrical/Power distribution system are controlled individually. In this system, there is no link between two systems. The building control locally using computer as an interface. There is no interaction with Humans as system operates individually and locally. In case of emergency, one system can't pass the signal to the other system to react. No integration is involved to interact the 
system to one another.

\section{Typical Building Approach to Automation}

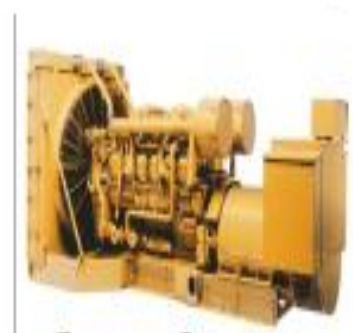

Emergency Generator
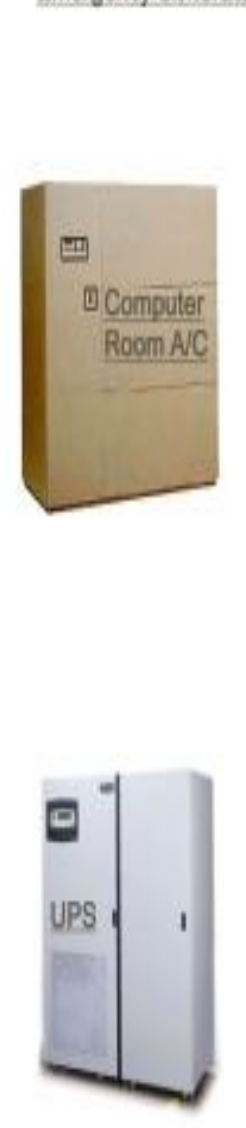

No Integration!

5 User Interface Workstations!

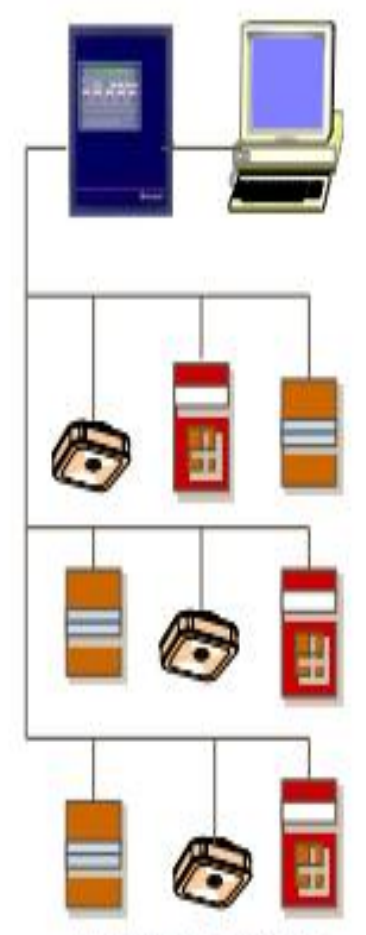

Fire Management System

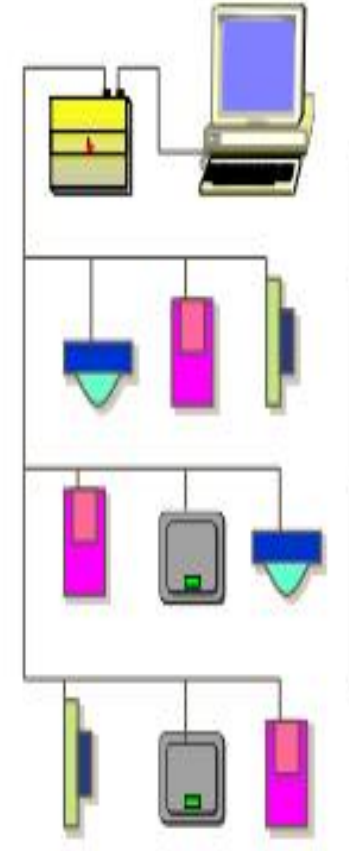

Door Access Control \& Intrusion Detection

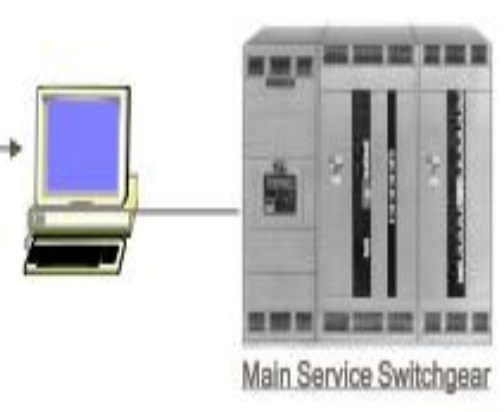

Figure-3. Typical Building with No integration 


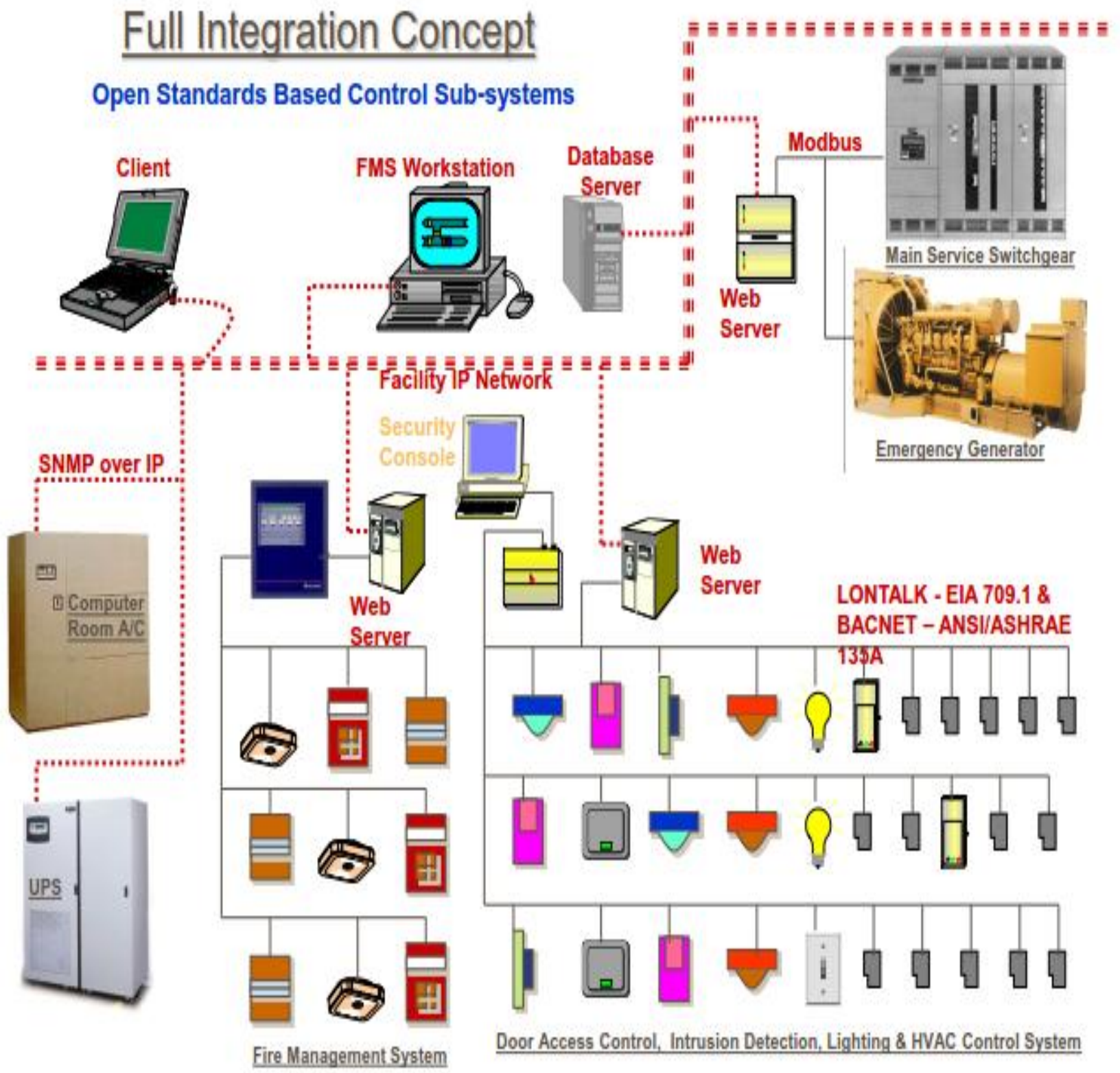

\section{Figure 4 . fully integrated Building}

As shown in figure-4, all systems are connected on a common platform to interact with each other. Finally, entire system has one interface to control, monitor and feedback. The end user 
whether occupant or operator can interact with the system. End user interact with the system and the system respond to the end user's request.(9).(10).(11) 


\subsection{Characteristic Intelligent Building}

- Designed around Users : Intelligent buildings are designed keeping end user in mind. The end user is play an important role in operating the building. The Occupant of the building input the value to get comfort in the building. Human interaction is needed to control the building.

- Improves Security : Secure access and CCTV camera are the main component of the intelligent building for security. The occupant enters the building through secure designated access. The building track the occupant and provide security through its various systems.(15).

- Enhances Comfort : One of the best feature of intelligent building is to provide comfort to the end user. The end user has capability to change the comfort levelby changing the set point. This set point is taken by building automation control system to adjust heating/cooling to provide comfort.(17)

- Provides Energy Savings : This another important feature of the intelligent building to save energy. Building receives data from its sensors all the time. This data get processed by system all the time and take decision to save energy without compromising the comfort of the occupant.(21)

- Enterprise-wide Energy Monitoring : Intelligent building has capability to integrate all the system of the building and bring it to common work station. This work station can access locally as well as remotely. It also has access to all data remotely and monitor in real time. (19). 
- Everything Communicates : Any intelligent building has HVAC system, Fire system, CCTV system, Energy monitoring system, Security access control system as main components. These all system can interact with each other. Also, they can send and receive command from other systems to re act to the situation. So everything communicates to one another. (17)

- Local Command and Control : All building control systems are connected to common platform and unified the data to a single point control. This single point control is the local work station.(5)

- Remote Command and Control : Building control system is connected to the web server. This web server has capability to access, monitor and control the system remotely.(22)

- The right data to the right people : This system has different layers of access and control capabilities. Different user has different access level to control the system at different level. The system has admin level, programmer level, graphics level, maintenance manger level, engineer level, operator level and guest user level. All this category has different capabilities (22)(16) 


\subsection{Benefits}

- Energy \& Operational Savings

- Reduced Equipment Downtime

- Reduced Risks

- Better Customer Experience

- Higher Profits

\section{Benefits of Intelligent Building over Conventional Building}

\section{Conventional Building}

- Manual control for mechanical equipment

- No fault diagnosis

- Alarm can't send remotely to outside of the building

- No graphics to view the real time system

- No integration of all equipment. Need to control individually

- No trends to view and enhance the performance

- No data storage for performance analysis

\section{Intelligent Building}

- Centralized control over mechanical equipment

- Fault diagnosis using real time data and archive data

- Generate and transmit alarm remotely to outside world

- Graphics or HMI to view real time system

- Integration of all equipment to control better.

- Trends to view and enhance the performance 


\subsection{Example}

\section{Manitoba Hydro Place}
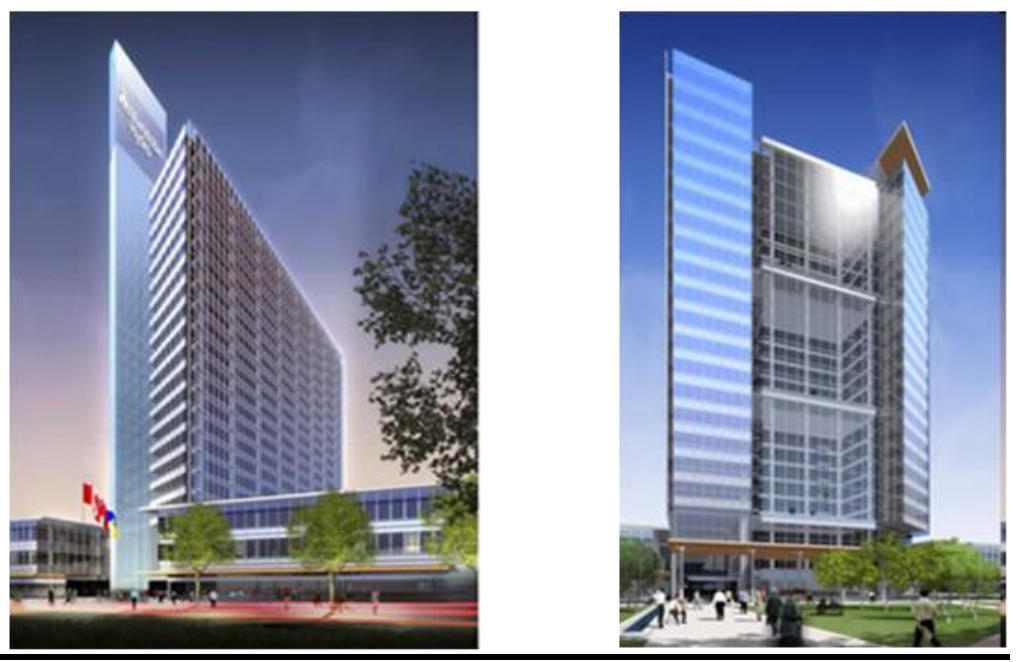

Figure - 5 Manitoba Hydro Place

- LEED Platinum

- Exceeded the original target of $60 \%$ energy savings

- $\$ 15$ million in annual operating costs savings

- Integrated natural ventilation, shades, blinds, geothermal, atrium water feature 


\section{$\underline{\text { 2. Practical Design for Building Automation }}$}

As we seen so far the theory of Building automation. Now here we introduce the practical design of one of the building. Below are the control drawings of the building to design. (20)

First of all, I need to work out with wiring layout using mechanical drawings. This is also called rough in estimate. This will include field wiring for peripheral devices and network wiring which is link between controllers. In this project, I use BACnet protocol for building automation.(16)

Once wiring lay out is done for field wiring and control wiring, I generate the control drawing showing details about how mechanical equipment is controlled using field controllers. How many inputs and outputs are used to control the mechanical equipment. Each control points needs to be configured in controller with proper range to control the equipment properly.(22)

Next part, I design the sequence of operation based on specs provided by design engineer. Sequence of operation decide how the mechanical equipment needs to be operated. This sequence of operation is needs to be converted into the program to load into the controller for proper operation.(23)

Now, I choose hardware for controller and peripheral devices. Both needs to be chosen based on operation of the unit. Peripheral devices are the sensors 
giving data from the field and based upon the data, the control sequence work using the residual program.

Once hardware chosen, it needs to be installed with proper installation method. Each controller has its input and output controlling the mechanical equipment. It also need regulated power supply and network connection to communicate with its peer controllers.(20)

After I installed controllers and field devices, program needs to be downloaded into the controller to perform the design sequence of operation. These sequence need to be verified for proper operation of the unit. These commissioning process can be done using graphics or using controllers communicating to the central hub.

I design the Graphics which is the final product of the build ing automation and face of the entire control system. Graphics represents all control inputs and outputs with set points,schedules, trends and keep the log of entire system.(19)(22)

Below, I mention the step by step process of designing. 
$\underline{\text { 2.1 Control Drawing }}$ 
BAPS Swaminarayan Sanstha Shri Swaminarayan Mandir, Toronto

Community Hall HVAC

$+$

Floor Heating

61,Claireville Drive, Toronto, ON,M9W 5Z7, Canada

\begin{tabular}{|c|c|c|}
\hline \multicolumn{3}{|c|}{ DRAWING INDEX } \\
\hline$\#$ & SYSTEM & DESCRIPTION \\
\hline 01 & TITLE & Title Page \& Drawing Index \\
\hline 02 & NETWORK & NETWORK LAYOUT \\
\hline 03 & RTU-1 & ROOF TOP UNIT 1 \\
\hline 03 & RTU1-PANEL & RTU1-CONTROLLER LAYOUT \\
\hline 04 & RTU-2 & ROOF TOP UNIT 2 \\
\hline 05 & RTU2-PANEL & RTU2-CONTROLLER LAYOUT \\
\hline 06 & RTU-3 & ROOF TOP UNIT 3 \\
\hline 07 & RTU3-PANEL & RTU3-CONTROLLER LAYOUT \\
\hline 08 & RTU-4 & ROOF TOP UNIT 4 \\
\hline 09 & RTU4-PANEL & RTU4-CONTROLLER LAYOUT \\
\hline 10 & RTU-5 & ROOF TOP UNIT 5 \\
\hline 11 & RTU5-PANEL & RTU5-CONTROLLER LAYOUT \\
\hline 12 & RTU-6 & ROOF TOP UNIT 6 \\
\hline 13 & RTU6-PANEL & RTU6-CONTROLLER LAYOUT \\
\hline 14 & RTU-7 & ROOF TOP UNIT 7 \\
\hline 15 & RTU7-PANEL & RTU7-CONTROLLER LAYOUT \\
\hline 16 & M1M6-CONTROL & MANIFOLD1-MANIFOLD6-CONTROLLER LAYOUT \\
\hline 17 & M2-CONTROL & MANIFOLD2-CONTROLLER LAYOUT \\
\hline 18 & M3-CONTROL & MANIFOLD3-CONTROLLER LAYOUT \\
\hline 19 & M4M5M7-CONTROL & MANIFOLD4-MANIFOLD5-MANIFOLD7-CONTROLLER LAYOUT \\
\hline
\end{tabular}




\section{Network Layout}

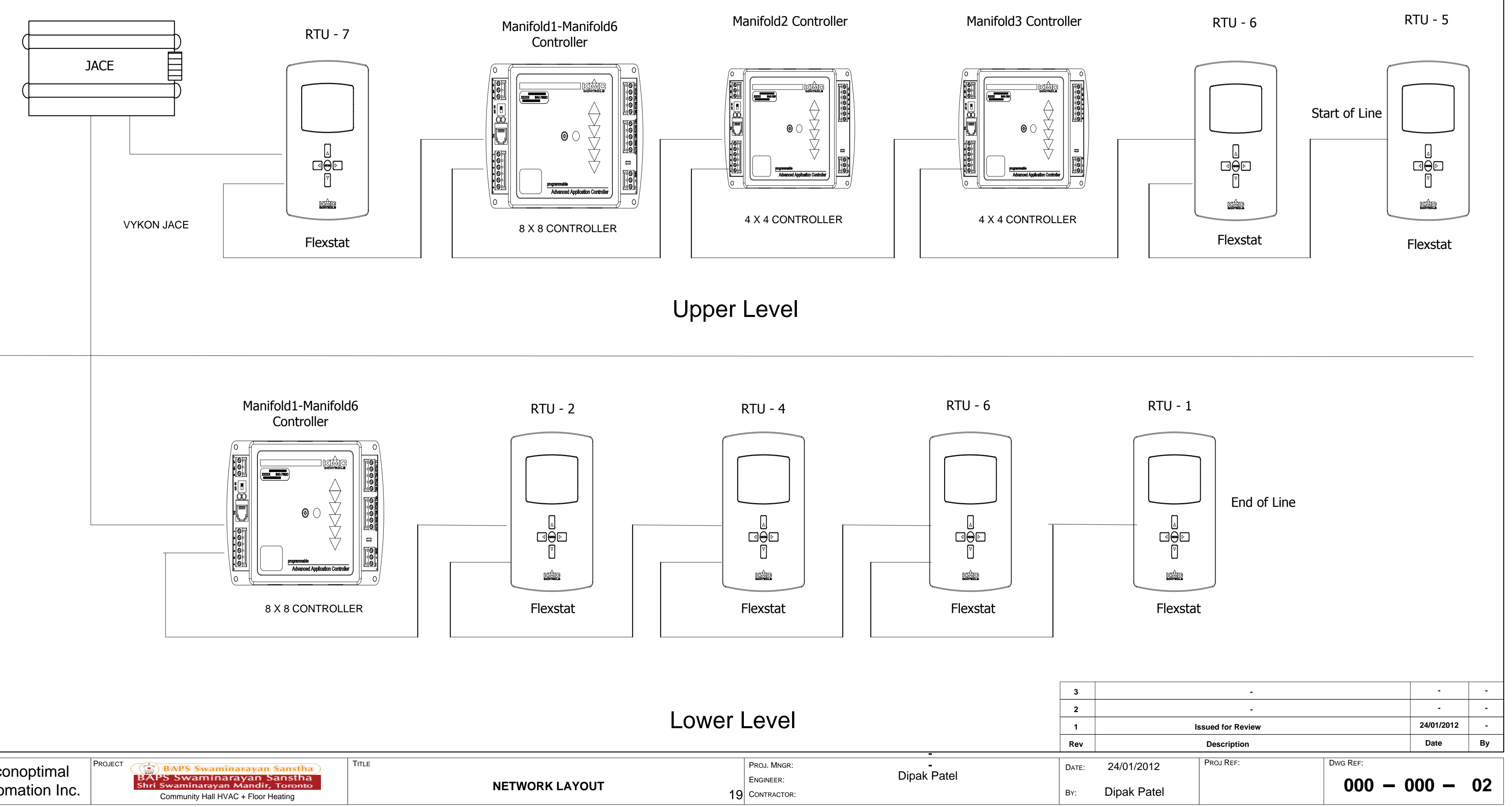


RTU - 1 Feeding NW corner of the Community Hall

Proposed way of controlling the system for optimum efficiency:

System will start up based on the time of day schedule (operator adjustable) or Occupancy.

\section{Heating Mode}

In the occupied mode system will maintain its setpoint, (operator adjustable);

In the winter mode; the system will maintain the setpoint by the heating coil of the HVAC unit.

In the unoccupied mode, the system will be in the night set back mode, (operator adjustable) if the system is below the night setpoint the system will be enabled until it reaches the night set back setpoint.

\section{Cooling Mode:}

In the occupied mode system will maintain its setpoint, (operator adjustable)

In the summer mode: the system will maintain the setpoint by the cooling coil of the HVAC unit.

In the unoccupied mode, the system will be in the night set back mode, (operator adjustable).

Temperature

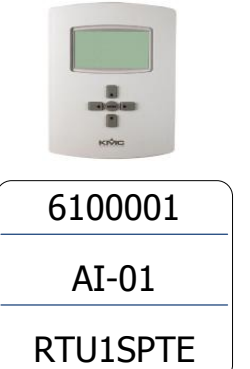

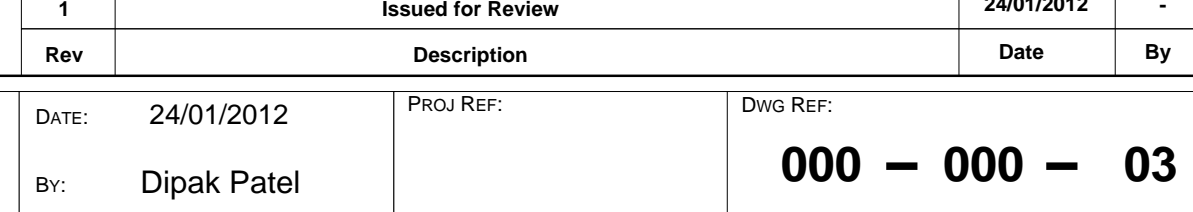




\section{RTU-1 CONTROL PANEL LAYOUT}

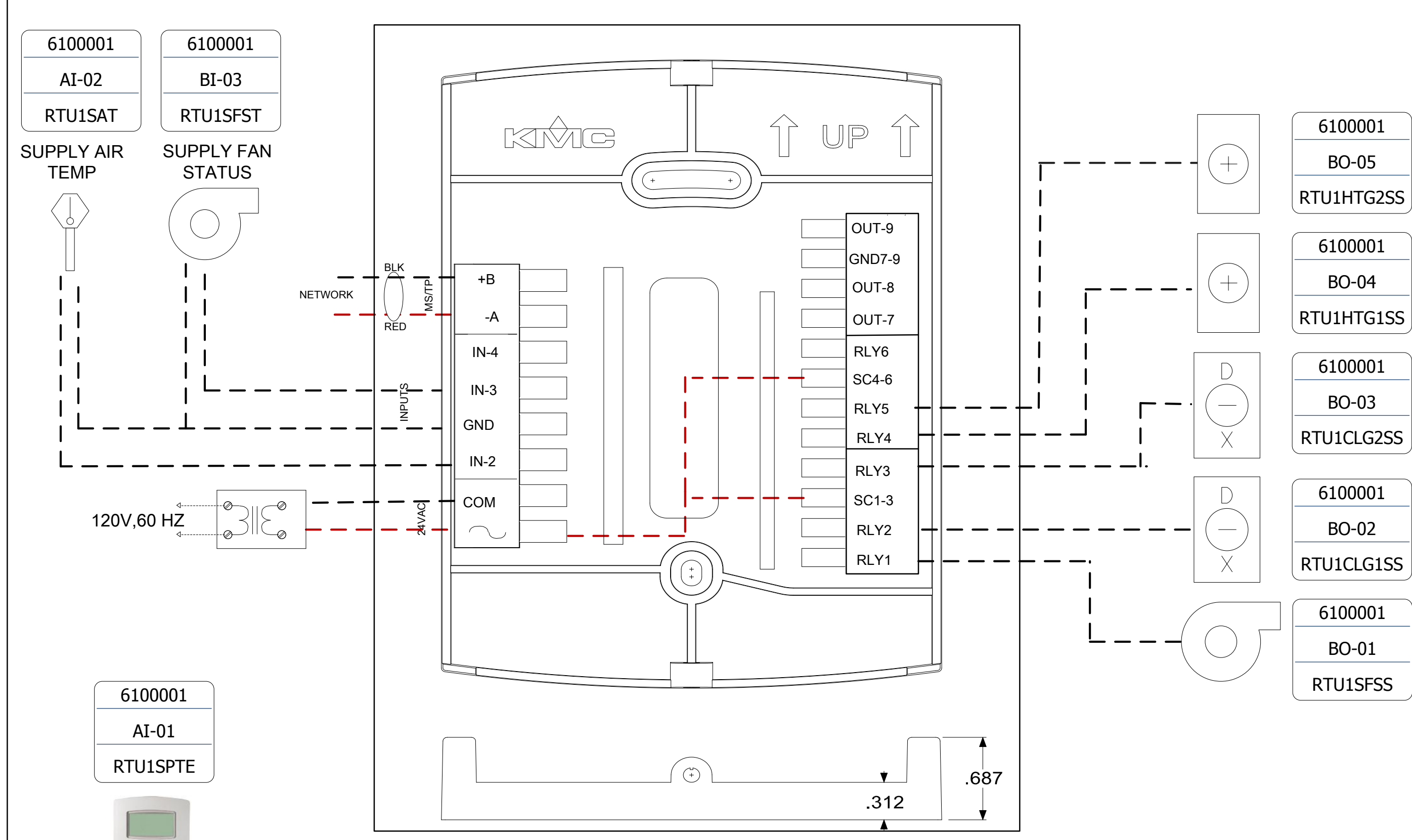

\begin{tabular}{|c|c|c|c|}
\hline DEMCE & PON & INar & Description \\
\hline 6100001 & RTUISPTE & AL-01 & Space Temperature \\
\hline 6100001 & RTUISAT & AI-O2 & Supply Air Temperature \\
\hline 6100001 & RTUISFST & $\mathrm{B} \mathrm{B}-03$ & SupplyFan Status \\
\hline 6100001 & & AI-O4 & \\
\hline 6100001 & RTUISFSS & BO-01 & Supply Fan Start/Stop \\
\hline 6100001 & RTUIAGSS & $\mathrm{BO}-02$ & Cooling1Start/Stop \\
\hline 6100001 & RTUIAGSS & $\mathrm{BO}-03$ & Cooling 2Start/Stop \\
\hline 6100001 & RTUIHTGSS & BO-04 & Heating 1Start/Stop \\
\hline 6100001 & RTUIHTGSSS & BO-05 & Heating 2Start/Stop \\
\hline 6100001 & & AO-06 & \\
\hline 6100001 & & $\mathrm{AO}-07$ & \\
\hline 6100001 & & $\mathrm{AO}-08$ & \\
\hline 6100001 & & $\mathrm{AO}-09$ & \\
\hline
\end{tabular}




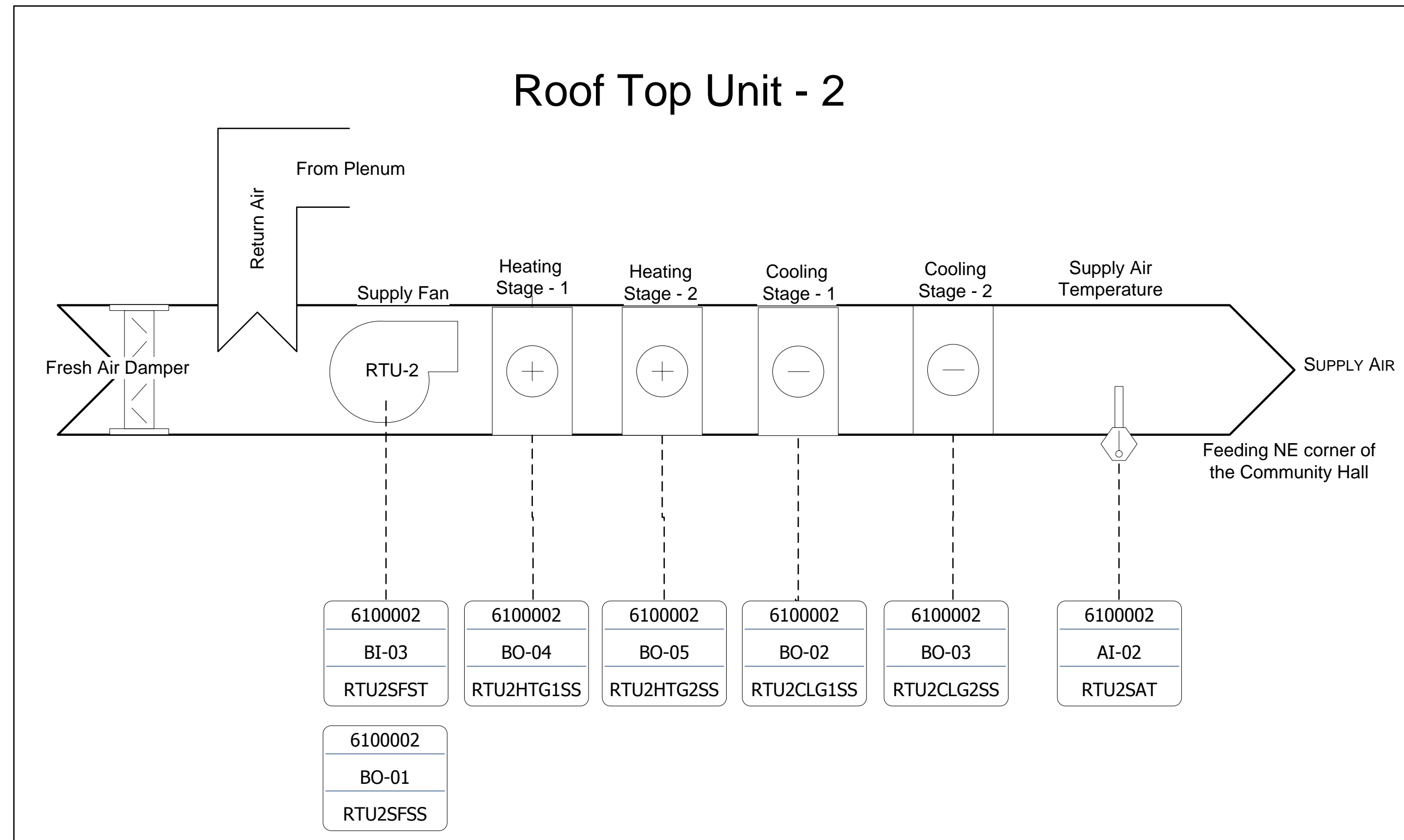

\section{RTU - 2 Feeding NE corner of the Community Hall}

Proposed way of controlling the system for optimum efficiency:

System will start up based on the time of day schedule (operator adjustable) or Occupancy.

Heating Mode

In the occupied mode system will maintain its setpoint, (operator adjustable);

In the winter mode; the system will maintain the setpoint by the heating coil of the HVAC unit.

In the unoccupied mode, the system will be in the night set back mode, (operator adjustable) if the system is below the night setpoint the system will be enabled until it reaches the night set back setpoint.

Cooling Mode:

In the occupied mode system will maintain its setpoint, (operator adjustable)

In the summer mode: the system will maintain the setpoint by the cooling coil of the HVAC unit.

In the unoccupied mode, the system will be in the night set back mode, (operator adjustable).

Temperature

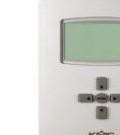

6100002

AI-01

RTU2SPTE

\begin{tabular}{|c|c|c|c|c|c|}
\hline 3 & \multicolumn{3}{|c|}{-} & . & \\
\hline 2 & \multirow{2}{*}{\multicolumn{3}{|c|}{$\frac{\cdot}{\text { Issued for Review }}$}} & - & 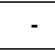 \\
\hline 1 & & & & 240101/2012 & \\
\hline Rev & \multicolumn{3}{|c|}{ Description } & Date & By \\
\hline & 24/01/2012 & PROS REF: & DWG REF: & & \\
\hline & Dipak Patel & & 000 & $00-$ & 05 \\
\hline
\end{tabular}




\section{RTU-2 CONTROL PANEL LAYOUT}

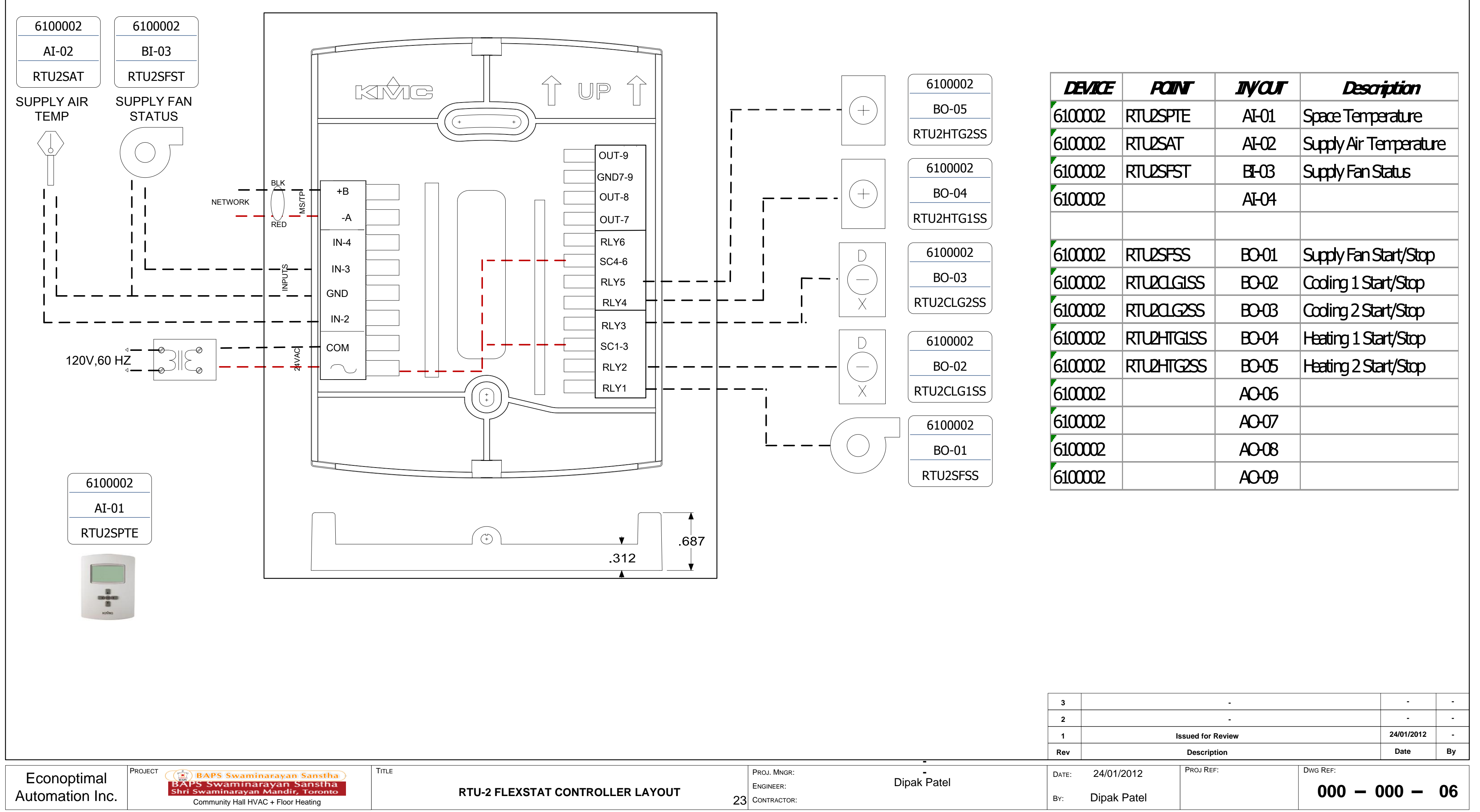




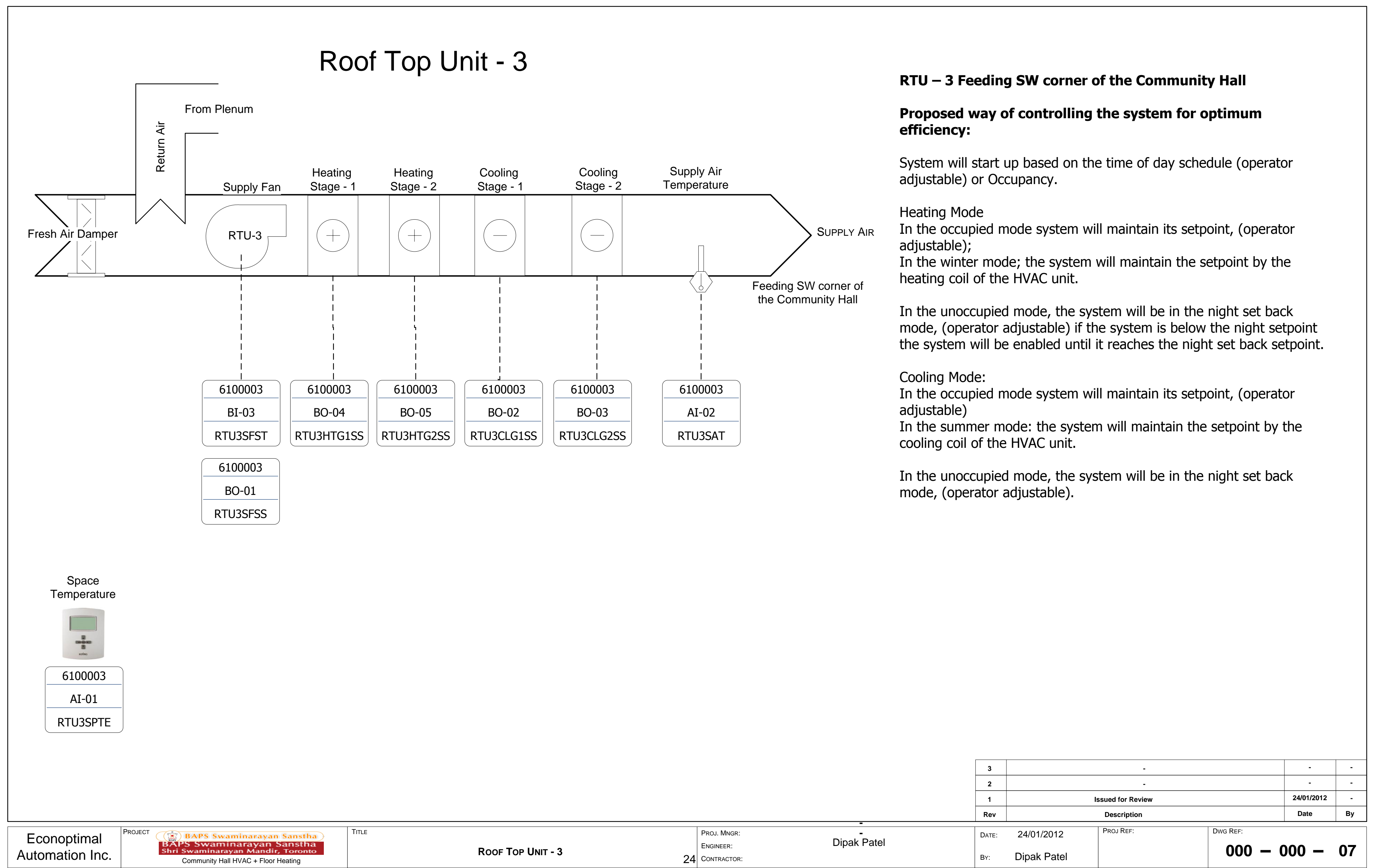




\section{RTU-3 CONTROL PANEL LAYOUT}

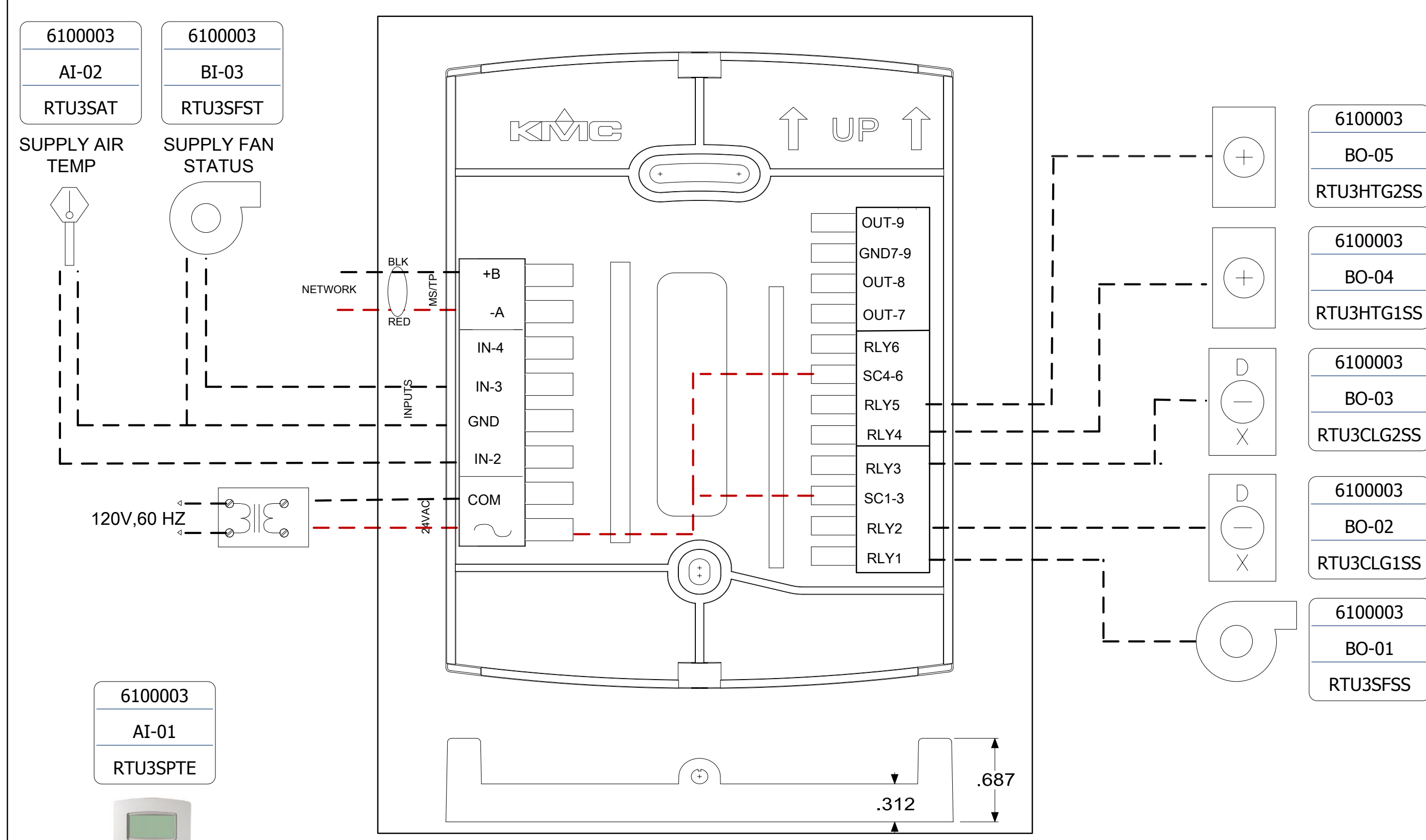

\begin{tabular}{|c|c|c|c|}
\hline DEMICE & PON & Ivar & Descaiption \\
\hline 6100003 & RTUBSPTE & AI-01 & Space Terperature \\
\hline 6100003 & RTUBSAT & AI-02 & Supply Air Terperature \\
\hline 6100003 & RTUBSFST & $\mathrm{BH}-03$ & Supply Fan Status \\
\hline 6100003 & & AI-04 & \\
\hline 6100003 & RTUBSFSS & BO-01 & SupplyFan Start/Stop \\
\hline 6100003 & RIUBGGSS & BO-OR & Cooling 1Start/Stop \\
\hline 6100003 & RTUBOGSS & BO-03 & Cooling2Start/Stop \\
\hline 6100003 & RTUBHTGSS & BO-04 & Heating 1Start/Stop \\
\hline 6100003 & RTUBHTESS & BO-05 & Heating 2Start/Stop \\
\hline 6100003 & & AO-06 & \\
\hline 6100003 & & AO-07 & \\
\hline 6100003 & & AO-08 & \\
\hline 6100003 & & AO-09 & \\
\hline
\end{tabular}




\section{RTU - 4 Feeding SE corner of the Community Hall}

Proposed way of controlling the system for optimum efficiency:

System will start up based on the time of day schedule (operator adjustable) or Occupancy.

\section{Heating Mode}

In the occupied mode system will maintain its setpoint, (operator adjustable);

In the winter mode; the system will maintain the setpoint by the heating coil of the HVAC unit.

In the unoccupied mode, the system will be in the night set back mode, (operator adjustable) if the system is below the night setpoint the system will be enabled until it reaches the night set back setpoint.

\section{Cooling Mode:}

In the occupied mode system will maintain its setpoint, (operator adjustable)

In the summer mode: the system will maintain the setpoint by the cooling coil of the HVAC unit.

In the unoccupied mode, the system will be in the night set back mode, (operator adjustable).

Temperature

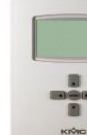

610000

AI-01

RTU4SPTE

Pвou. MNGR

26 CONTRACTOR:

\begin{tabular}{|c|c|c|c|c|c|}
\hline 3 & \multicolumn{3}{|c|}{ - } & - & - \\
\hline 2 & \multirow{2}{*}{\multicolumn{3}{|c|}{$\begin{array}{c}-\cdot \\
\text { Issued for Review }\end{array}$}} & - & \\
\hline 1 & & & & $24 / 01 / 2012$ & - \\
\hline Rev & \multicolumn{3}{|c|}{ Description } & Date & By \\
\hline & $\begin{array}{l}\text { 24/01/2012 } \\
\text { Dipak Patel }\end{array}$ & PROO REF: & $\begin{array}{l}\text { DWG REF: } \\
\mathbf{0 0 0}\end{array}$ & $00-$ & 09 \\
\hline
\end{tabular}




\section{RTU- 4 CONTROL PANEL LAYOUT}

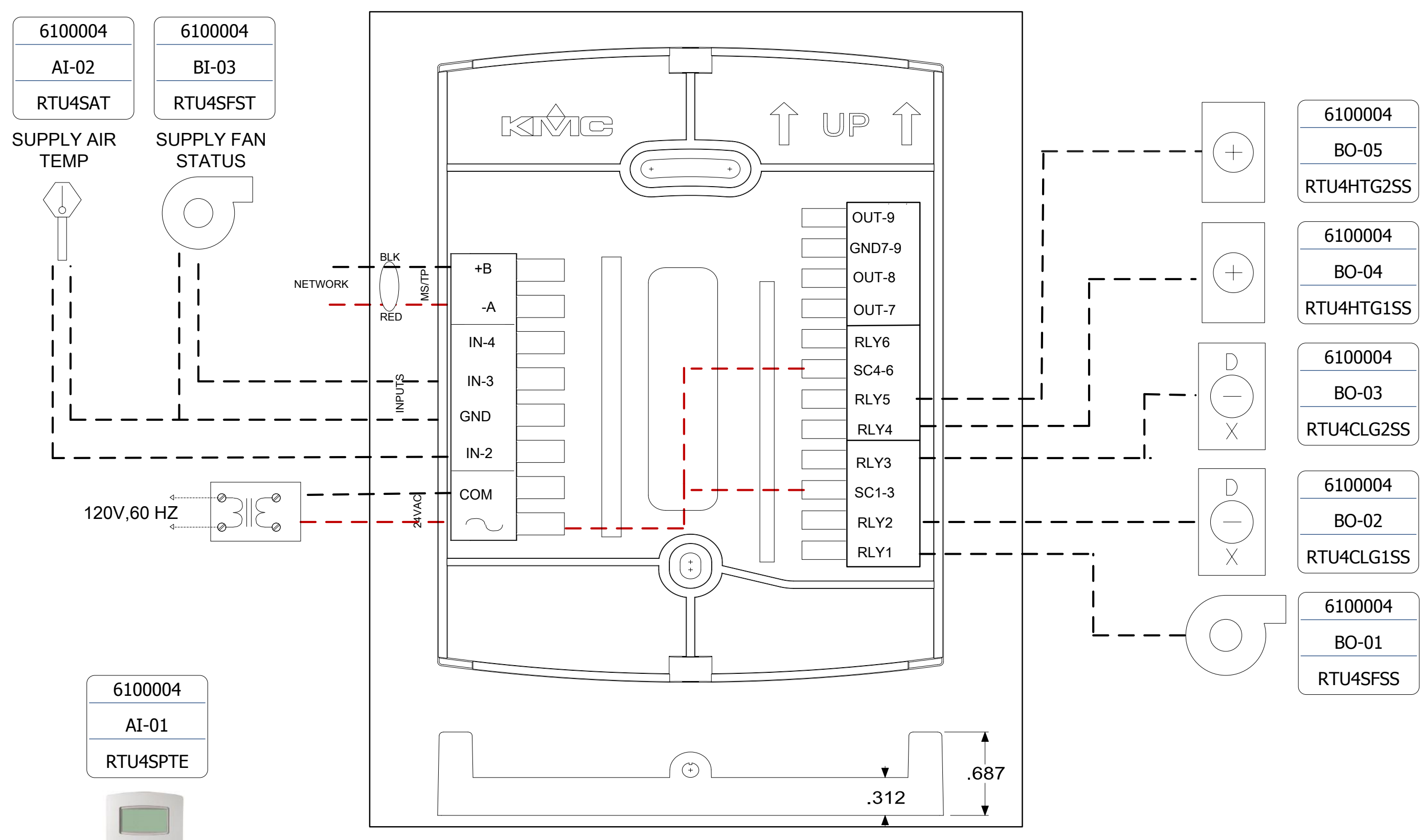

\begin{tabular}{|c|c|c|c|}
\hline DEMCE & PaN & Iyar & Descaiption \\
\hline 6100004 & RTUASPTE & AI-01 & Space Terperature \\
\hline 6100004 & RTUASAT & $\mathrm{AI}-02$ & Supply Air Temperature \\
\hline 6100004 & RTUASEST & BE-0B & Supply Fan Status \\
\hline 6100004 & & AI-04 & \\
\hline 6100004 & RTUASFSS & $\mathrm{BO}-01$ & Supply Fan Start/Stop \\
\hline 6100004 & RTUACGSS & $\mathrm{BO}-02$ & Coding 1Start/Stop \\
\hline 6100004 & RTUACESS & $\mathrm{BO}-03$ & Cooling2Start/Stop \\
\hline 6100004 & RTUAHTGISS & $\mathrm{BO}-04$ & Heating 1Start/Stop \\
\hline 6100004 & RTUAHTESS & BO-05 & Heating2Start/Stop \\
\hline 6100004 & & $\mathrm{AO}-06$ & \\
\hline 6100004 & & $\mathrm{AO}-07$ & \\
\hline 6100004 & & AO-08 & \\
\hline 6100004 & & $\mathrm{AO}-09$ & \\
\hline
\end{tabular}




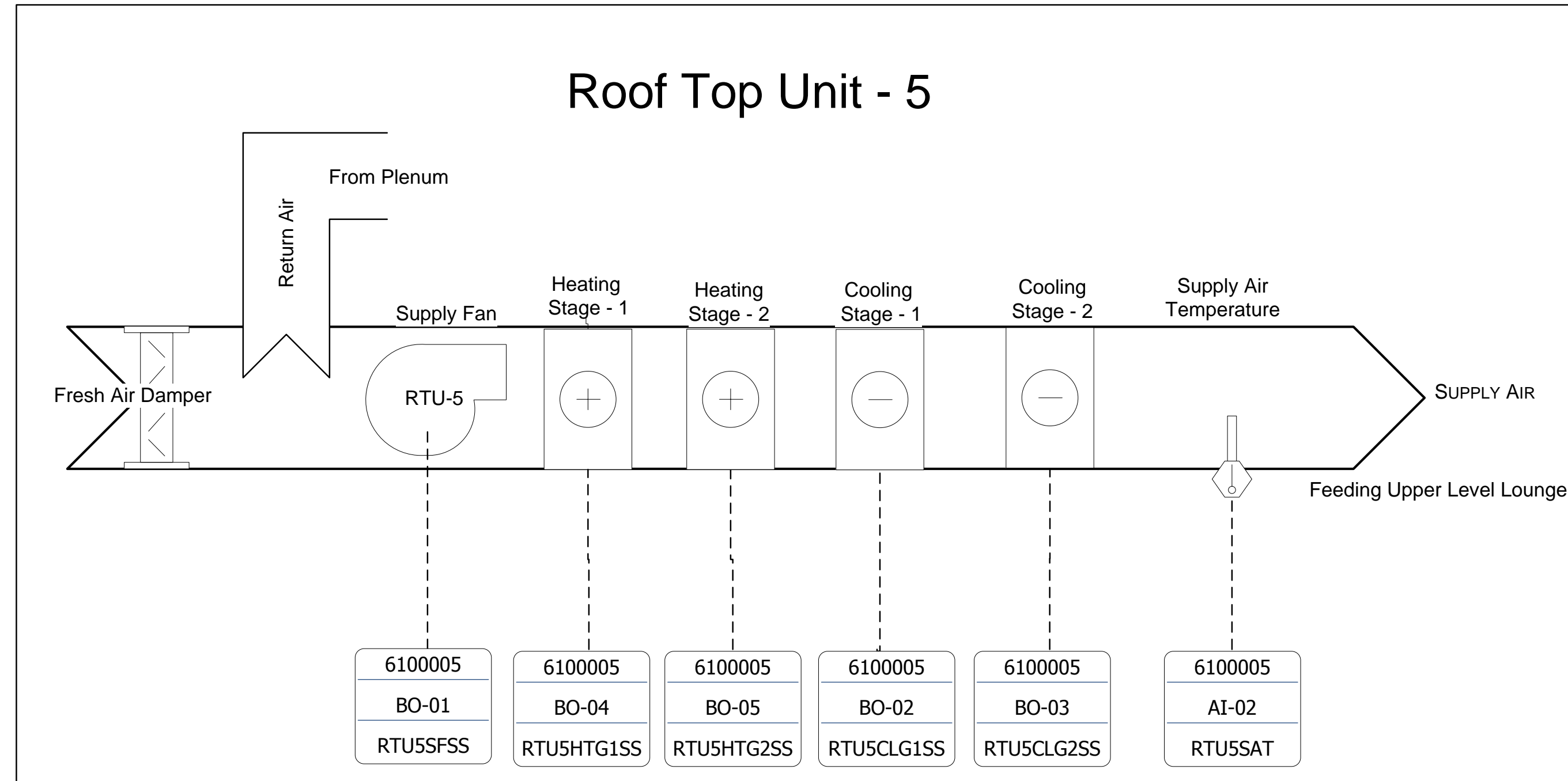

\section{RTU - 5 Feeding Upper Level Lounge}

\section{Proposed way of controlling the system for optimum} efficiency:

System will start up based on the time of day schedule (operator adjustable) or Occupancy.

\section{Heating Mode}

In the occupied mode system will maintain its setpoint, (operator adjustable);

In the winter mode; the system will maintain the setpoint by the heating coil of the HVAC unit.

In the unoccupied mode, the system will be in the night set back mode, (operator adjustable) if the system is below the night setpoint the system will be enabled until it reaches the night set back setpoint.

Cooling Mode:

In the occupied mode system will maintain its setpoint, (operator adjustable)

In the summer mode: the system will maintain the setpoint by the cooling coil of the HVAC unit.

In the unoccupied mode, the system will be in the night set back mode, (operator adjustable).

\section{BAPA's Room Damper Control}

Space Temperature with display and setpoint is located in the BAPA's Room. Space temperature and setpoint are sent to the Flexstat -5 . Modulation output is connected to the damper actuator located in the Duct feeding BAPA's room. Damper is modulated based on the set point set by the end-user.

PACE TEMPERATUR

6100005

AI-01

RTU5SPTE

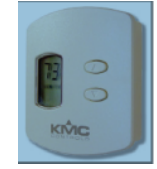

BAPA'S ROOM BAPA'S ROOM

TEMP.

6100005

SETPT

BI-03

BAPARMTE

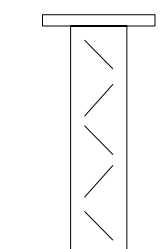

MODULATION

DAMPER

6100005

AO-08

DMPCTL 


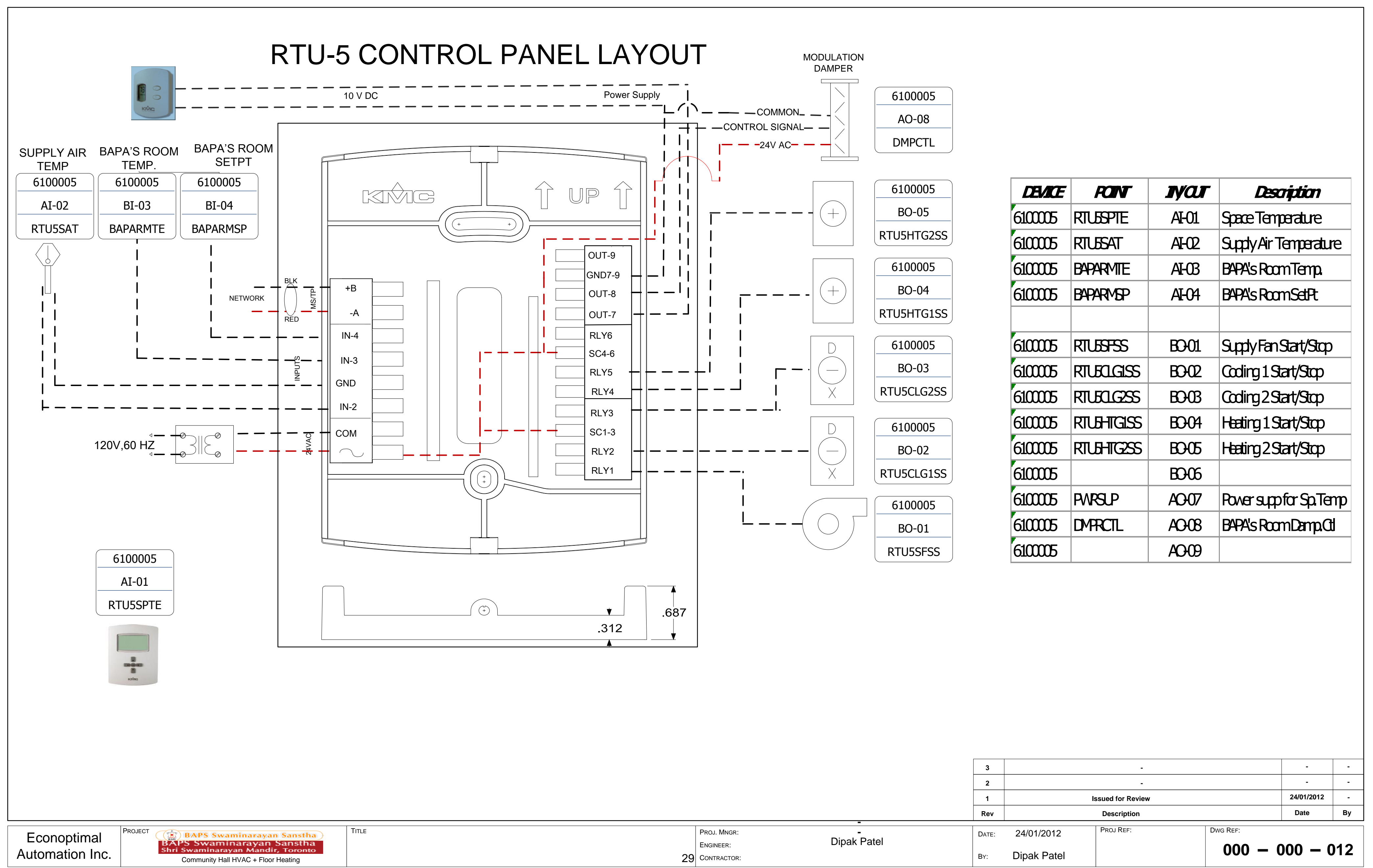




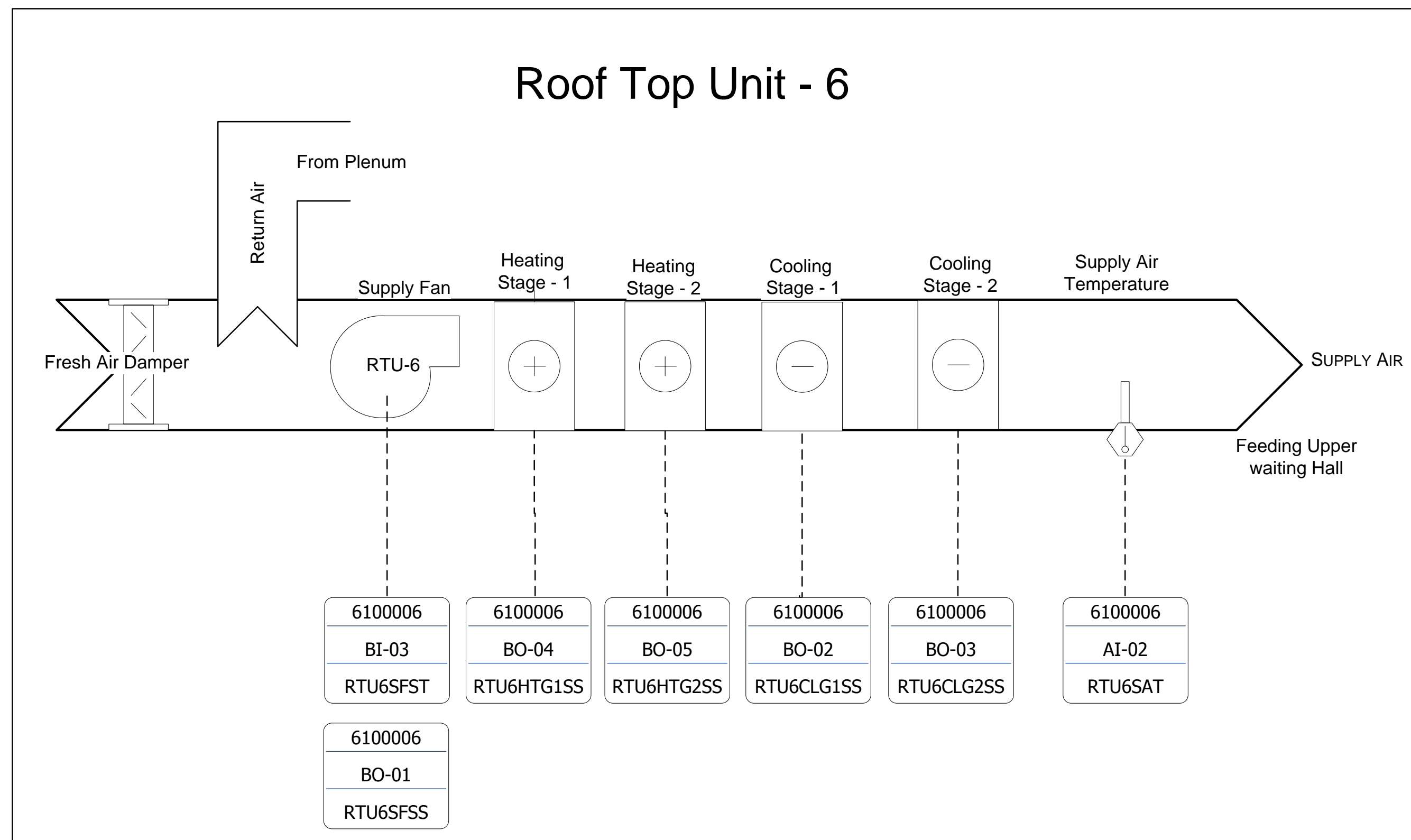

\section{RTU - 6 Feeding Upper Waiting Hal}

\section{Proposed way of controlling the system for optimum} efficiency:

System will start up based on the time of day schedule (operator adjustable) or Occupancy.

\section{Heating Mode}

In the occupied mode system will maintain its setpoint, (operator adjustable);

In the winter mode; the system will maintain the setpoint by the heating coil of the HVAC unit.

In the unoccupied mode, the system will be in the night set back mode, (operator adjustable) if the system is below the night setpoint the system will be enabled until it reaches the night set back setpoint.

Cooling Mode:

In the occupied mode system will maintain its setpoint, (operator adjustable)

In the summer mode: the system will maintain the setpoint by the cooling coil of the HVAC unit.

In the unoccupied mode, the system will be in the night set back mode, (operator adjustable).

PROJEC

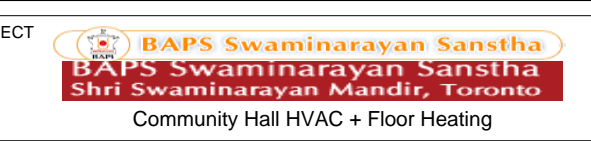

TTILE

$+2$

AC5-SCALE HOUSE

\begin{tabular}{l|l}
\hline PRoJ. MngR: \\
ENGINEER:
\end{tabular}

30 ENGINERA:

Dipak Patel

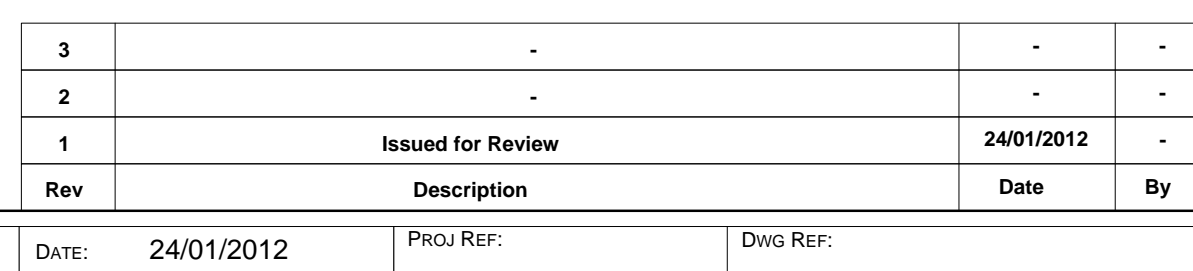




\section{RTU- 6 CONTROL PANEL LAYOUT}

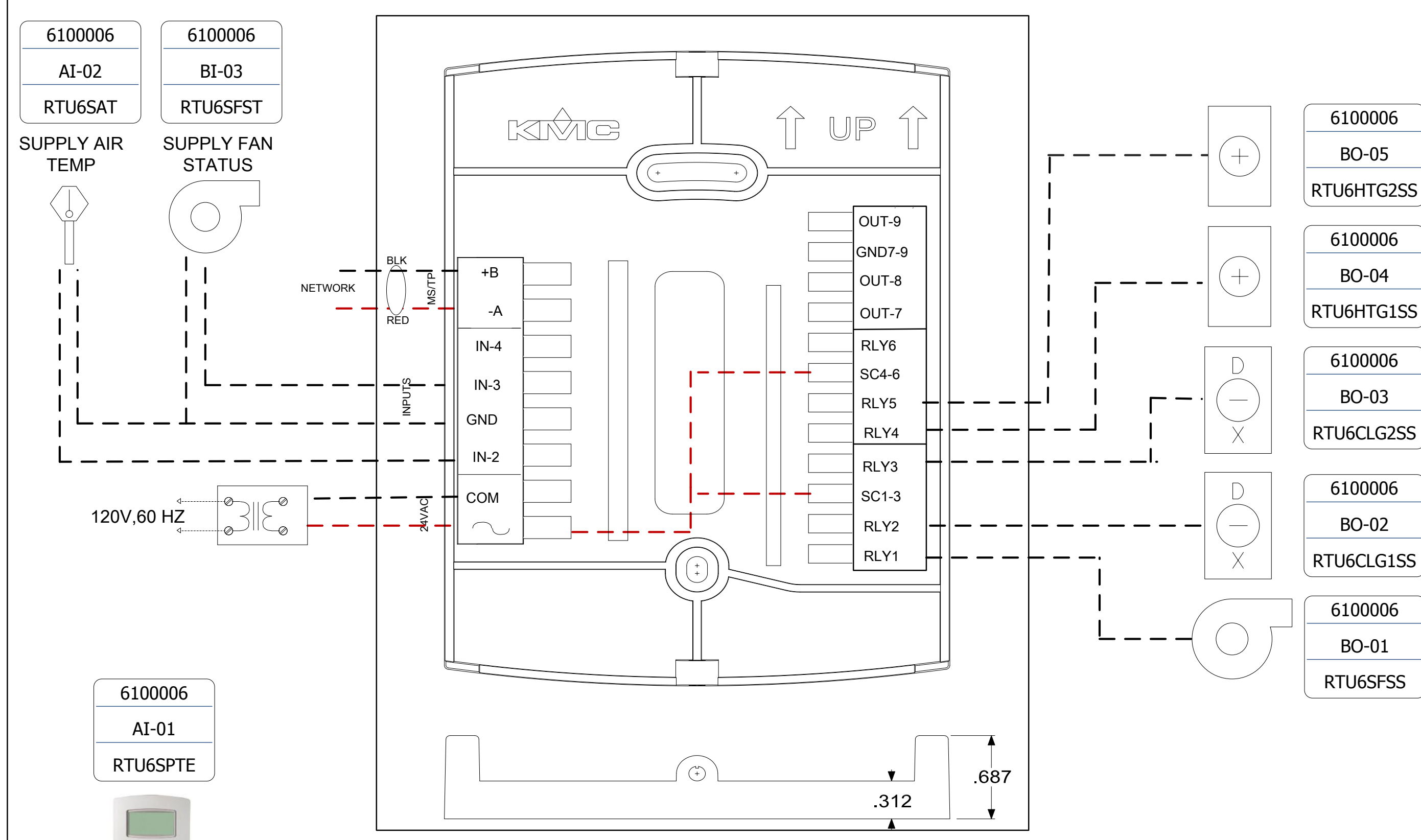

\begin{tabular}{|c|c|c|c|}
\hline DEMCE & PON & INar & Desaiption \\
\hline 6100006 & RTUGSPTE & AI-01 & Space Temperature \\
\hline 6100006 & RTUGSAT & AI-O2 & Supply Air Terperature \\
\hline 6100006 & RTUGSFST & BI-OB & Supply Fan Status \\
\hline 6100006 & & AI-04 & \\
\hline 6100006 & RTUGSFSS & $\mathrm{BO}-01$ & SupplyFanStart/Stop \\
\hline 6100006 & RTU6CGSS & $\mathrm{BO}-02$ & Coding1Start/Stop \\
\hline 6100006 & RTLEAGSS & $\mathrm{BO}-03$ & Cooling2Start/Stop \\
\hline 6100006 & RTUEHTGSS & $\mathrm{BO}-04$ & Heating 1Start/Stop \\
\hline 6100006 & RTUGHGSS & $B O-05$ & Heating2Start/Stop \\
\hline 6100006 & & $A O-06$ & \\
\hline 6100006 & & $\mathrm{AO}-07$ & \\
\hline 6100006 & & $A O-08$ & \\
\hline 6100006 & & $A O-09$ & \\
\hline
\end{tabular}




\section{RTU - 7 Feeding Upper North Offices}

\section{Proposed way of controlling the system for optimum}

\section{efficiency:}

System will start up based on the time of day schedule (operator adjustable) or Occupancy.

Heating Mode

In the occupied mode system will maintain its setpoint, (operator adjustable);

In the winter mode; the system will maintain the setpoint by the heating coil of the HVAC unit.

In the unoccupied mode, the system will be in the night set back mode, (operator adjustable) if the system is below the night setpoint the system will be enabled until it reaches the night set back setpoint.

Cooling Mode:

In the occupied mode system will maintain its setpoint, (operator adjustable)

In the summer mode: the system will maintain the setpoint by the cooling coil of the HVAC unit.

In the unoccupied mode, the system will be in the night set back mode, (operator adjustable).

Space

Temperature

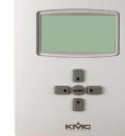

6100007

AI-01

RTU7SPTE
SpTe Rm114

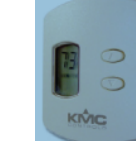

6100007

AI-04

SPTERM114

PROJ. MNGGR:
ENGGEER:

32 CONTRACTOR:

Dipak Patel

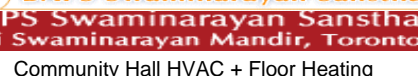

:

(n)

Dipak Pate

TITLE




\section{MANIFOLD1-MANIFOLD6-CONTROL}

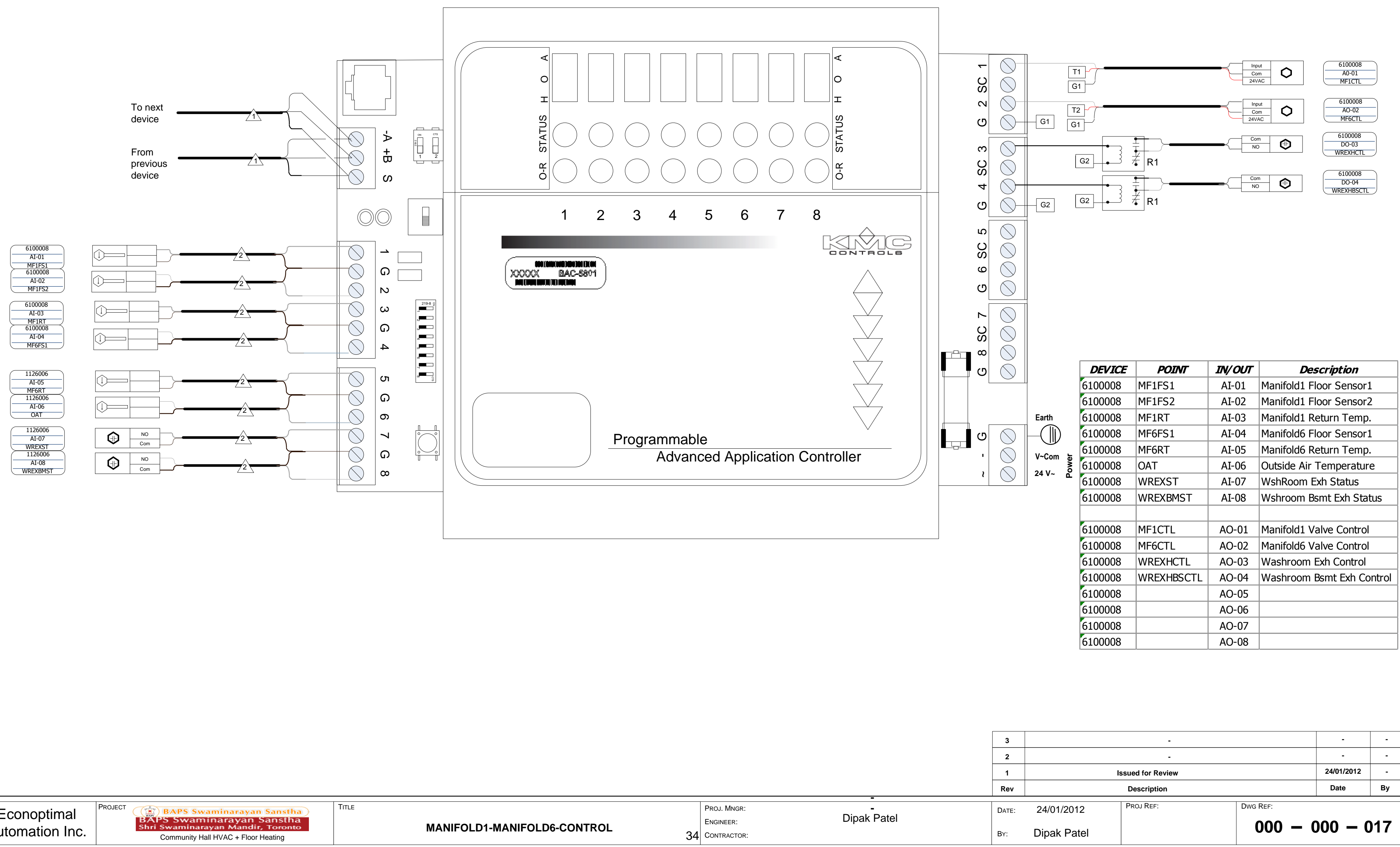




\section{MANIFOLD 2-CONTROL}

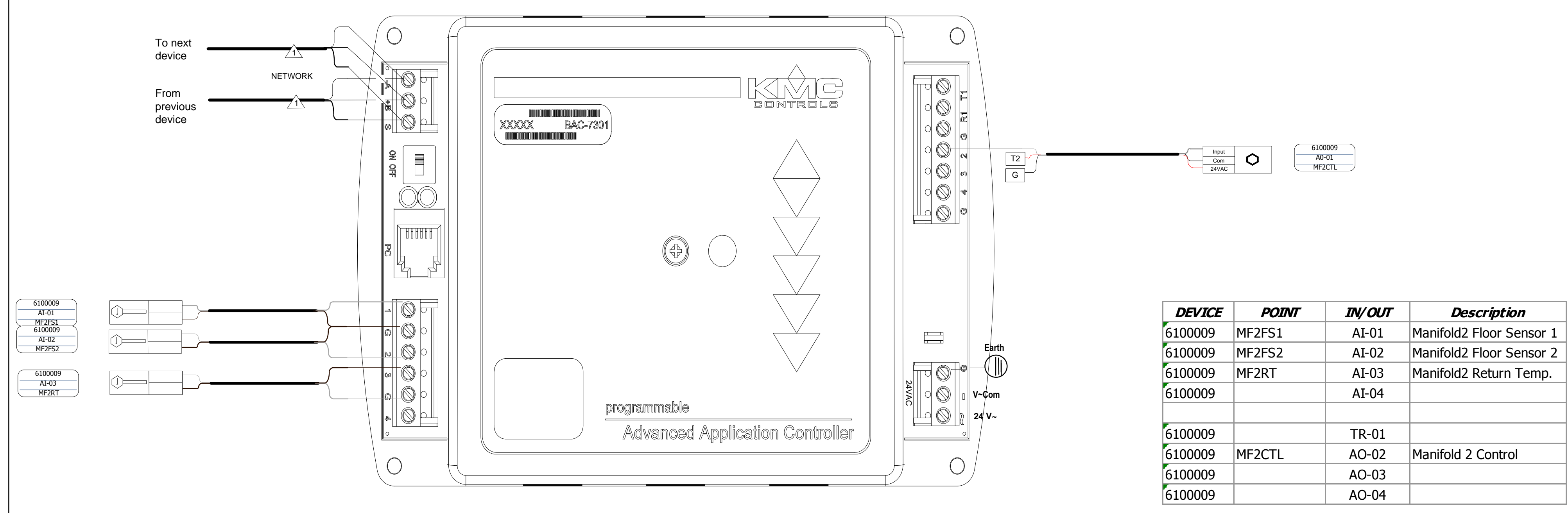




\section{MANIFOLD 3-CONTROL}

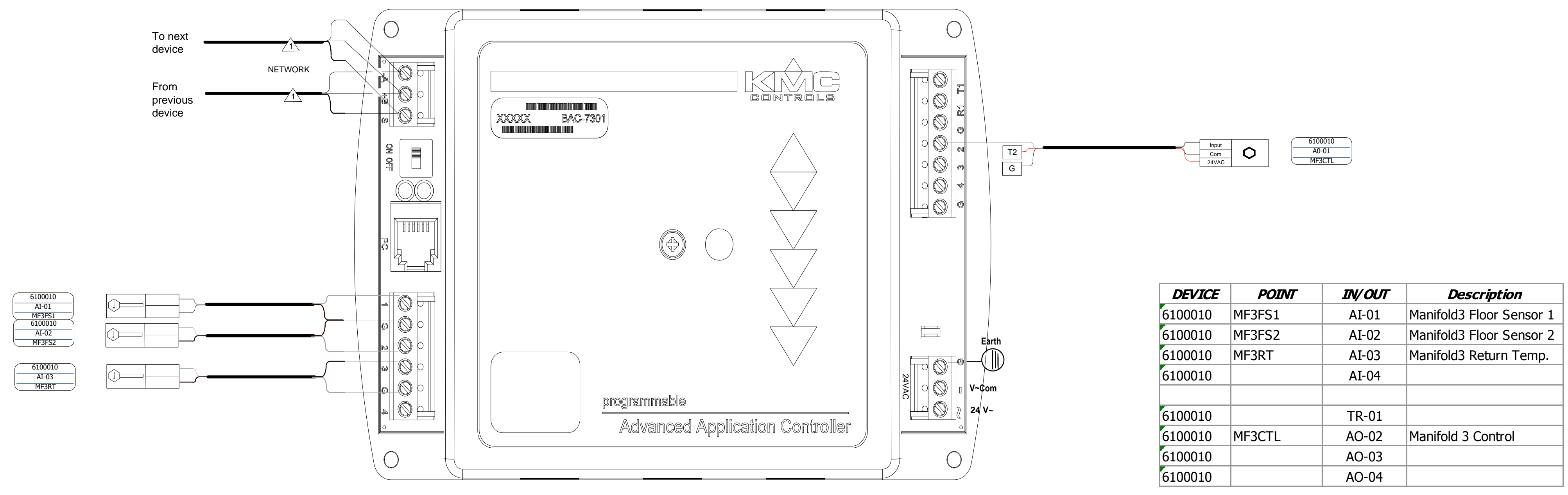

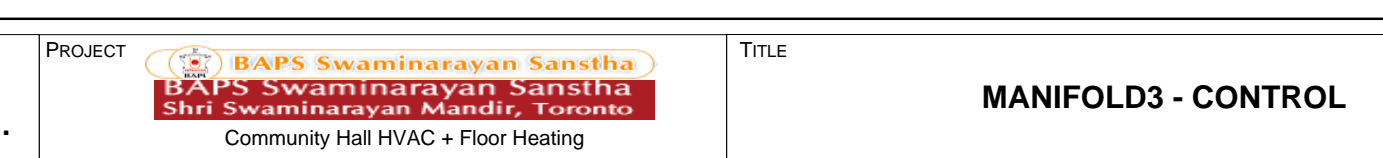




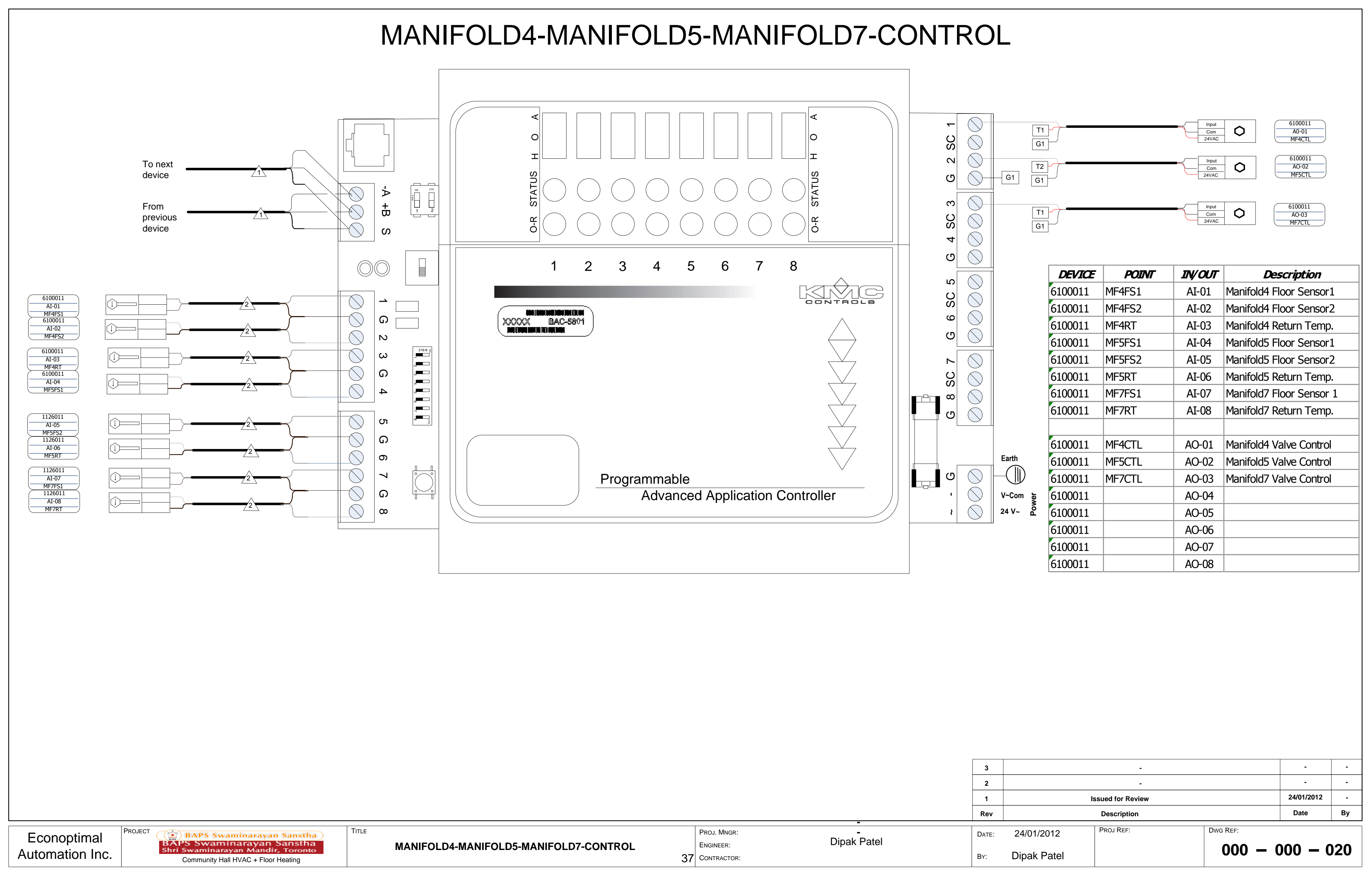




\section{$\underline{2.2 \text { Coding Example }}$}




\section{Line By Line code example}

Below is the example of the Dehumidity Control. This code execures if Dehumidity control is enable. Once it enable, it compares Space humidity with its setpoint. If space humidity is more than its setpoint than it will start Dehumidity mode other wise it stops it. Again it checks again and executes function based on humidity parameters.(18).(20)

DEHUM_CONTROL:

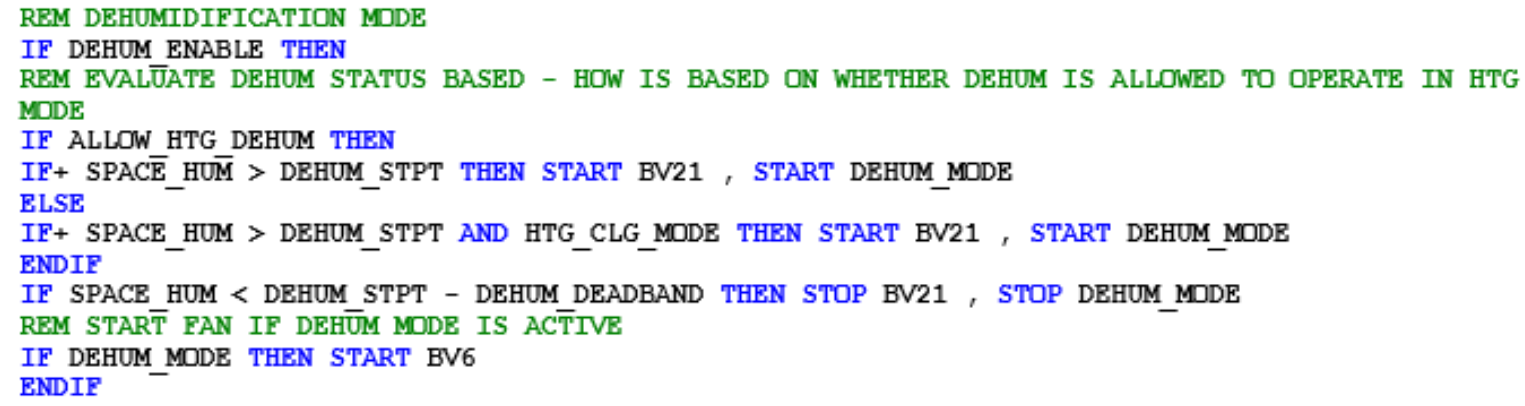




\section{Functional Block Coding Example}

Below is the example of Heating valve control with temperatures of floor sensors and return temperature using the temperature set point. Input parameters are temperatures of floor or return temperature from floor. It has temperature set point. All input parameters are connected to PID loop which calculates based on its internal parameters. If temperatures are lower than the set point, it opens the heating valve to provide more heating. Once it match the

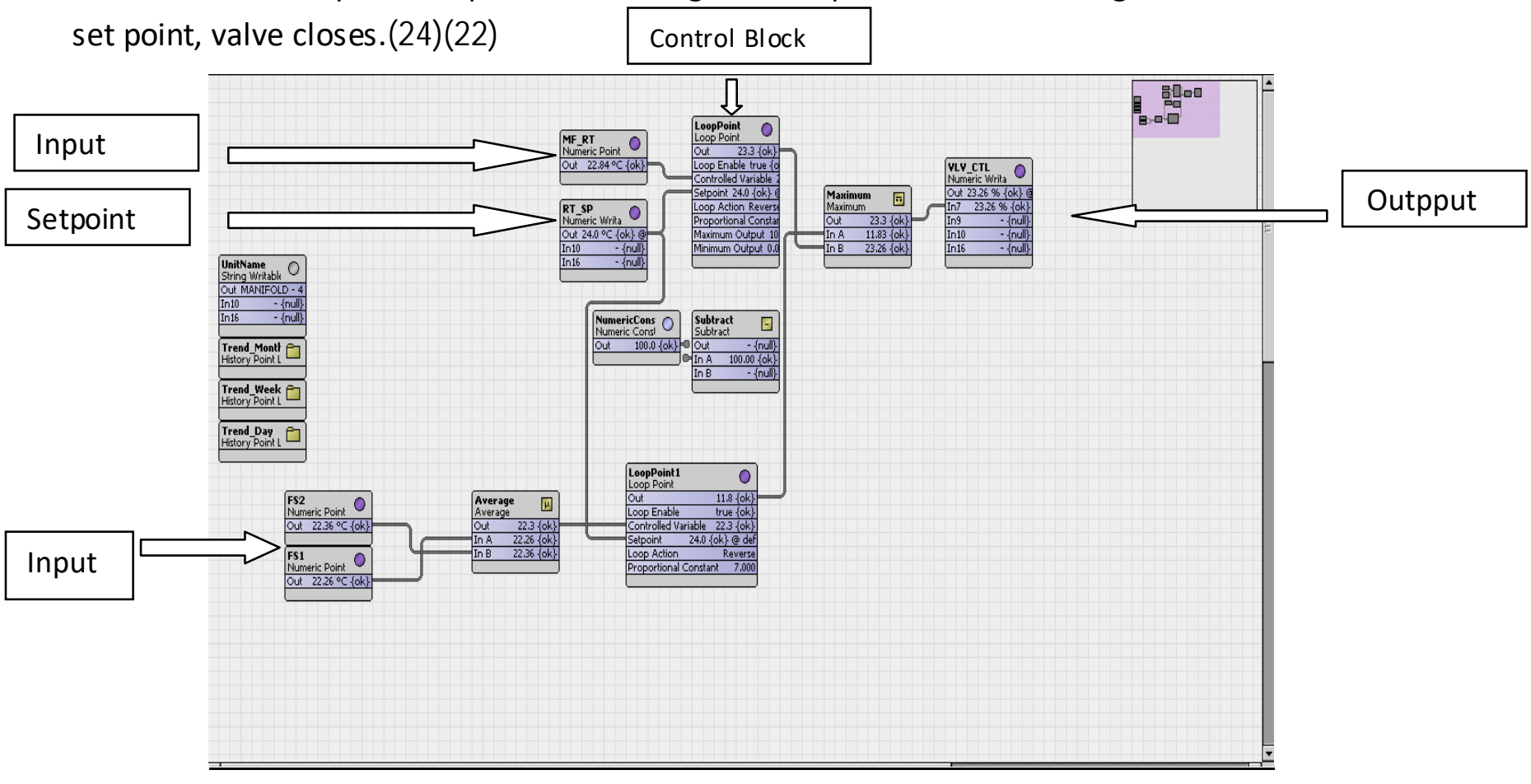

Figure - 6 Functional Block Coding Example 


\section{$\underline{2.3 \text { Graphics Example }}$}




\section{Graphics}

\section{Main Page}

Below image is created as main page of the graphics. This represents the link for main systems of the graphics and system functions.

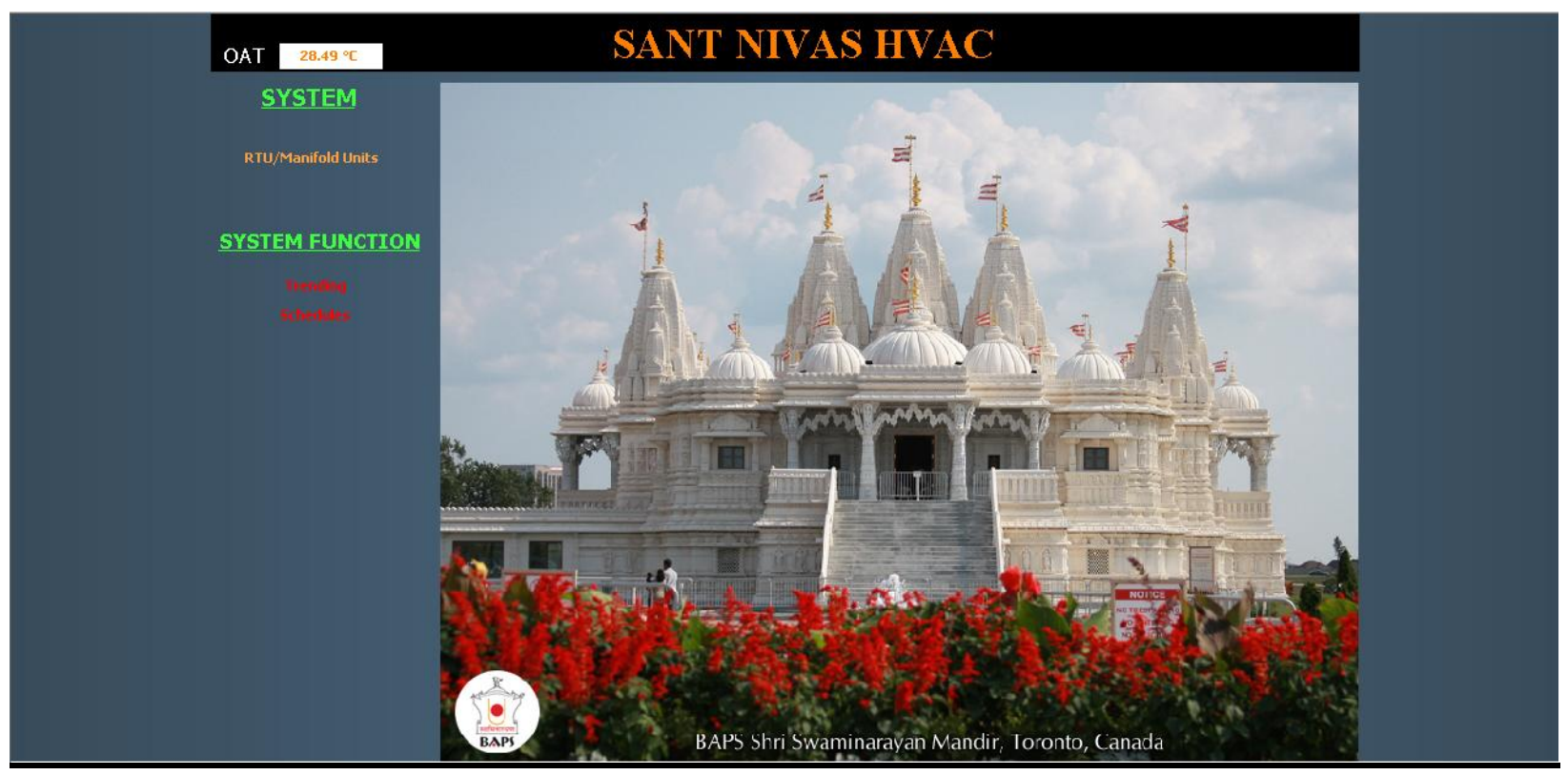

Figure -7 Graphics 


\section{Roof Top Unit}

Below is the image for Roof Top Unit. This graphics contains all control component for this unit. It has also contains set points for heating and cooling. It has all real time data showing the present condition of the unit.

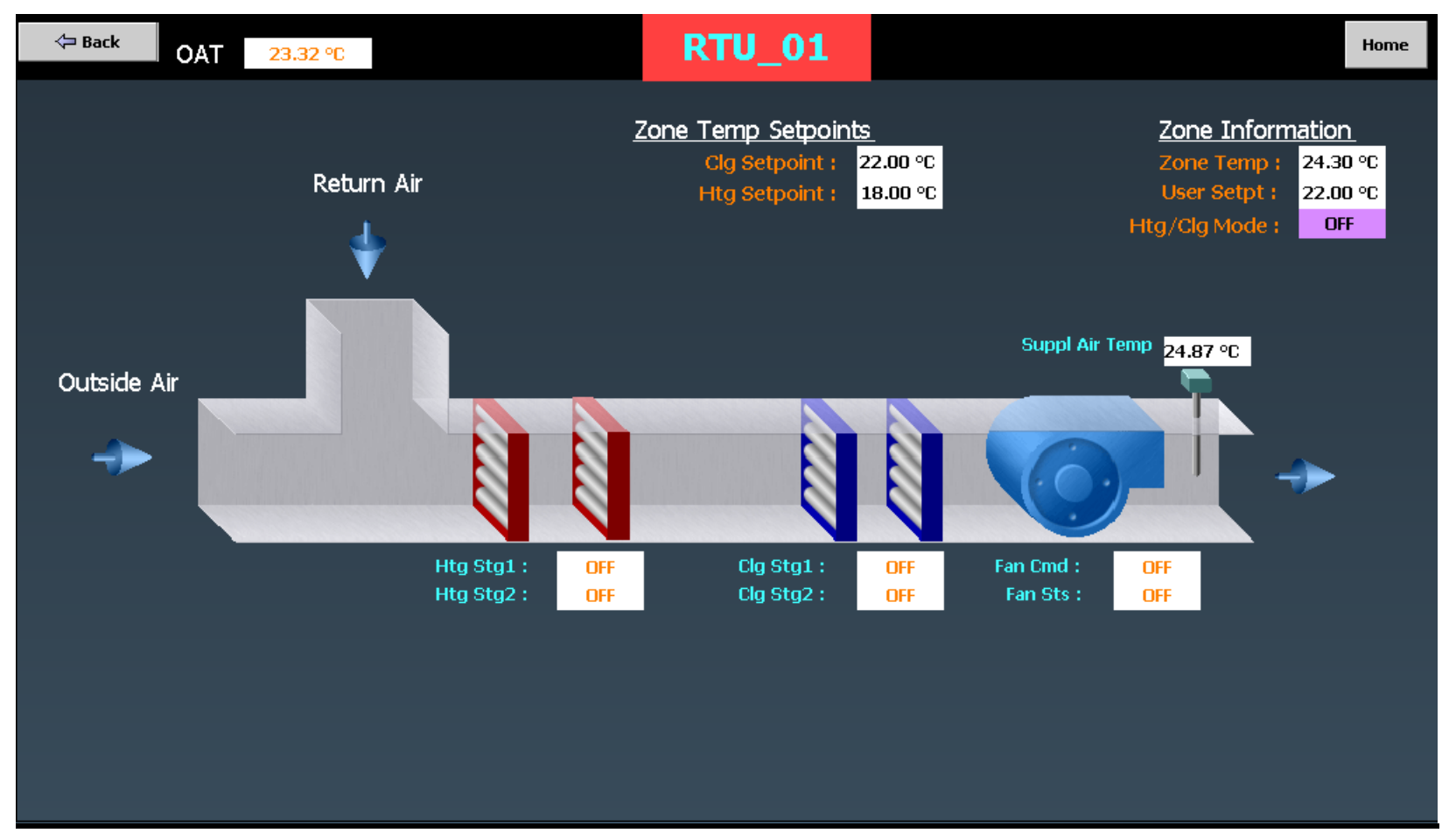

Figure - 8 Roof Top Unit 


\section{Manifold}

Below graphics shows the details about the under floor heating controls. It shows the floor sensor reading and its set point. It also represents the heating valve operation via its position. It also represents daily, weekly and monthly trend for temperature vs set point.

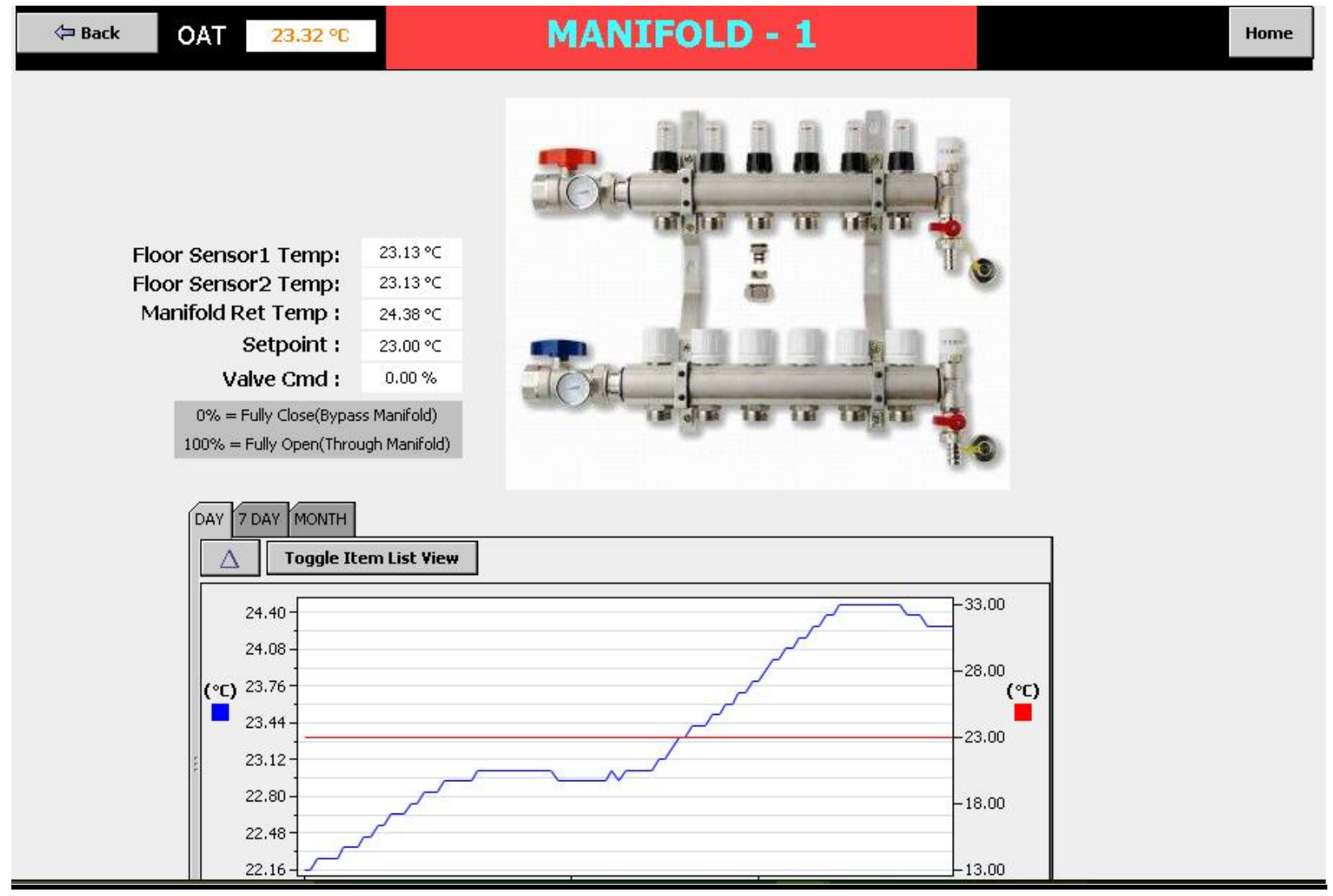

Figure - 9 Manifold 


\subsection{Live Presentation of the Intelligent Building Project}

As we seen until now that we design the project using different phases. First of all design the wiring layout in detail for control wiring. After that choosing the right hardware for particular application. Then design the control drawing for details about the controller wiring. Then write the code to perform the sequence of operation. Later create the graphics template and configure data to the graphics for real time operation. (23)

Now using internet web browser with username and password we can watch, operate and control the entire site using the graphics. All equipment are control using graphics. 


\subsection{Conclusion}

In conclusion, we can state that based on the requirement of the project, entire site was designed to implement the Intelligent building automation system.(21)

These building needs control system design which requires detail study of mechanical equipment and how it functions using controls. First of all, I designed a sequence of operation for each mechanical equipment. Then, choose controller and peripheral devices to accommodate the sequence of operation. After hardware selection, need wiring diagram to do wiring between controller and equipment. To perform centralized control system, there is a need for network between controllers and communicate them to one another over common protocol language. Now, peripheral devices like space sensors, duct sensors, relay wiring to control the equipment and under floor sensors, control valves etc. All these controllers are wired and programmed as per sequence of operation. Next step is to commission the controller and verify the operation of the mechanical equipment as per design sequence.(24)(20)

Graphics are created and display all points as per requirement. In nutshell, this project describe the details about design and implementation of intelligent building automation system. 
Appendix I

Wiring Diagram with layout 


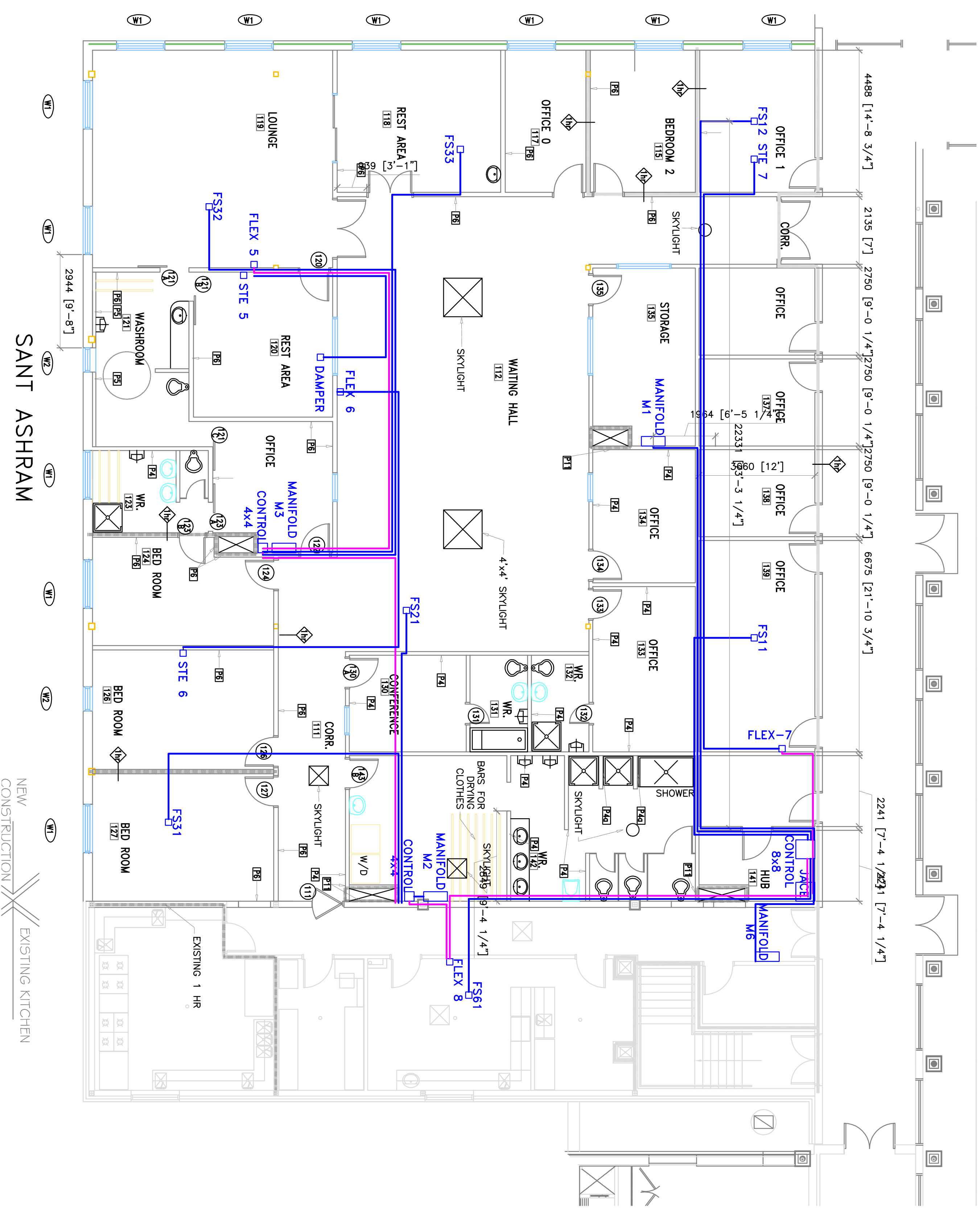




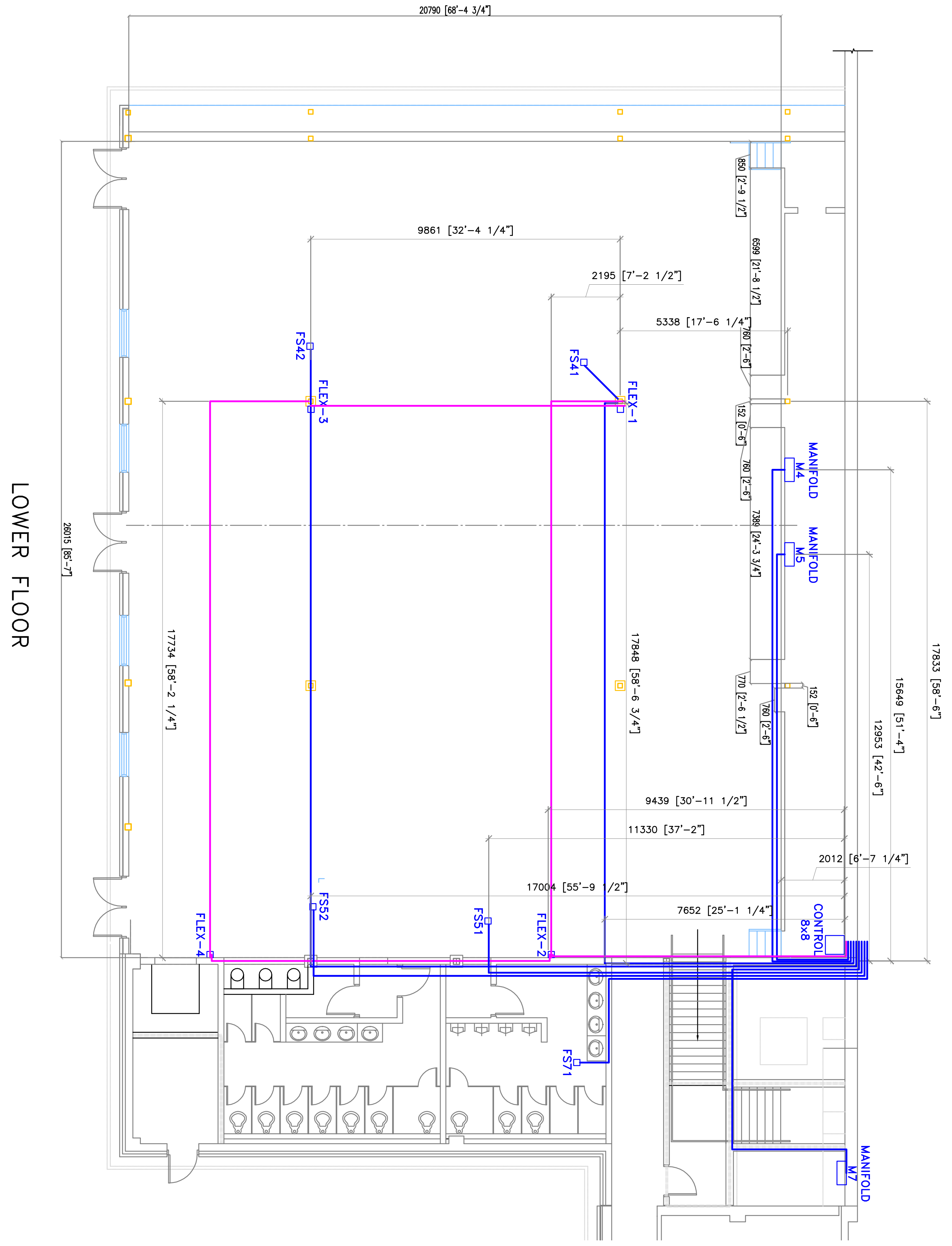

Figure - 11 Wiring Diagram-2 


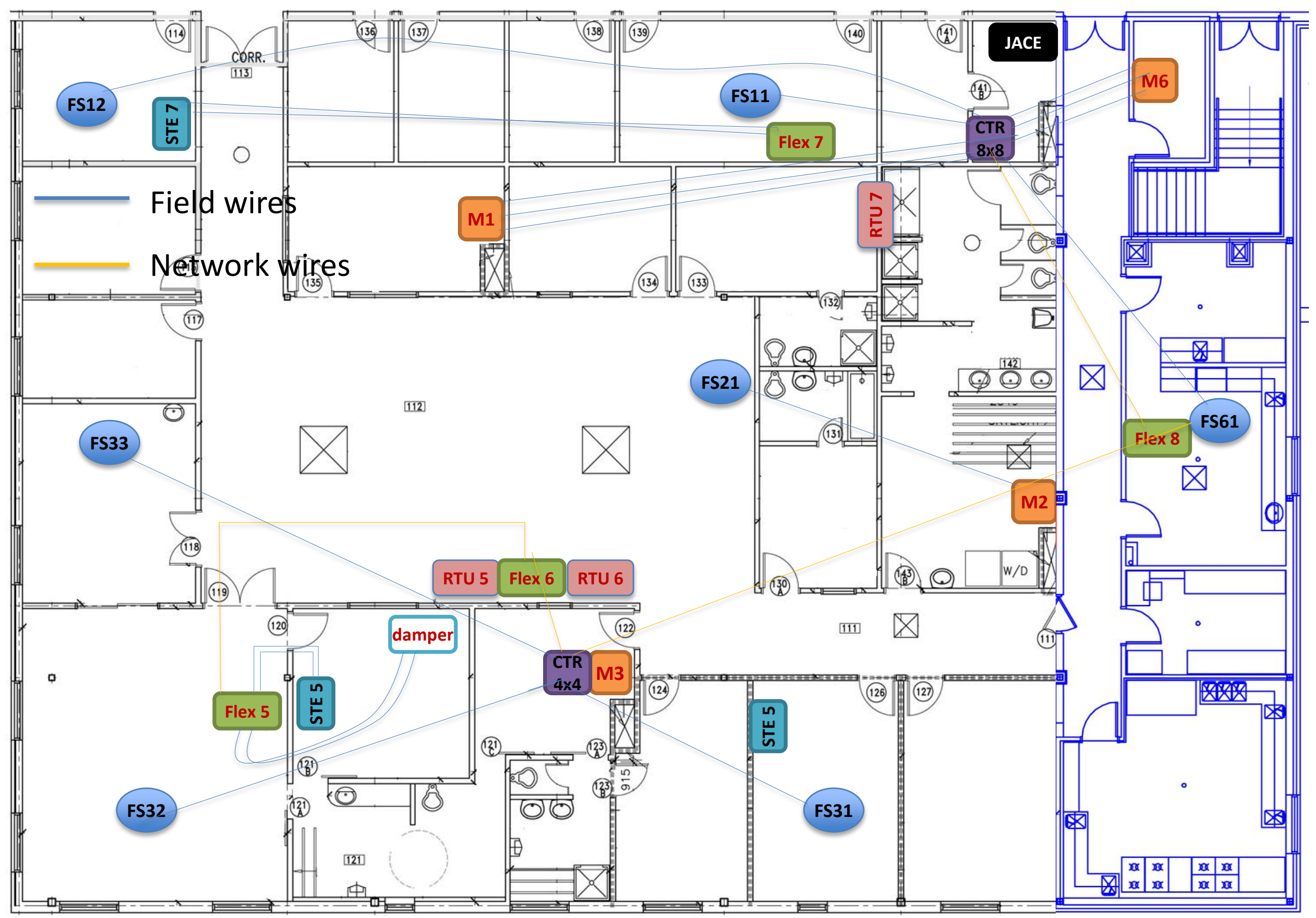




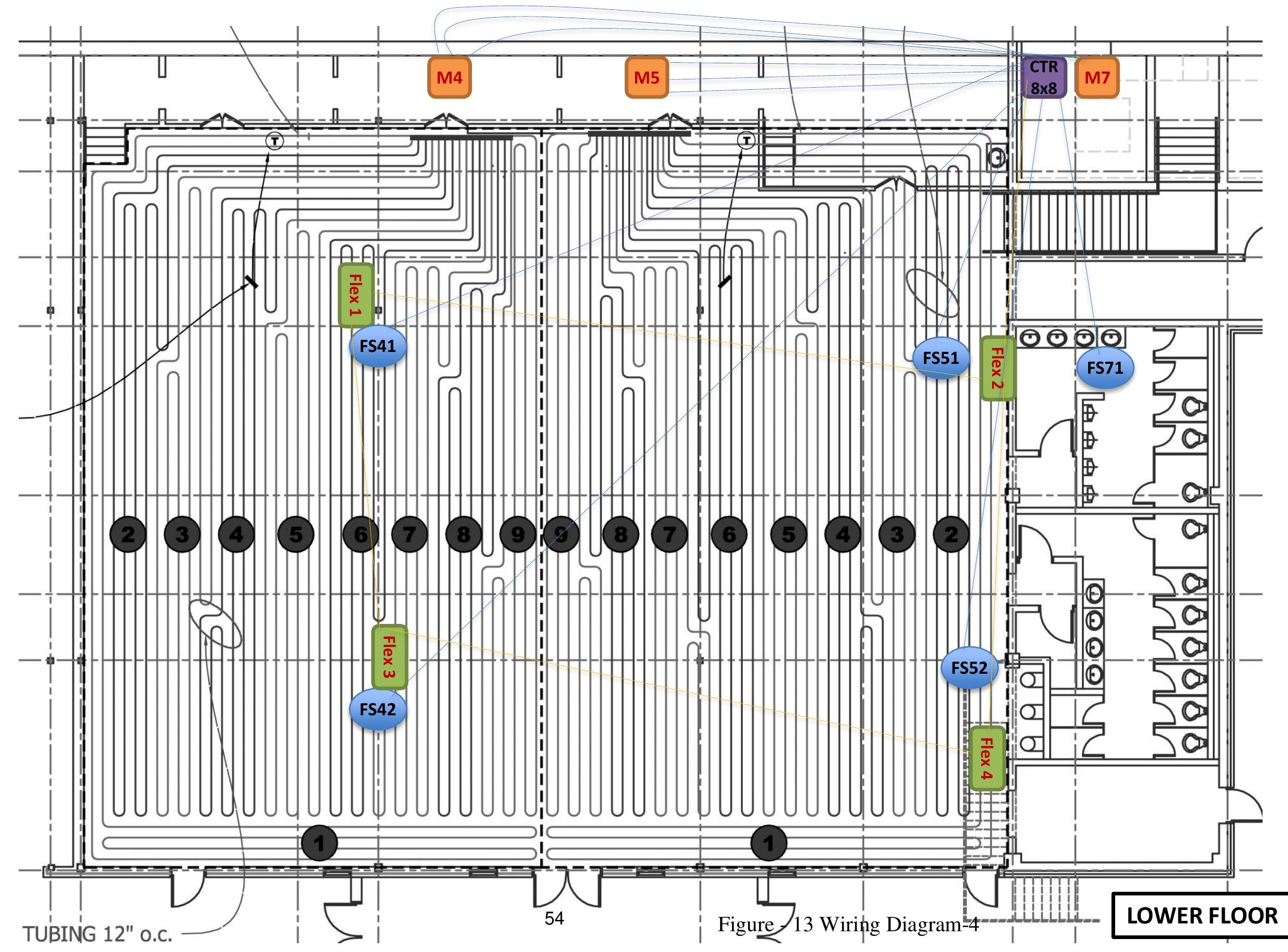




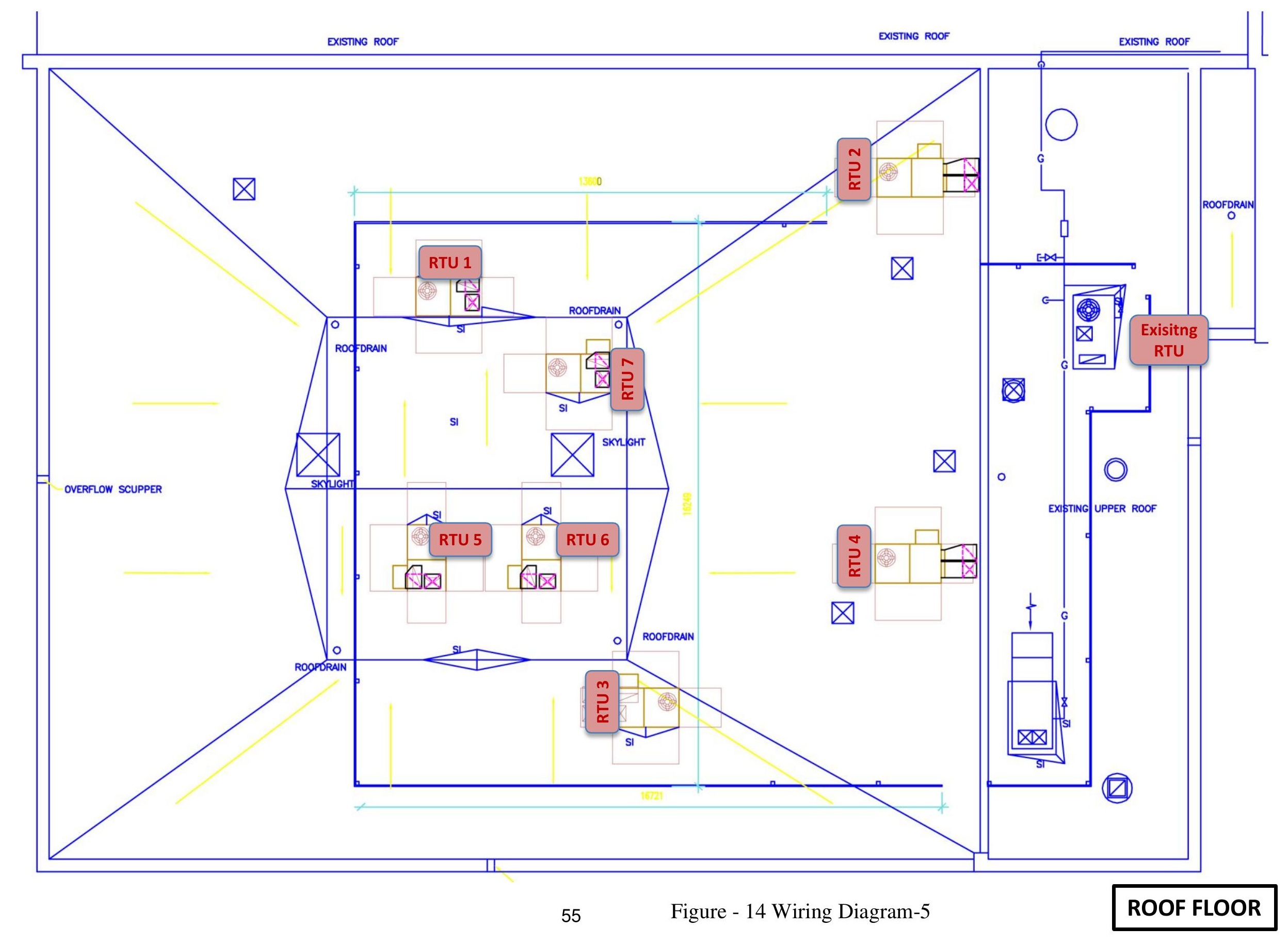


Appendix II

Technical Documentation on Hardware Selection and its Specification 


\section{Product Description}

The Lynxspring JENE-PC1000 controller is a compact, embedded controller/server platform. It combines integrated control, supervision, data logging, alarming, scheduling and network management functions with Inter-net connectivity and web serving capabilities in a small, compact platform. The JENE makes it possible to control and manage external devices over the Internet and present real time information to users in webbased graphical views.

The JENE is a member of the JENEsys ${ }^{\text {TM }}$ suite of Java-based controller/server products, software applications and tools, which are designed to integrate a variety of devices and protocols into unified, distributed systems. JENEsys ${ }^{\mathrm{TM}}$ products are powered by the revolutionary NiagaraAX Framework®, the industry's first software technology designed to integrate diverse systems and devices into a seamless system. Niagara supports a wide range of protocols including LonWorks ${ }^{\mathrm{TM}}$, BACnet $^{\mathrm{TM}}$, Modbus ${ }^{\mathrm{TM}}$ and Internet standards. The AX Framework also includes integrated network management tools to support the design, configuration, installation and maintenance of interoperable networks.

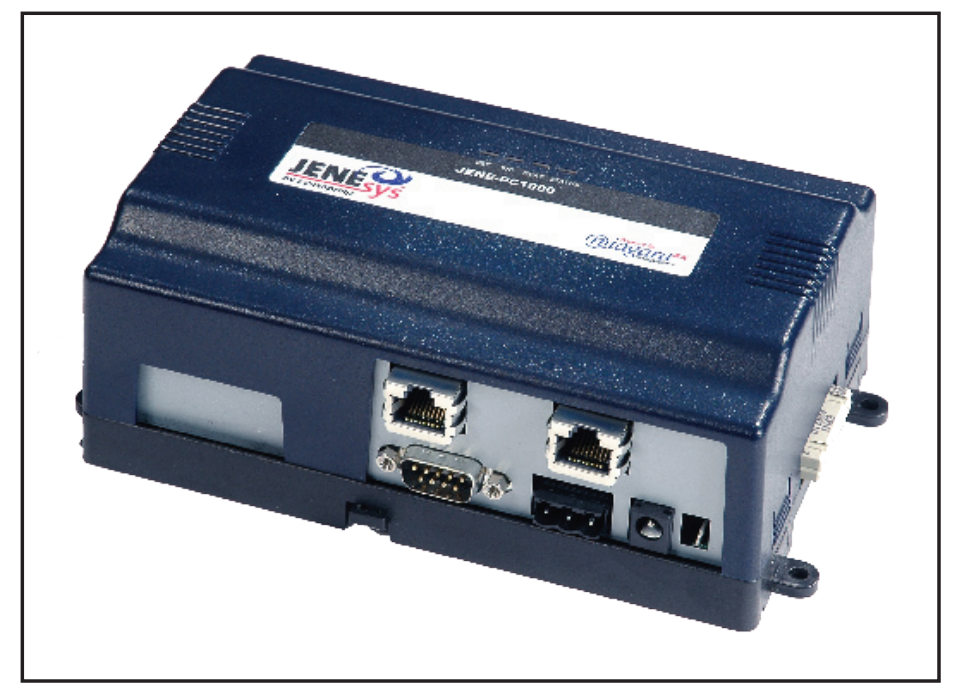

\section{Features and Application Highlights}

The JENE-PC1000 is ideal for smaller facilities, remote sites, and for distributing control and monitoring throughout large facilities. Optional input/output modules can be plugged in for applications where local control is required. The JENE-PC1000 also supports a wide range of fieldbuses for connection to remote I/O and stand-alone controllers. In small facility applications, the JENE-PC1000 is all you need for a complete system.

The JENE-PC1000 serves data and rich graphical displays to a standard web browser via an Ethernet LAN or remotely over the Internet, or dial-up modem. In larger facilities, multi-building applications and large-scale control system integrations, NiagaraAX Supervisor ${ }^{\mathrm{TM}}$ software can be used to aggregate information (real-time data, history, alarms, etc.) from large numbers of JENEs into a single, unified application. The AX Supervisor can manage global control functions, support data passing over multiple networks, connect to enterprise level software applications, and host multiple, simultaneous client workstations connected over the local network, the Internet, or a dial-up modem.

- Standard: Two RJ-45 Ethernet Ports, one RS-232 port, and one RS-485 port

- Interoperable: BACnet, LON, Fox or Modbus ready, with the addition of a license and/or communication modules

- Versatile: Fully-customizable with an array of software drivers and custom modules

- Reliable: All program data is backed up in nonvolatile EEPROM; battery back-up

- Fast: Onboard Ethernet communication provides rapid data transmission

\section{Mounting}

WARNING: Do not mount in a location subject to electrical noise. This includes the proximity of large electrical contactors, variable frequency drives, electrical machinery, welding equipment, spark igniters, and any high-voltage-producing equipment.

You must remove the JENE cover to install this unit. The cover snaps onto the base with four plastic tabs (two on each end). To remove the cover, press in the four tabs on both ends of the unit, and lift the cover off. To replace the cover, orient it so the cutout area for communications ports are cor-rect, and then push inwards to snap in place.

Mount the JENE in a horizontal position. It is necessary to remove the cover before mounting. Mount on a $35 \mathrm{~mm}$ wide DIN rail. The JENE unit base has a molded DIN rail slot and locking clip. The following procedure provides step-by-step DIN rail mounting instructions for the JENE.

Step 1 Securely install the DIN rail using at least two screws, near both ends of the rail.

Step 2 Position the JENE on the rail, tilting to hook DIN rail tabs over one edge of the DIN rail.

Step 3 Push down and in to force the DIN rail clip to snap over the other edge of the DIN rail.

Step 4 To prevent the JENE from sliding on the DIN rail, place a screw in two of the four mounting tabs in the base of the JENE. 


\title{
Technical Data
}

\author{
Platform \\ - IBM PowerPC 405EP $250 \mathrm{MHz}$ processor \\ - 64MB SDRAM \& 64 MB Serial Flash \\ - Battery Backup - 5 minutes typical - shutdown begins within 10 seconds \\ - Real-time clock - 3 month backup max via battery \\ Communications \\ - 2 Ethernet Ports - 10/100 Mbps (RJ-45 Connectors) \\ - 1 RS 232 Port (9 pin D-shell connector) \\ - 1 RS 485 non isolated port (3 Screw Connector on base board) \\ Optional Communi- \\ cations Cards \\ Operating System \\ - JCOM-1LON - Optional 78 Kbps FTT10 A LON Adapter \\ - JCOM-1232 - Optional RS-232 port adapter with 9 pin D-shell connector \\ - JCOM-2485 - Optional dual port RS-485 adapter; electrically isolated \\ - QNX RTOS \\ - IBM J9 JVM Java Virtual Machine \\ - NiagaraAX \\ Power Supply $\quad$ - JPWR-DRPM - Optional: 24 Volt AC/DC power supply module, Din Rail mounted \\ - Optional Wall Power Modules - \\ (Note: All modules are universal input $90-240$ volts, $50 / 60 \mathrm{~Hz}$.; the model numbers below represent the various plug con- \\ figurations only) \\ -JPWR-WWPM-US - 120 Vac, $50-60 \mathrm{~Hz}$. US \\ - JPWR-WWPM - 230 Vac, 50-60 Hz. Europe/Asia \\ -JPWR-WWPM - 230 Vac 50-60 Hz. UK \\ Chassis \\ Environment \\ - Construction: Plastic, Din rail or screw-mount chassis, plastic cover \\ - Cooling: Internal air convection \\ - Operating temperature range: $0^{\circ}$ to $50^{\circ} \mathrm{C}\left(32^{\circ} \mathrm{F}\right.$ to $\left.122^{\circ} \mathrm{F}\right)$ \\ - Storage Temperature range: $-20^{\circ} \mathrm{C}$ to $60^{\circ} \mathrm{C}\left(-4^{\circ} \mathrm{F}\right.$ to $\left.140^{\circ} \mathrm{F}\right)$. \\ - Relative humidity range: $5 \%$ to $95 \%$, non-condensing \\ Agency Listings \\ - UL 916, C-UL listed to Canadian Standards Association (CSA) C22.2 No. 205-M1983 "Signal Equipment", CE, FCC part 15 \\ Class A, C-Tick (Australia)
}

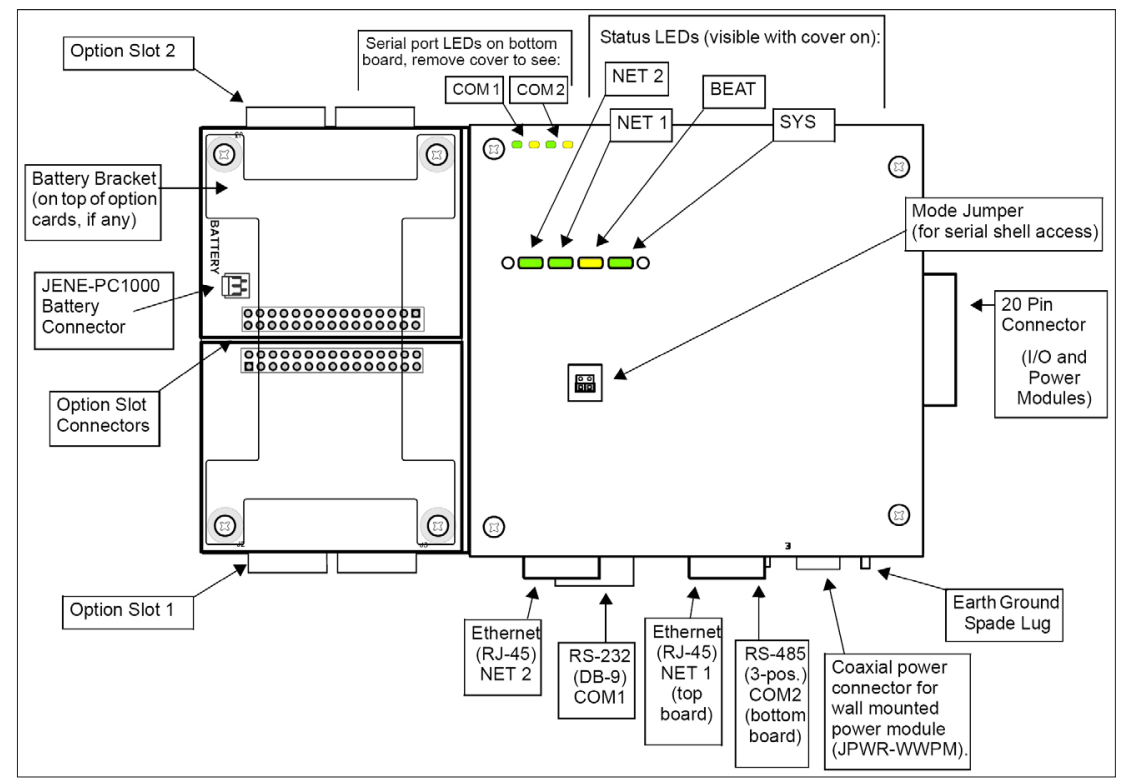

\section{Ordering Information}

\begin{tabular}{|l|l|}
\hline Model \# & Description \\
\hline JENE-PC1064 & JENE-PC1000 Controller w/64 MB RAM \\
JENE-PC1128 & JENE-PC1000 Controller w/128 MB RAM \\
JENE-PC1-128-LIC & 128MB Upgrade License \\
See Price Sheet for Additional PC1000 Options & \\
\hline
\end{tabular}




\section{BAC-5801 and BAC-5802}

\section{Advanced Application Controllers, 8 × 8}

\section{Description and application}

The BAC-5801 and BAC-5802 are native BACnet, fully programmable, direct digital controllers. Use these versatile general purpose controllers in standalone environments or networked to other BACnet devices. As part of a complete facilities management system, the BAC-5801 and BAC-5802 controllers provide precise monitoring and control of connected points.

- BACnet MS/TP compliant

- Automatically assigns the MAC address and the device instance

- Easy to install, simple to configure, and intuitive to program

- Controls room temperature, humidity, fans, monitors refrigeration, lighting, and other building automation functions.

\section{Specifications}

\section{Inputs}

- 8 universal inputs, each of which is programmable as an analog, binary, or accumulator object. Accumulators limited to three per controller.

- Standard units of measure

- Pull-up resistors for switch contacts and other unpowered equipment. Switch selects none or $10 \mathrm{~K}$ ohms.

- Removable screw terminal blocks, wire size 14-22 AWG

- 10-bit analog-to-digital conversion

- Pulse counting to $16 \mathrm{~Hz}$

- 0-5 volts DC analog input range

- Overvoltage input protection

- Compatible with KMD-1160 and KMD-1180 series NetSensors

\section{Outputs}

- 8 universal outputs, each of which is programmable as an analog or binary object

- Standard and custom units of measure

- Slots for HPO-6700 series output override boards

- Removable screw terminal blocks, wire size 14-22 AWG

- 0-10 volts DC for analog objects

- 0 or 12 volts DC for binary objects

- Short-protected outputs, output current limited

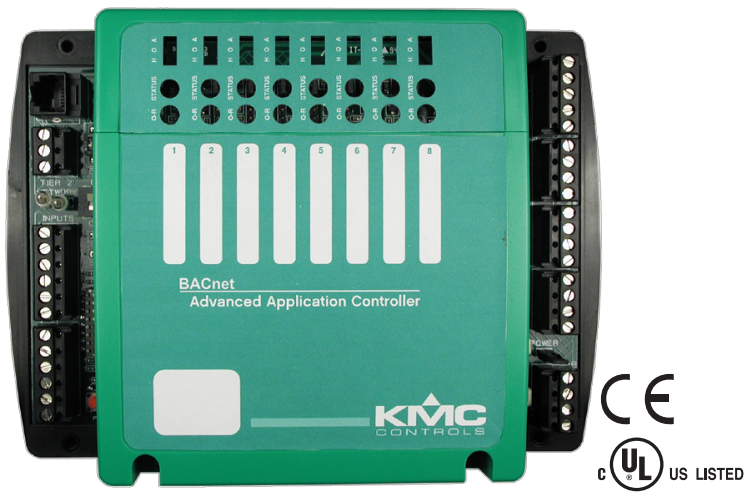

Programmable features

- 10 Control Basic program areas

- 40 analog and 40 binary value objects

- Real time clock with power backup for 72 hours (BAC-5801 only)

- 8 PID loop objects

- See PIC statement for supported BACnet objects Schedules

- 8 Schedule objects

- 3 Calendar objects

Alarms and events

- Supports intrinsic reporting

- 8 Notification class objects

Trends

- 8 Trend objects

Memory

- Programs and program parameters are stored in nonvolatile memory

- Auto restart on power failure

\section{Communications}

- MS/TP operating at up to 76.8 kilobaud (network connections are supervised in smoke control applications)

- Automatically assigns MAC addresses and device instance numbers

- Modular jack for NetSensor connection (5 VDC at $25 \mathrm{~mA}$ typical) 
Specifications ((continued)

\section{Dimensions}
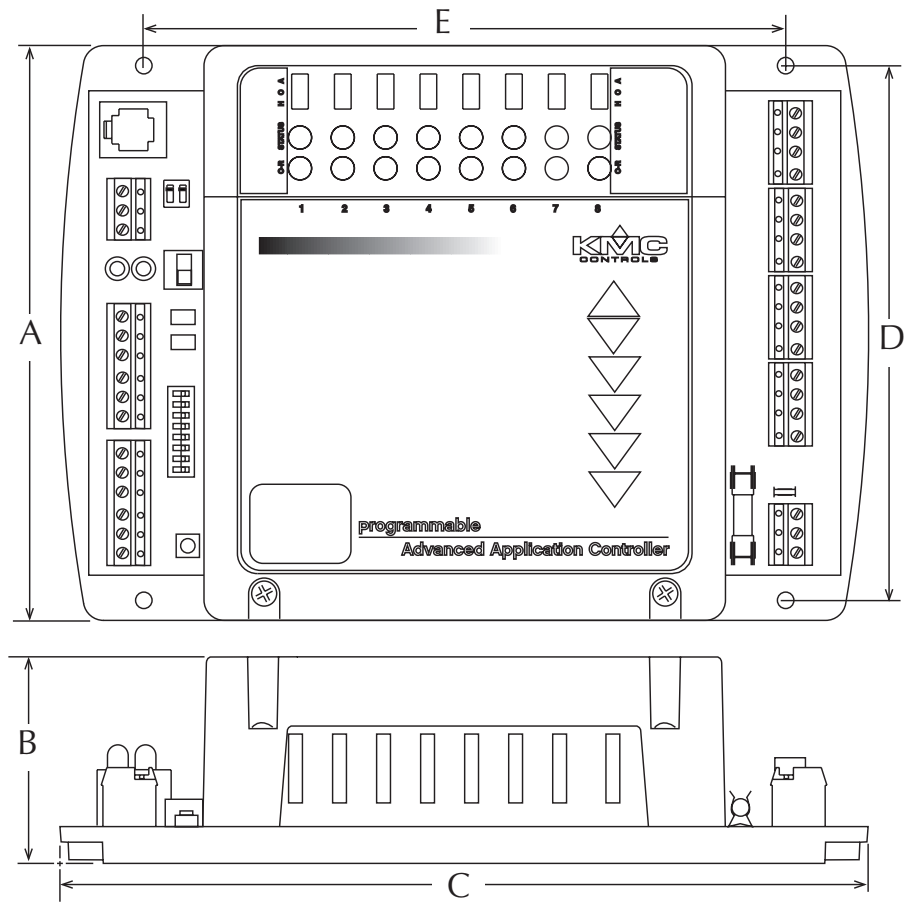

\begin{tabular}{ccccc}
\hline $\mathbf{A}$ & $\mathbf{B}$ & $\mathbf{C}$ & $\mathbf{D}$ & $\mathbf{E}$ \\
\hline $5.38 \mathrm{in.}$ & $1.98 \mathrm{in}$. & $7.55 \mathrm{in}$. & $5.0 \mathrm{in.}$ & $6.0 \mathrm{in.}$ \\
\hline $137 \mathrm{~mm}$ & $50 \mathrm{~mm}$ & $192 \mathrm{~mm}$ & $127 \mathrm{~mm}$ & $152 \mathrm{~mm}$ \\
\hline
\end{tabular}

\section{Installation}

\section{Supply voltage}

24 volts AC $(-15 \%,+20 \%), 60 \mathrm{~Hz}, 36 \mathrm{VA}$, Class 2

only, non-supervised (all circuits, including supply

voltage, are power limited circuits)

\section{Weight \\ 14 ounces (395 g) \\ Case material \\ Green and black flame \\ retardant plastic}

\section{Environmental limits}

Operating 32 to $120^{\circ} \mathrm{F}\left(0\right.$ to $\left.49^{\circ} \mathrm{C}\right)$

Shipping -40 to $140^{\circ} \mathrm{F}\left(-40\right.$ to $\left.60^{\circ} \mathrm{C}\right)$

Humidity 0-95\% RH (non-condensing)

Regulatory

- FCC Class B, Part 15, Subpart B

- BACnet Testing Laboratory listed

- CE compliant

- UL 916 Energy Management Equipment listed

- UL 864 Smoke Control Equipment listed (UUKL) (for smoke control applications, see Smoke Control Manual For BACnet Systems, P/N 000035-08)

\section{Software compatibility}

Requires the current version of BACstage or TotalControl for full configuration and programming features.
Accessories

Connectors and fuses

902-602-04 Replacement three-pin removable terminal block

031-602-02 Replacement four-pin removable terminal block

883-602-17 Replacement six-pin removable terminal block

902-600-04 Replacement fuse, 1.0 A, fast acting, $5 \times 20 \mathrm{~mm}$

HPO-0054 Replacement fuse bulb

HPO-0063 Replacement two-pin jumper

Enclosure

HCO-1102 Steel control enclosure, 10.1 W x 2.4 $\mathrm{H} \times 7.1 " \mathrm{D}(257 \times 62 \times 181 \mathrm{~mm})$

NOTE: For smoke control applications, the controller must be mounted in a UL Listed FSCS enclosure or listed enclosure with minimum dimensions - see Smoke Control Manual For BACnet Systems (P/N 000-035-08)

\section{Output override boards (HPO-6700 series)}

NOTE: See the (P/N 902-035-10) HPO-6700 series data sheet (only the HPO-6701/6704 boards are approved for smoke control applications)

\section{Power transformers}

XEE-6111-40 Transformer, 120-to-24 VAC, 40 VA, single-hub

XEE-6112-40 Transformer, 120-to-24 VAC, 40 VA, dual-hub

XEE-6112-100 Transformer, 120-to-24 VAC, 96 VA, dual-hub (required in smoke control applications)

\section{Models}

BAC-5801

Controller with real-time clock

BAC-5802

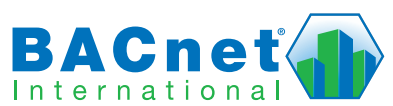

KMC Controls, Inc.

19476 Industrial Drive, New Paris, IN 46553 574.831.5250

www.kmccontrols.com; info@kmccontrols.com 


\section{BAC-10000 Series}

\section{FlexStat $^{\mathrm{TM}}$}

\section{Description and Application}

The award-winning FlexStat is a controller and sensor in a single, attractive package that creates a flexible solution to stand-alone control challenges or BACnet network challenges. Temperature sensing is standard with optional humidity and motion sensing. Flexible input and output configurations and built-in or custom programming ensure that a variety of application needs can be met. Such applications include single- and multi-stage packaged, unitary, and split systems (including high SEER/EER variable speed packaged equipment), as well as factory-packaged and field-applied economizers, water-source and air-to-air heat pumps, fan coil units, central station air handling units, and other similar applications.

In addition, an on-board library of programs permits a single model to be rapidly configured for a wide range of HVAC control applications. Thus, a single "one size fits all" FlexStat model can replace multiple competitor models. A single BAC-10163CW, for example, can be configured for any and all of these application options:

- Air handling unit, with proportional heating and cooling valves, and with optional economizer, dehumidification, and/or fan status

- Fan coil unit, 2-pipe or 4-pipe, proportional or 2-position valves, with optional dehumidification (w/ 4-pipe option) and/or fan status

- Heat pump unit, with up to two compressor stages, and with optional auxiliary heat, emergency heat, dehumidification, and/or fan status

- Roof top unit, with up to two H/C stages, and with optional economizer, dehumidification, and/ or fan status

FlexStats also provide the capability to customize the standard library of sequences using KMC's BACstage programming tool. This enables a local authorized KMC installing contractor to adapt the standard library to the unique site needs and application specific requirements of a particular project.

Standard hardware options include a mix of output configurations (relays and universal outputs), optional on-board humidity/motion sensing, and inputs for additional remote external sensors such as outside air temperature and fan status sensors.

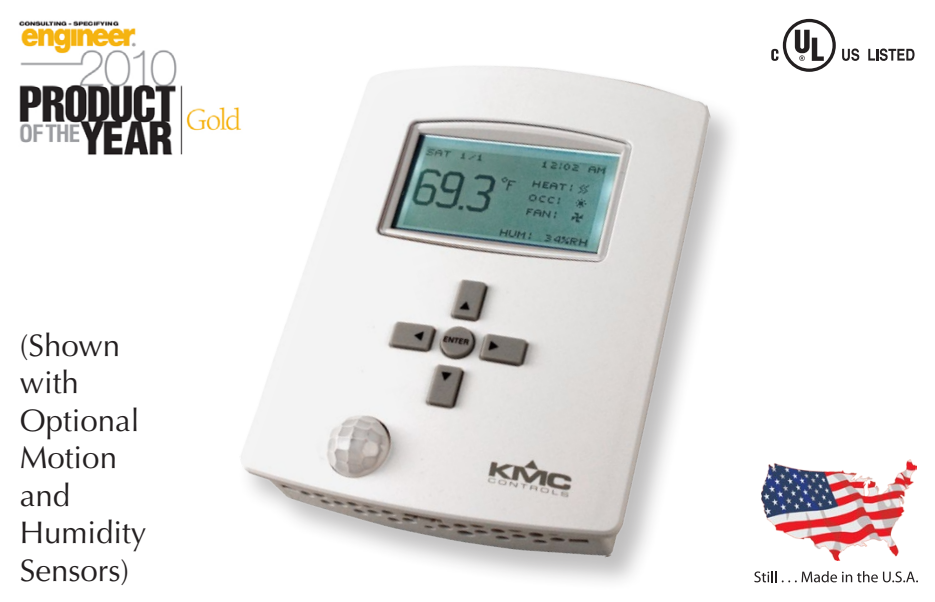

\section{Features}

\section{Interface and Function}

- User-friendly English-language menus (no obscure numeric codes) on a $64 \times 128$ pixel, dot-matrix LCD display with 5 buttons for data selection and entry

- Built-in, factory-tested libraries of configurable application control sequences

- Integral energy management control with deadband heating and cooling setpoints and other advanced features

- Schedules can easily be set uniquely by weekdays (Mon.-Fri.), weekend (Sat.-Sun.), entire week (Mon.-Sun.), individual days, and/or holidays

- Six On/Off and independent heating and cooling setpoint periods are available per day

- Three levels of password-protected access (user/ operator/administrator) prevent disruption of operation and configuration-plus Hospitality mode and Locked User Interface mode offer additional tamper resistance

- Integral temperature and optional humidity and/ or motion sensors (shown in photo above)

- Model choices enable "best fit" of sequence in new and retrofit applications with other field devices, such as proportional or 3-wire "floating" actuators and staged equipment; functionally replace most Viconics and other competitors' products

- All models have 72-hour power (capacitor) backup and a real time clock for network time synchronization or full stand alone operation 


\section{Features (Cont.)}

\section{Inputs}

- Three analog inputs (that can also be mapped as binary inputs in Control Basic) for use with external devices such as mixed air temperature, fan status, outside air, and $\mathrm{CO}_{2}$ sensors

- Analog inputs accept industry-standard 10K ohm thermistor sensors or dry contacts

- Inputs can be configured via a switch for $10 \mathrm{~K}$ ohm pull-up resistors (for unpowered contacts or devices) or 0-12 VDC

- Input overvoltage protection (24 VAC, continuous)

- 12-bit analog-to-digital conversion on inputs

\section{Outputs}

- Up to nine outputs, analog and binary (relays)

- Each short-circuit protected analog output capable of driving up to $20 \mathrm{~mA}$ (at 0-12 VDC)

- The NO, SPST (Form "A") relays carry 1 A max. per relay or 1.5 A per bank of 3 relays (relays 1-3, 4-6, and 7-9) @ 24 VAC/VDC

- 8-bit digital-to-analog conversion on outputs

\section{Installation}

- Backplate mounts on a standard vertical $2 x$ 4-inch wall handy-box (or, with an HMO-10000 adapter, a horizontal or $4 \times 4$ handy-box), and the cover is secured to the backplate by two concealed hex screws

- Two-piece design provides easy, flexible wiring and installation (see the Dimensions and Connectors section)

- Attractive white (standard) or light almond (optional) plastic case

\section{Connections}

- Screw terminal blocks, wire size 14-22 AWG, for inputs, outputs, power, and BACnet network

- Integral peer-to-peer BACnet MS/TP LAN network communications on all devices (with configurable baud rate from 9600 to $76.8 \mathrm{~K}$ baud)

- A four-pin EIA-485 (formerly RS-485) data port on the underside of the case enables easy temporary computer connection to the BACnet network (access with a KMD-5624 cable-requires use of KMD-5576 or third-party interface)

\section{BACnet Standards}

- Meets or exceeds BACnet AAC specifications in the ANSI/ASHRAE BACnet Standard 135-2008

\section{Configurability}

$I / O$

- Up to 7 analog input objects (IN1 is space temperature, IN2-IN4 are 0-12 VDC inputs, IN5 is reserved for humidity, IN6 is reserved for motion detection, IN7 is reserved for $\mathrm{CO}_{2}$ )

- Up to 9 analog or binary output objects

\section{Value}

- 60 analog value objects

- 40 binary value objects

- 20 multi-state value objects (with up to 16 states each)

\section{Program and control}

- 10 PID loop objects

- 10 program objects (contains a library of 5 builtin programs and customized Control Basic programming in the other 5 program objects can be done through BACstage or TotalControl)

\section{Schedules and trends}

- 2 schedule objects

- 1 calendar object

- 8 trend objects, each of which holds 256 samples

\section{Alarms and events}

- 5 notification class (alarm/event) objects

- 10 event enrollment objects

\section{Dimensions and Connectors}

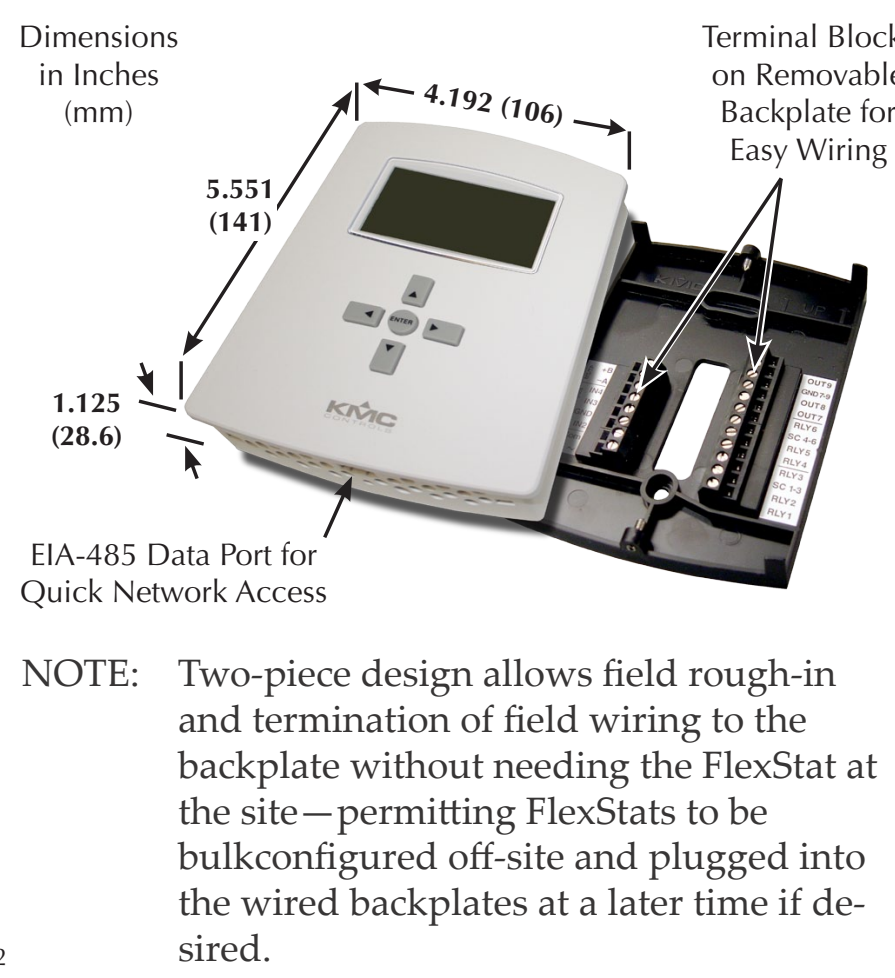


If your application is a:

- Packaged Unit, AHU (Air Handling Unit), RTU (Roof Top Unit) - see all models.

- FCU (Fan Coil Unit) - see the BAC-1xx36CW and BAC-1xx63CW models.

- HPU (Heat Pump Unit) - see the BAC-1xx63CW models or, for one compressor only, BAC-1xx$30 \mathrm{CW}$ models.
- Other 1 Heat or 1 Cool Unit-see the BAC-1xx$30 \mathrm{CW}$ models.

\section{For more details, see the Application/Model Selec- tion Guide on the next page.}

\begin{tabular}{|c|c|c|c|}
\hline Model* & Outputs** & Optional Sensors*** & Typical Applications \\
\hline BAC-10030CW & \multirow{4}{*}{$\begin{array}{c}3 \text { Relays } \\
\text { (Binary Outputs) } \\
\text { (All models have } \\
3 \text { analog inputs) }\end{array}$} & None & $\begin{array}{l}-1 \mathrm{H} / 1 \mathrm{C} \text { packaged and split systems } \\
-1 \mathrm{H} 2 \text {-position economizer applications } \\
\text { - } 1 \mathrm{H} / 1 \mathrm{C} \text { heat pumps (no auxiliary or emergency heat) } \\
\text { - Unit heaters } \\
\text { - Single-stage cooling applications }\end{array}$ \\
\hline BAC-10130CW & & Humidity & $\begin{array}{l}\text { - Same as BAC-10030CW } \\
\text { - Dehumidification sequence (AHU) }\end{array}$ \\
\hline BAC-11030CW & & Motion/Occupancy & $\begin{array}{l}\text { - Same as BAC-10030CW } \\
\text { - Occupancy-based operation }\end{array}$ \\
\hline BAC-11130CW & & $\begin{array}{l}\text { Humidity and } \\
\text { Motion/Occupancy }\end{array}$ & $\begin{array}{l}\text { - Same as BAC-10130CW } \\
\text { - Occupancy-based operation }\end{array}$ \\
\hline BAC-10036CW & \multirow{4}{*}{$\begin{array}{l}3 \text { Relays and } \\
6 \text { Analog Outputs }\end{array}$} & None & $\begin{array}{l}\text { - } 1 \mathrm{H} / 1 \mathrm{C} \text {, fan, and } 6 \text { universal outputs } \\
\text { - 3-speed fan, 2- or 4-pipe FCUs with modulating valves } \\
\text { - Central station AHUs with modulating/1/2 Heat/Cool } \\
\text { - Variable-speed fan output } \\
\text { - Single-stage applications }\end{array}$ \\
\hline BAC-10136CW & & Humidity & $\begin{array}{l}\text { - Same as BAC-10036CW } \\
\text { - Dehumidification sequence } \\
\text { - Humidification sequence (AHU or 4-pipe FCU) }\end{array}$ \\
\hline BAC-11036CW & & Motion/Occupancy & $\begin{array}{l}\text { - Same as BAC-10036CW } \\
\text { - Occupancy-based operation }\end{array}$ \\
\hline BAC-11136CW & & $\begin{array}{l}\text { Humidity and } \\
\text { Motion/Occupancy }\end{array}$ & $\begin{array}{l}\text { - Same as BAC-10136CW } \\
\text { - Occupancy-based operation }\end{array}$ \\
\hline BAC-10063CW & \multirow{4}{*}{$\begin{array}{l}6 \text { Relays and } \\
3 \text { Analog Outputs }\end{array}$} & None & $\begin{array}{l}\text { - } 1 \text { or } 2 \mathrm{H} \text { and } 1 \text { or } 2 \mathrm{C} \text {, fan } \\
\text { - Multi-stage packaged or split systems } \\
\text { - Multi-stage heat pumps with or without factory-packaged economizers } \\
\text { - Central station AHUs with modulating Heat/Cool } \\
\text { - 3-speed fan, 2- or 4-pipe FCUs with modulating or 2-position valves }\end{array}$ \\
\hline BAC-10163CW & & Humidity & $\begin{array}{l}\text { - Same as BAC-10063CW } \\
\text { - Dehumidification sequence (AHU, 4-pipe FCU, or RTU) }\end{array}$ \\
\hline BAC-11063CW & & Motion/Occupancy & $\begin{array}{l}\text { - Same as BAC-10063CW } \\
\text { - Occupancy-based operation }\end{array}$ \\
\hline BAC-11163CW & & $\begin{array}{l}\text { Humidity and } \\
\text { Motion/Occupancy }\end{array}$ & $\begin{array}{l}\text { - Same as BAC-10163CW } \\
\text { - Occupancy-based operation }\end{array}$ \\
\hline \multicolumn{4}{|c|}{$\begin{array}{l}\text { *The standard color is white. To order the optional light almond color, remove the "W" at the end of the model number } \\
\text { (e.g., BAC-11163C instead of BAC-11163CW). All models have a real-time clock. All models have optional discharge air } \\
\text { temperature monitoring/trending or fan status monitoring. } \\
\text { ** Analog outputs produce 0-12 VDC @ } 20 \text { mA maximum, and relays carry } \mathbf{1} \text { A max. per relay or } \mathbf{1 . 5} \text { A per bank of } 3 \text { relays }\end{array}$} \\
\hline
\end{tabular}


Applications and Options

FlexStat Models and Outputs

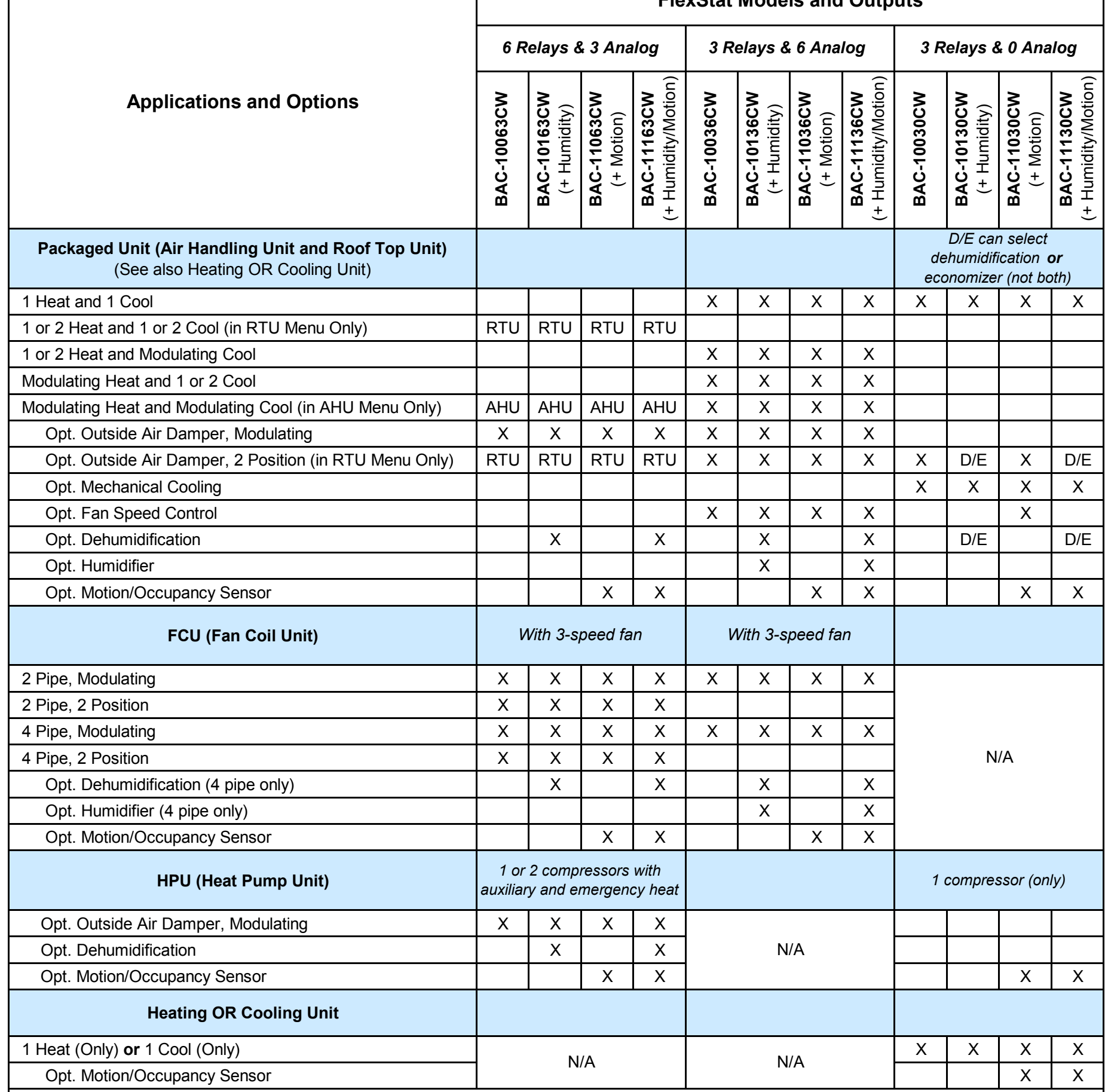

All models have a real-time clock. They also have optional discharge air temperature monitoring/trending or fan status monitoring (but not both).

To order light almond instead of white, remove $W$ from the end of the model number (e.g., BAC-10036C).

$\begin{array}{lll}\text { Model "Code" for BAC-1mhra CW: } & \text { BAC = BACnet Device } & r=\text { Number of Relays }(3 / 6) \\ 1=\text { Model Series } & a=\text { Number of Analog Outputs (0/3/6) } \\ & m=\text { Motion Sensor }(0 / 1) & \text { C = Real-Time Clock } \\ & h=\text { Humidity Sensor }(0 / 1) & \text { W = White Color (no W = light almond) }\end{array}$




\section{Supply Voltage \\ Supply Power \\ Connections \\ 24 VAC (+20\%/-15\%), Class 2 \\ 13 VA \\ Wire clamp type terminal blocks; 14-22 AWG, copper \\ Four-pin EIA-485}

Outputs (up to 9)

Inputs (IN2-IN4)

Display

Case Material

Dimensions

Approvals

Weight

Analog outputs (if any) produce 0-12 VDC, $20 \mathrm{~mA}$ maximum

Binary outputs (NO, SPST, Form "A" relays) carry $\mathbf{1}$ A max. per relay or a total of $1.5 \mathrm{~A}$ per bank of 3 relays (relays 1-3, 4-6, and 7-9)@ 24 VAC/VDC sive contacts, $10 \mathrm{~K}$ thermistors) $64 \times 128$ pixel dot matrix LCD White (standard) or light almond flame-retardant plastic

$5.551 \times 4.192 \times 1.125$ inches $(141 \times 106 \times 28.6 \mathrm{~mm})$

\section{UL 916 Energy Management}

Equipment

FCC Class B, Part 15, Subpart B BTL listing pending
Analog 0-12 VDC (active/pas-

\section{Humidity Sensor (Optional)}

Sensor Type CMOS

Range

Accuracy @ $25^{\circ} \mathrm{C} \quad \pm 2 \% \mathrm{RH}(10$ to $90 \% \mathrm{RH})$

Response Time Less than or equal to 4 seconds

Motion Sensor (Opt.) Passive infrared with 10 meter (33 feet) range (see diagrams at right)

\section{Temperature Sensor (without Humidity)}

Sensor Type Thermistor, Type II

Accuracy $\quad \pm 0.36^{\circ} \mathrm{F}\left( \pm 0.2^{\circ} \mathrm{C}\right)$

Resistance $\quad 10,000 \mathrm{ohms}$ at $77^{\circ} \mathrm{F}\left(25^{\circ} \mathrm{C}\right)$

Operating Range 48 to $96^{\circ} \mathrm{F}\left(8.8\right.$ to $\left.35.5^{\circ} \mathrm{C}\right)$

Temperature Sensor (with Humidity)

Sensor Type CMOS

Accuracy $\quad \pm 0.9^{\circ} \mathrm{F}$ offset $\left( \pm 0.5^{\circ} \mathrm{C}\right)$ from 40 to $104^{\circ} \mathrm{F}\left(4.4\right.$ to $\left.40^{\circ} \mathrm{C}\right)$

Operating Range 36 to $120^{\circ} \mathrm{F}\left(2.2\right.$ to $\left.48.8^{\circ} \mathrm{C}\right)$

\section{Environmental Limits}

Operating

Shipping

Humidity

34 to $125^{\circ} \mathrm{F}\left(1.1\right.$ to $\left.51.6^{\circ} \mathrm{C}\right)$

-40 to $140^{\circ} \mathrm{F}$ ( -40 to $60^{\circ} \mathrm{C}$ )

0 to $95 \%$ RH (non-condensing)
Motion/Occupancy Sensor

Detection Performance
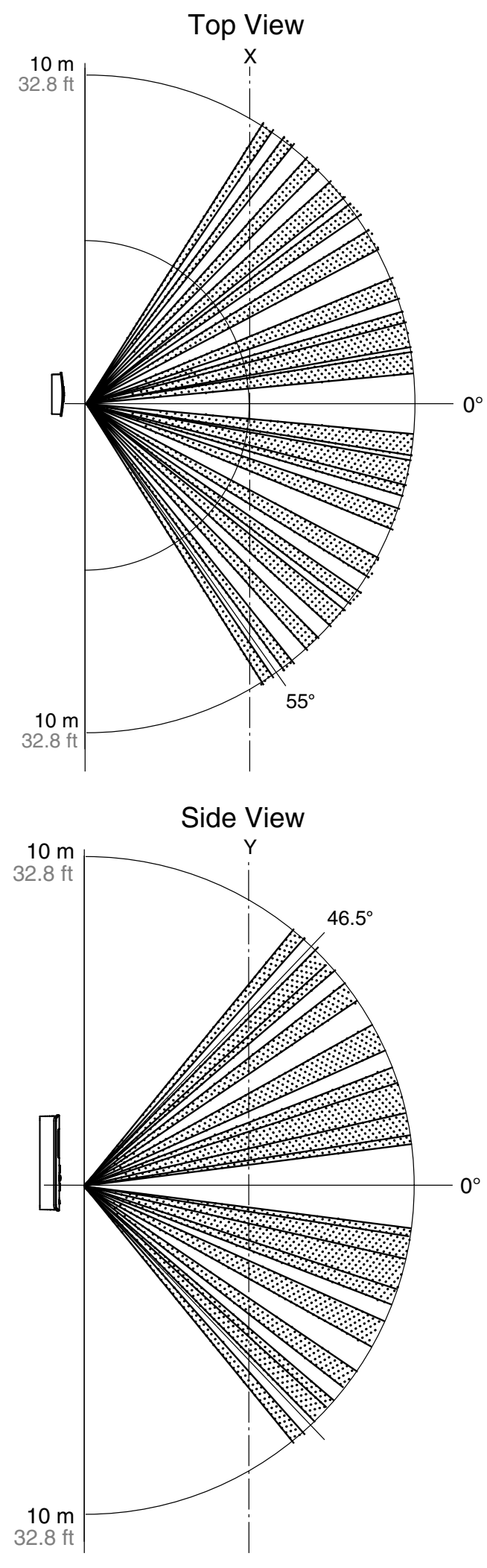

For more details about operation of the motion sensor, see the FlexStat Application Guide (913-019-03). 


\section{Accessories}

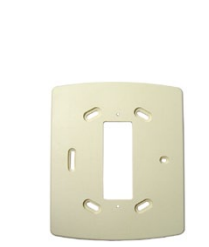

$=$
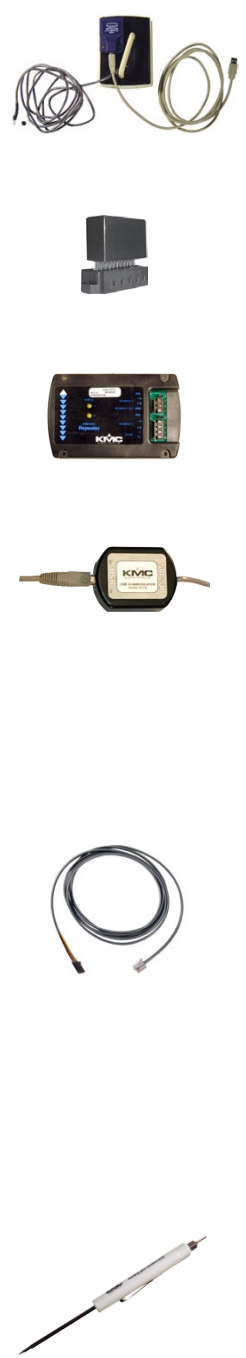

SP-001

XEE-6111-040

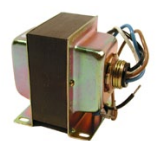

HMO-10000

HTO-1103

(formerly

KMD-5699)

KMD-5567

KMD-5575

KMD-5624

XEE-6111-040
KMD-5576 $40 \mathrm{VA}$, single-

XEE-6112-040 ransformer, 120-to-24 VAC, hub

Horizontal or 4 $x 4$ handy box wall mounting plate, light almond (shown)

HMO-10000 in white

Replacement cover hex screw

FlexStat firmware flash upgrade kit

Network surge suppressor

Network repeater/isolator

EIA-485 to USB Communicator

PC data port (EIA-485) cable (FlexStat to USB Communicator)-included with the KMD5576 (buy for third-party EIA232 interfaces)

Flat blade and hex end screwdriver (with KMC logo) for cover hex screws

Transformer, 40 VA, dual-hub

\section{Sample Installation}

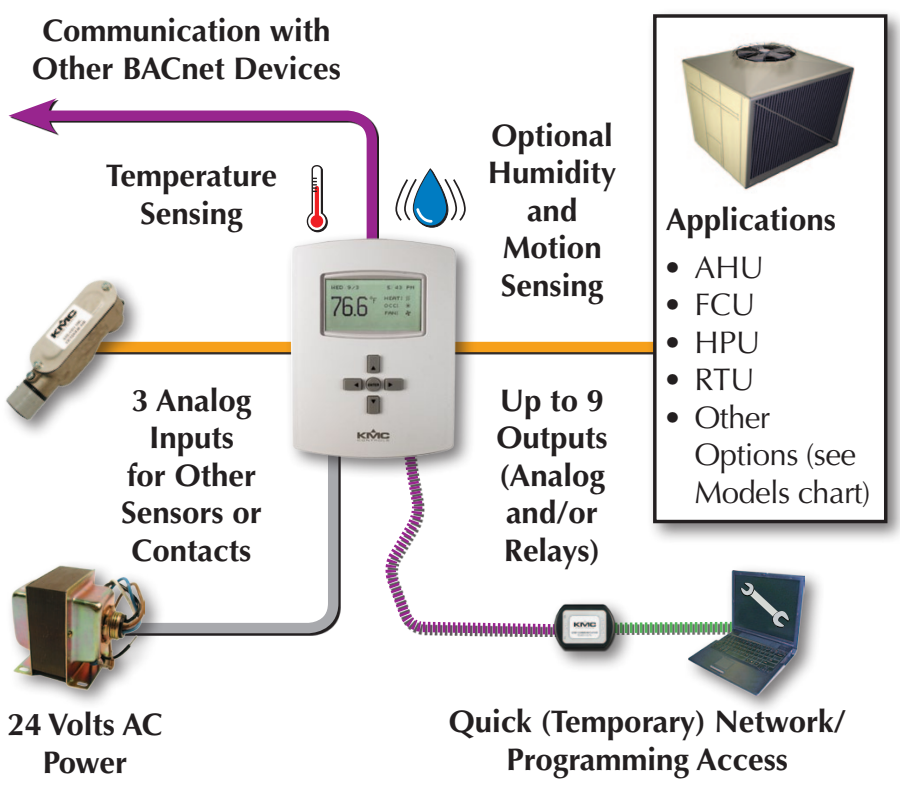

\section{Support}

FlexStats come with a printed Installation Guide. Additional award-winning resources for configuration, application, operation, programming, upgrading and much more is available on the KMC Controls web site (www.kmccontrols.com).

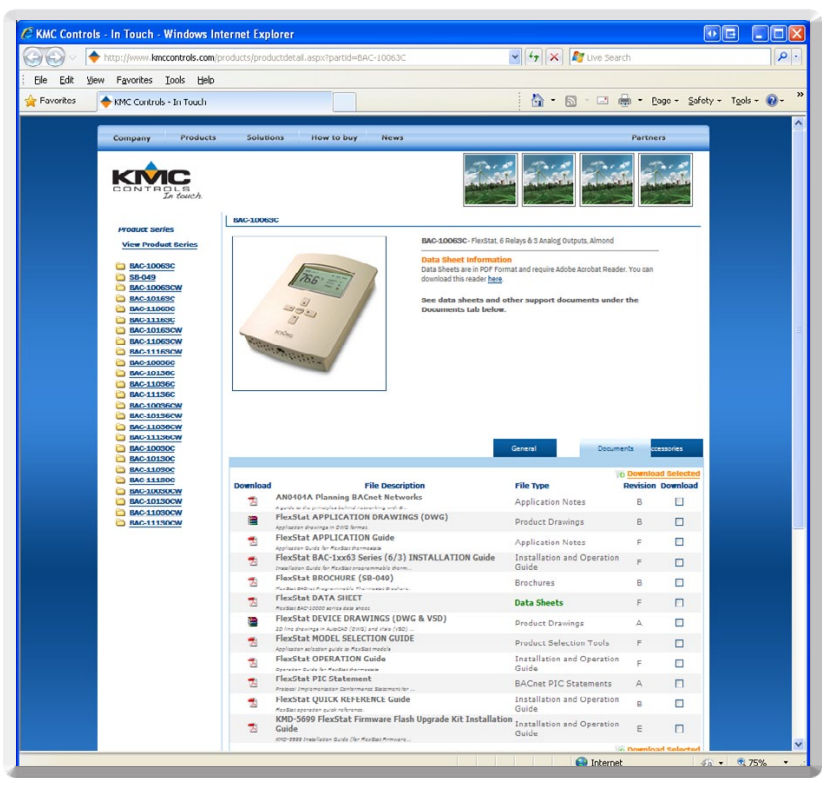

KMC Controls, Inc.

19476 Industrial Drive, New Paris, IN 46553

574.831 .5250

www.kmccontrols.com

info@kmccontrols.com 


\section{Description}

These compact, stylish, and economical room temperature sensors and transmitters are designed for use in KMC Digital controllers or other building automation systems. They incorporate a $10,000 \mathrm{ohm}$ (@ $77^{\circ} \mathrm{F}$ ) thermistor for precise, stable temperature sensing and offer a variety of features.

The durable, low-profile, thermostat-style cover is visually appealing. These sensors may be surface mounted on a hollow wall or (using an HMO-6036 universal backplate) to a $2 \times 4$ in. electrical box.

\section{Models}

The following models are available:

\begin{tabular}{|c|c|c|c|c|c|c|c|c|c|c|}
\hline \multirow[b]{2}{*}{$\begin{array}{l}\text { STE- } \\
601 x \\
\text { Model } \\
\text { Number }\end{array}$} & \multicolumn{2}{|c|}{$\begin{array}{l}\text { Setpoint } \\
\text { Adjust }\end{array}$} & \multicolumn{3}{|c|}{$\begin{array}{l}\text { Other } \\
\text { Interface } \\
\text { Features }\end{array}$} & \multicolumn{3}{|c|}{$\begin{array}{c}\text { Cable } \\
\text { Connections }\end{array}$} & \multicolumn{2}{|c|}{$\begin{array}{l}\text { Temper- } \\
\text { ature } \\
\text { Output }\end{array}$} \\
\hline & 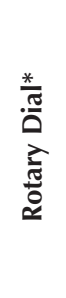 & 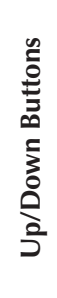 & 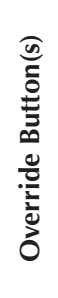 & $\begin{array}{l}\frac{\lambda}{a} \\
\frac{0}{0} \\
0 \\
0 \\
0\end{array}$ & 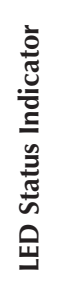 & 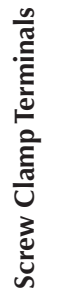 & 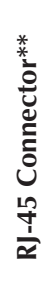 & 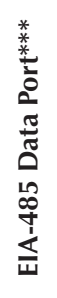 & 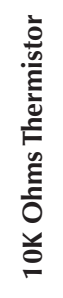 & 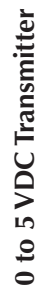 \\
\hline $6010-10$ & & & & & & & $X$ & $X$ & $x$ & \\
\hline $6011-10$ & & & & & & $x$ & & & $x$ & \\
\hline 6013-10 & & & $X$ & & $X$ & $X$ & & & $x$ & \\
\hline $6015-10$ & & & $X$ & & $X$ & & $X$ & $X$ & $x$ & \\
\hline $6012-10$ & & $X$ & $X$ & $X$ & & $X$ & & & & $X$ \\
\hline $6016-10$ & & $X$ & $X$ & $X$ & & & $x$ & $X$ & & $x$ \\
\hline 6014-10 & $X$ & & & & & & $X$ & $X$ & $x$ & \\
\hline $6017-10$ & $x$ & & $X$ & & & & $x$ & $X$ & $x$ & \\
\hline $6019-10$ & $x$ & & $X$ & & & $x$ & & & $x$ & \\
\hline $6018-10$ & $x$ & & $X$ & & $x$ & & $x$ & $X$ & $x$ & \\
\hline $6020-10$ & $X$ & & $X$ & & $X$ & $X$ & & & $x$ & \\
\hline \multicolumn{11}{|c|}{$\begin{array}{l}{ }^{*} \text { Earlier rotary dial models were marked with }{ }^{\circ} \mathrm{F} \text { or }{ }^{\circ} \mathrm{C}, \\
\text { but dials now have warmer/cooler icons instead of numbers } \\
{ }^{* *} \text { Requires KMD-569x sensor to controller cable } \\
\text { ***Requires KMD-5624 PC data port cable (see Accessories) }\end{array}$} \\
\hline
\end{tabular}

The standard color is almond. To order in white, add $\mathrm{a}$ " $\mathrm{W}$ " in the place of the hyphen near the end of the model number (e.g., STE-6012W10).

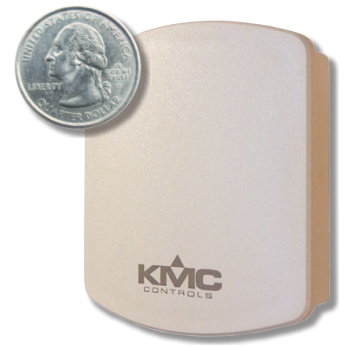

STE-6010/6011

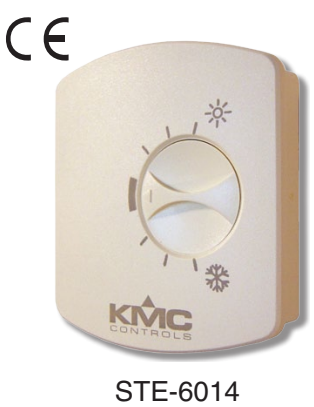

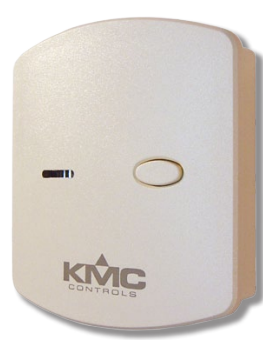

STE-6013/6015

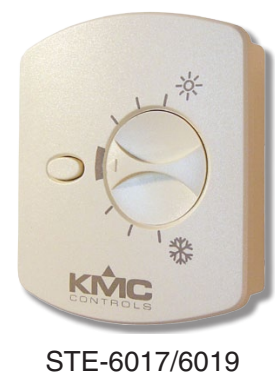

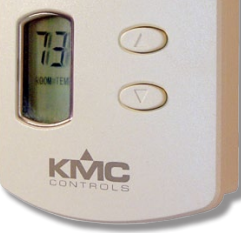

STE-6012/6016

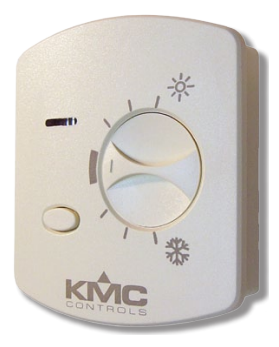

STE-6018/6020

\section{Features and Applications}

An STE-6014/6017/6019/6018/6020 includes a rotary setpoint dial with warmer/cooler icons.

An STE-6013/6015/6017/6019/6018/6020 allows selection of an override condition by pushing the button on the front. A green status LED (not on the STE6017/6019) illuminates according to the user-defined controller configuration (e.g., during setback/setup or during normal/override modes).

An STE-6012/6016 transmitter includes an LCD display for the room temperature and setpoint. The temperature display can be toggled between Fahrenheit and Celsius scales. The setpoint is adjustable via the up and down arrow buttons on the front panel. If the system is in normal/override mode, pressing a button will raise or lower the setpoint. When either button is pushed, the display will toggle from room temperature to the setpoint. When the button is released, the number displayed is the new setpoint, and the display will return to room temperature after ten seconds. If the system is in setback/setup (for heating/cooling) mode, pressing either button selects override mode. (See Power Requirements in the Specifications section.)

An STE-6010/6014/6015/6016/6017/6018 includes a fourpin EIA-485 (formerly RS-485) data port on the cover's underside for easy temporary computer connection to the network. (Access with a KMD-5624 cable.) 


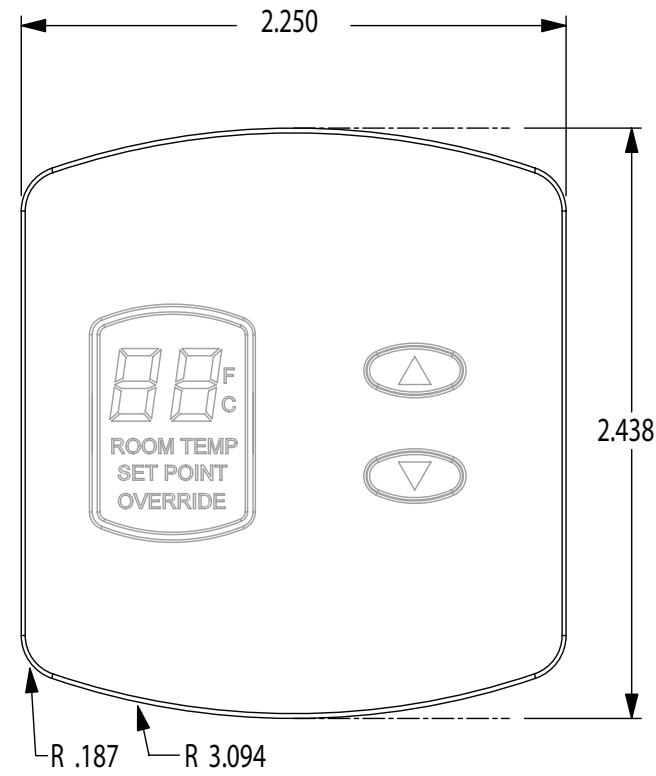

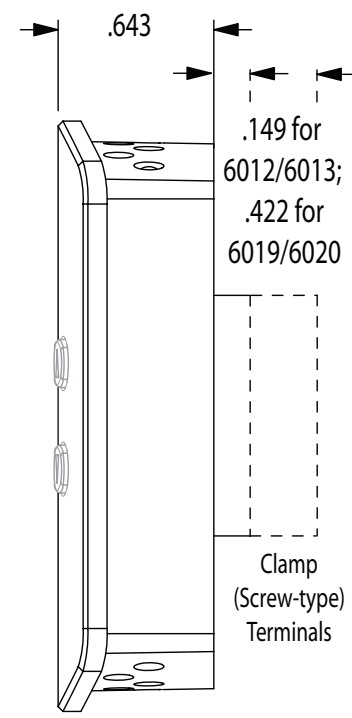

STE-6012/6013/6019/6020
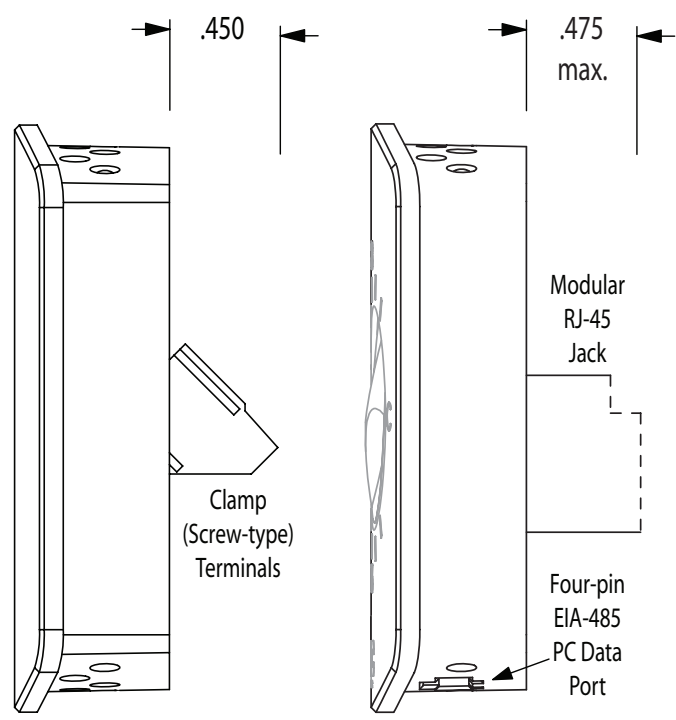

STE-6011

STE-6010/6014/6015/6016/6017/6018
Specifications

\section{Connections}

Material

Weight

Sensor

Type

Accuracy

Resistance

NTC

Dissipation Constant $2 \mathrm{~mW} /{ }^{\circ} \mathrm{C}$

Temp. Reading

Thermistor resistance only from all models except the 0-5 VDC voltage output from the STE-6012/6016 transmitter

Rotary Setpoint Pot. $0-10 \mathrm{~K}$ ohms $\pm 20 \%\left(54-90^{\circ} \mathrm{F}\right.$ or $12-32^{\circ} \mathrm{C}$ ) linear

\section{Accessories}

HMO-6036
HMO-6036W
KMD-569x

Universal Backplate, Almond

KMD-569x

KMD-5624

KMD-5576
Clamp (screw-type) terminals or modular RJ-45 jack (see Models chart)

Flame-retardant plastic, light almond or white

Approx. 1.25 oz. (35 grams)

Type II thermistor

$\pm 0.36^{\circ} \mathrm{F}\left( \pm 0.20^{\circ} \mathrm{C}\right)$

10,000 ohms @ $77^{\circ} \mathrm{F}\left(25^{\circ} \mathrm{C}\right)$

$4.37 \% /{ }^{\circ} \mathrm{C} @ 25^{\circ} \mathrm{C}$

\section{Front Buttons}

STE-6013/6015/6017/6019/6018/6020

One momentary push button, shunts temperature sensor to signal override condition

STE-6012/6016 Two momentary push buttons, signal override condition, adjust setpoint, toggle ${ }^{\circ} \mathrm{C}$ or $\mathrm{F}$, calibrate temperature reading

\section{Power Requirements}

LED Indicator

10 VDC (12 VDC max); $5 \mathrm{~mA}$ max. current draw at $12 \mathrm{VDC}$

LCD Display 7.5 VDC (10.4 mA max. current draw) for setback/setup mode or 12 VDC (9.7 mA) for normal/override modes

\section{Approvals CE compliant}

\section{Environmental Limits}

Display $(6012 / 6016) 35^{\circ}$ to $90^{\circ} \mathrm{F}\left(2^{\circ}\right.$ to $\left.32^{\circ} \mathrm{C}\right)$

Operating $\quad 34^{\circ}$ to $125^{\circ} \mathrm{F}\left(1.1^{\circ}\right.$ to $\left.51.6^{\circ} \mathrm{C}\right)$

Shipping $\quad-40^{\circ}$ to $140^{\circ} \mathrm{F}\left(-40^{\circ}\right.$ to $\left.60^{\circ} \mathrm{C}\right)$

Humidity $\quad 0$ to $95 \%$ RH non-condensing

\section{KMC Controls, Inc.}

19476 Industrial Drive, New Paris, IN 46553

574.831 .5250

www.kmccontrols.com; info@kmccontrols.com 


\section{STE-1400 Series Temperature Sensors}

\section{Descriptions and Applications}

STE-1400 Series 10,000 ohm, Type III thermistor, temperature sensors are available in different housings for surface, duct, duct averaging, immersion, strap-on, and outside air applications. All probes are constructed to provide good heat transfer and fast response. The averaging sensors are available in both plenum-rated cable or with a copper probe.

Each STE-1401/1402/1404/1405/1405 duct sensor is encapsulated in a 1/4-inch OD stainless-steel probe. The probe protrudes from the bottom of the sensor housing (if included), minimizing lead-length error. The probe can be inserted directly into the duct for single-point monitoring, and mounting holes are provided to rigidly support the assembly.

An STE-1411/1412/1413/1414/1415/1416/1417 averaging duct sensor incorporates numerous sensors inside a copper tube and is available in a 5/16-inch OD bendable copper probe or in a flexible plenumrated cable. The completed assembly acts as a single sensor and any temperature change is averaged across the sensor. The probes can be bent to fit any size duct.

An STE-1421/1422 immersion sensor is encapsulated in a 1/4-inch OD 304 stainless-steel probe. The probe protrudes from the bottom of the sensor housing, minimizing lead length error. The probe has a 1/2-inch NPT fitting to be screwed into the HMO4533/4543 brass well or HMO-4534/4544 stainlesssteel well.

The STE-1455 strap-on sensor is encapsulated in a two-inch-long, 1/4-inch OD stainless-steel probe. The probe has a five-foot lead wire. The STE-1454 strapon sensor also comes with an enclosure.

The STE-1451 outside air sensor is mounted in a weatherproof gasketed enclosure with a sun shield for protection against the outdoor elements. It comes with an LB c/w 1/2" NPT fitting for connection to conduit.

The STE-1430 room sensor, designed for temperature measurement of occupied spaces, can be mounted on an interior hollow wall in a standard singlegang electrical box. The sensor is mounted behind a flat brushed stainless-steel plate.

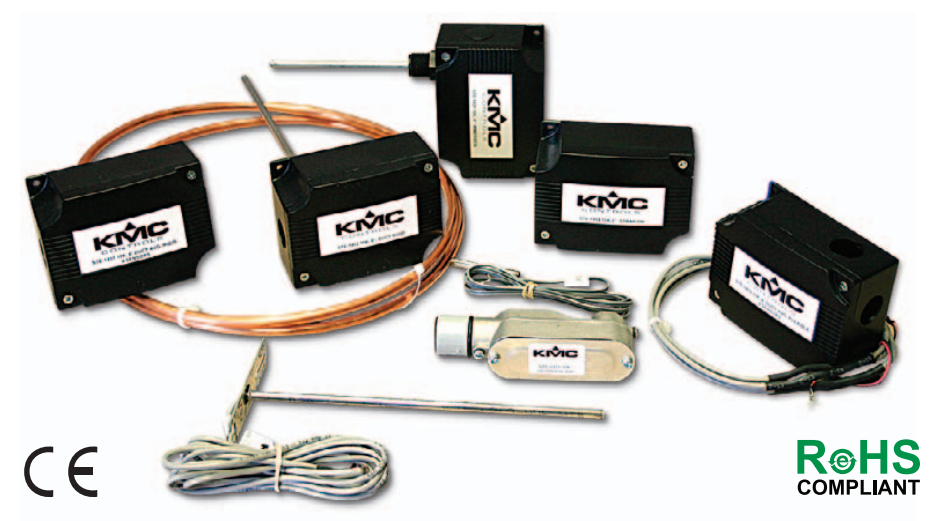

Features

- Type III 10,000 ohm thermistor encapsulated temperature sensors.

- Available in a number of models to accommodate various installation applications.

- Some models are available in either a black ABS plastic utility box or optional metal enclosure.

\section{Models}

STE-1401

STE-1402

STE-1404

STE-1405

STE-1411

STE-1412

STE-1413

STE-1414

STE-1415

STE-1416

STE-1417

STE-1421

STE-1422

STE-1430

STE-1451

STE-1454

STE-1455 8-inch Duct Rigid (w/ 10-ft. plenum-rated cable and w/o enclosure)

8-inch Duct Rigid (w/ 5-ft. nonplenum-rated cable)

12-inch Duct Rigid

4-inch Duct Rigid (w/o enclosure)

6-ft. Duct Averaging (copper)

12-ft. Duct Averaging (copper)

24-ft. Duct Averaging (copper)

20-ft. Duct Averaging (copper)

6-ft. Duct Averaging (flexible)

12-ft. Duct Averaging (flexible)

24-ft. Duct Averaging (flexible)

4-inch Immersion (without well)

6-inch Immersion (without well)

Room, Flat Plate

Outside Air

2-inch Strap-On

2-inch Strap-On (w/o enclosure) 


\section{Specifications}

\section{Sensor}

Type III thermistor, $10 \mathrm{~K}$ ohm @ $77^{\circ} \mathrm{F}\left(25^{\circ} \mathrm{C}\right)$

Accuracy $\pm 0.36^{\circ} \mathrm{F}\left( \pm 0.20^{\circ} \mathrm{C}\right)$

Temperature Limits

Std. Limits:
Outdoor Air only: -4 to $221^{\circ} \mathrm{F}$ ( -20 to $105^{\circ} \mathrm{C}$ )

Wiring

Mfg. Process

-40 to $221^{\circ} \mathrm{F}\left(-40\right.$ to $\left.105^{\circ} \mathrm{C}\right)$ 22 AWG wire leads

ISO 9001 registered quality system

Regulatory

CE and RoHS Compliant

\section{Enclosure Ratings}

\begin{tabular}{|l|l|}
\hline STE-1451 OAT, Aluminum LB & NEMA 4 \& IP66 \\
\hline Other metal (steel) enclosures & NEMA 1 \& IP30 \\
\hline Rectangular ABS enclosures & NEMA 12 \& IP64 \\
\hline STE-1405, STE-1430, STE-1455 & (No Enclosure) \\
\hline
\end{tabular}

\section{Accessories}

For the STE-1421 and STE-1422, these thermowells and thermal compound are available:

HMO-4532

Thermal compound for wells, $1 \mathrm{oz}$.

HMO-4534

4" 304 Stainless-steel well

HMO-4544

NOTE: NPT Thread Size $=1 / 2 "$

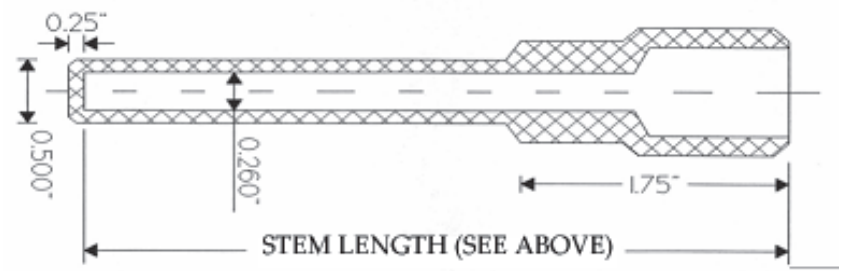

\section{Enclosures}

A black $3.3 \times 2.1 \times 4.55 "(84 \times 53 \times 116 \mathrm{~mm})$ ABS plastic utility box comes as the standard enclosure for these sensors:

STE-1402

STE-1403

STE-1404

STE-1411
STE-1412

STE-1413

STE-1414

STE-1421
STE-1422

STE-1454

To order the optional metal enclosure in place of plastic, add an $\mathrm{M}$ to the end of the part number. The steel enclosure is a $2 \times 4 " 1110$ handy box with wings that are 3-7/8" across. See, for example, the STE-1402M to the right.

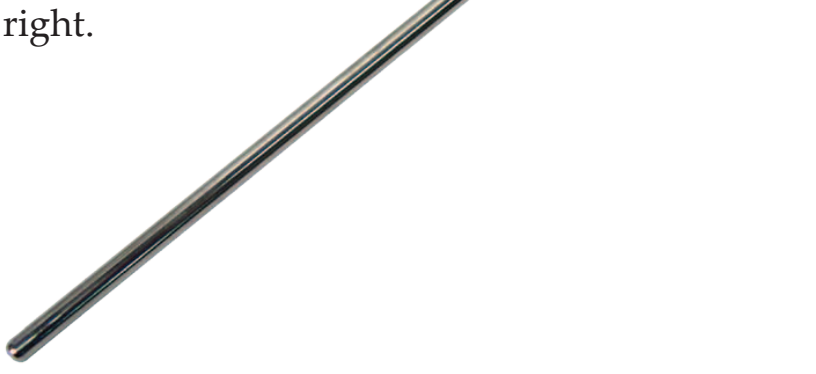

KMC Controls, Inc.

19476 Industrial Drive

New Paris, IN 46553

574.831 .5250

www.kmccontrols.com info@kmccontrols.com 


\section{XEE-6000 Series}

\section{Transformers}

\section{Description and Application}

XEE-6000 series transformers can be mounted using either the mounting base pad or the threaded hub(s). Models are available to provide power for UL Listed or UL Recognized applications. All XEE-6100 series transformers 75 VA and higher and all XEE-6300 series multi-tap transformers have a manual reset circuit breaker on the secondary output.

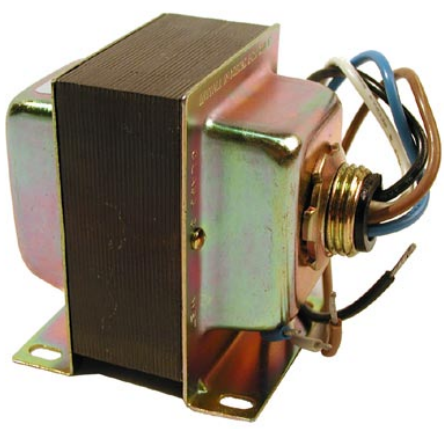

Models and Specifications

(Single hub shown above—specifications and design subject to change without notice)

\section{Model Selection Guide}

24 VAC Secondaries - all circuits are non-supervised and all secondaries (except for XEE-6111-150) are power limited

\begin{tabular}{|c|c|c|c|c|c|c|c|}
\hline Model \# & $\begin{array}{l}\text { Primary } \\
\text { Voltage }\end{array}$ & $\begin{array}{l}\text { Power } \\
\text { Rating }\end{array}$ & $\begin{array}{l}\text { Circuit } \\
\text { Breaker }\end{array}$ & $\begin{array}{c}\text { Threaded } \\
\text { Hub }\end{array}$ & $\mathrm{UL}^{*}$ & $\begin{array}{c}\text { Dimensions (w/o hubs) } \\
\text { (inches/millimeters) }\end{array}$ & $\begin{array}{l}\text { Mounting Hole } \\
\text { Dimensions }\end{array}$ \\
\hline XEE-6111-040 & \multirow{4}{*}{$\begin{array}{l}120 \mathrm{VAC} \\
60 \mathrm{~Hz}\end{array}$} & \multirow{2}{*}{$40 \mathrm{VA}$} & \multirow{6}{*}{ None } & Single & R C 2 & \multirow{2}{*}{$\begin{array}{c}2.7 \mathrm{~W} \times 2.9 \mathrm{H} \times 2.2 \mathrm{D} \\
(68.6 \times 73.7 \times 55.9 \mathrm{~mm})\end{array}$} & \multirow{2}{*}{$\begin{array}{c}2.0 \mathrm{~W} \times 1.8 \mathrm{D} \mathrm{D} \\
(50.8 \times 45.7 \mathrm{~mm})\end{array}$} \\
\hline XEE-6112-040 & & & & Dual & L C 2 & & \\
\hline XEE-6111-050 & & \multirow{5}{*}{$50 \mathrm{VA}$} & & Single & R C 2 & \multirow{2}{*}{$\begin{array}{l}2.8 \mathrm{~W} \times 2.9 \mathrm{H} \times 2.2 " \mathrm{D} \\
(71.1 \times 73.7 \times 55.9 \mathrm{~mm})\end{array}$} & \multirow{2}{*}{$\begin{array}{c}2.0 \mathrm{~W} \times 1.8 \mathrm{D} \\
(50.8 \times 45.7 \mathrm{~mm}) \\
\end{array}$} \\
\hline XEE-6112-050 & & & & Dual & L C 2 & & \\
\hline XEE-6211-050 & \multirow{2}{*}{$\begin{array}{l}277 \mathrm{VAC} \\
50 / 60 \mathrm{~Hz}\end{array}$} & & & Single & R C 2 & \multirow{2}{*}{$\begin{array}{l}2.8 \mathrm{~W} \times 2.9 \mathrm{H} \times 2.2^{\prime \prime} \mathrm{D} \\
(71.1 \times 73.7 \times 55.9 \mathrm{~mm}) \\
\end{array}$} & \multirow{2}{*}{$\begin{array}{c}2.0 \mathrm{~W} \times 1.8 " \mathrm{D} \\
(50.8 \times 45.7 \mathrm{~mm}) \\
\end{array}$} \\
\hline XEE-6212-050 & & & & Dual & L C 2 & & \\
\hline XEE-6311-050 & $\begin{array}{c}120 / 240 / 277 / 480 \\
\text { VAC 50/60 Hz }\end{array}$ & & \multirow{8}{*}{ Included } & Dual & L C 2 & $\begin{array}{c}3.5 \mathrm{~W} \times 3.1 \mathrm{H} \times 2.5 " \mathrm{D} \\
(88.9 \times 78.7 \times 63.5 \mathrm{~mm})\end{array}$ & $\begin{array}{c}1.9 \mathrm{~W} \times 2.0^{\prime \prime} \mathrm{D} \\
(48.3 \times 50.8 \mathrm{~mm})\end{array}$ \\
\hline XEE-6111-075 & \multirow{2}{*}{$\begin{array}{l}120 \mathrm{VAC} \\
60 \mathrm{~Hz}\end{array}$} & \multirow{3}{*}{$75 \mathrm{VA}$} & & Single & R C 2 & $\begin{array}{l}3.9 \mathrm{~W} \times 3.1 \mathrm{H} \times 2.5 " \mathrm{D} \\
(99.1 \times 78.7 \times 63.5 \mathrm{~mm})\end{array}$ & $\begin{array}{c}2.3 \mathrm{~W} \times 2.0^{\prime \prime} \mathrm{D} \\
(58.4 \times 50.8 \mathrm{~mm})\end{array}$ \\
\hline XEE-6112-075 & & & & Dual & L C 2 & $\begin{array}{l}3.9 \mathrm{~W} \times 3.1 \mathrm{H} \times 2.5 " \mathrm{D} \\
(99.1 \times 78.7 \times 63.5 \mathrm{~mm})\end{array}$ & $\begin{array}{c}2.3 \mathrm{~W} \times 2.0^{\prime \prime} \mathrm{D} \\
(58.4 \times 50.8 \mathrm{~mm})\end{array}$ \\
\hline XEE-6311-075 & $\begin{array}{c}120 / 208 / 240 / 480 \\
\text { VAC 50/60 Hz }\end{array}$ & & & Single & R C 2 & $\begin{array}{l}3.9 \mathrm{~W} \times 3.0 \mathrm{H} \times 2.5 " \mathrm{D} \\
(99.1 \times 76.2 \times 63.5 \mathrm{~mm})\end{array}$ & $\begin{array}{c}2.3 \mathrm{~W} \times 2.0^{\prime \prime} \mathrm{D} \\
(58.4 \times 50.8 \mathrm{~mm})\end{array}$ \\
\hline XEE-6111-100 & \multirow{2}{*}{$\begin{array}{l}120 \mathrm{VAC} \\
60 \mathrm{~Hz}\end{array}$} & \multirow{3}{*}{$96 \mathrm{VA}$} & & Single & R C 2 & \multirow{2}{*}{$\begin{array}{c}4.1 \mathrm{~W} \times 3.1 \mathrm{H} \times 2.5 " \mathrm{D} \\
(104.1 \times 78.7 \times 63.5 \mathrm{~mm})\end{array}$} & \multirow{2}{*}{$\begin{array}{c}2.5 \mathrm{~W} \times 2.0^{\prime \prime} \mathrm{D} \\
(63.5 \times 50.8 \mathrm{~mm})\end{array}$} \\
\hline$X E E-6112-100^{* *}$ & & & & Dual & $\begin{array}{c}\text { L C } 2^{2} \\
\text { UUKL }^{* *}\end{array}$ & & \\
\hline XEE-6311-100 & $\begin{array}{c}120 / 240 / 277 / 480 \\
\text { VAC 50/60 Hz }\end{array}$ & & & Dual & L C 2 & $\begin{array}{c}4.3 \mathrm{~W} \times 3.1 \mathrm{H} \times 2.5 " \mathrm{D} \\
(109.2 \times 78.7 \times 63.5 \mathrm{~mm})\end{array}$ & $\begin{array}{c}2.6 \mathrm{~W} \times 2.0^{\prime \prime} \mathrm{D} \\
(66.1 \times 50.8 \mathrm{~mm})\end{array}$ \\
\hline$X E E-6111-150^{* * *}$ & $\begin{array}{c}120 \mathrm{VAC} \\
60 \mathrm{~Hz}\end{array}$ & $150 \mathrm{VA}$ & & Single & $\mathrm{REC}^{* * *}$ & $\begin{array}{c}3.5 \mathrm{~W} \times 3.3 \mathrm{H} \times 3.8^{\prime \prime} \mathrm{D} \\
(88.9 \times 83.8 \times 96.5 \mathrm{~mm})\end{array}$ & $\begin{array}{c}2.5 \mathrm{~W} \times 3.2^{\prime \prime} \mathrm{D} \\
(63.5 \times 81.3 \mathrm{~mm})\end{array}$ \\
\hline
\end{tabular}

*UL Certification $\quad$ R C $2=$ UL Recognized Class 2

L C 2 = UL Listed Class 2

$\mathrm{UUKL}^{* *}=$ Approved for use in smoke control systems REC $^{* * *}=$ UL Recognized (not for use with Class 2 devices)

Configuration

Wiring

Weight
Split bobbin design, steel end bells 18 AWG leads, 7.5 to 9.5 " (191 to $241 \mathrm{~mm}$ ) long, stripped \& tinned 2.4 to $5.3 \mathrm{lbs}$. (1.09 to $2.4 \mathrm{~kg}$ )
(See Smoke Control Manuals 000-035-08 (BACnet) and/or 000-035-09 (KMDigital) for smoke control application information.)

\section{KMC Controls, Inc.}

19476 Industrial Drive

New Paris, IN 46553

$$
574.831 .5250
$$

www.kmccontrols.com; info@kmccontrols.com 
$\underline{\text { 3.3 Literature Review }}$ 
1. KMC Controls. "Understanding Building Automation and Control Systems". Archived from the original on 19 May 2013. Retrieved 27 March 2013.

2. "CEDIA Find: Cool Automation Integrates Smart Air Conditioners with ThirdParty Control Systems". CEPro. Retrieved 16 Jun 2015.

3. Dragoicea, M.; Bucur, L.; Patrascu, M. (2013). "A Service Oriented Simulation Architecture for Intelligent Building Management". Proceedings of the 4th International Conference on Exploring Service Science 1.3. LNBIP 143: 14-28. doi:10.1007/978-3-642-36356-6_2.

4. Asadullah, Muhammad (22 Dec 2016). "An Overview of Home Automation Systems". Conference Paper. IEEE. Retrieved 22 Dec 2016.

5. $\quad$ "Lighting control saves money and makes sense" (PDF). Daintree Networks. Retrieved 2009-06-19.

6. "About VAV". SimplyVAV. Retrieved 5 October 2015.

7. US Dept. of Energy, Pacific Northwest National Laboratory, Building Re-Tuning Training Guide: AHU Discharge-Air Temperature Control

8. TAYLOR ENGINEERING, Resetting Setpoints Using Trim \& Respond Logic

9. TRANE, Engineers Newsletter, Energy-Saving Control Strategies For Rooftop VAV Systems, Supply-Air-Temperature Reset. (Page 2, Column 2, Paragraph 1) Volume 35-4, ADM-APN022-EN (October 2006)

10. "Building Automation System Clawson Michigan Clawson Manor". Retrieved January 3, 2016.

11. Patrascu, M.; Dragoicea, M. (2014). "Integrating Services and Agents for Control and Monitoring: Managing Emergencies in Smart Buildings". Service Orientation in Holonic and Multi- Agent Manufacturing and Robotics. Studies in Computational Intelligence Volume 544: 209-224. doi:10.1007/978-3-31904735-5_14.

12. Intelligence, Critical (12 April 2014). "European researchers explore the possibility of BACnet botnets". Retrieved 4 September 2016.

13. Khera, Mandeep (1 September 2016). "Is IoT Security a Ticking Time Bomb?". /securityintelligence.com. Retrieved 4 September 2016.

14. Dickson, Ben (16 August 2016). "How to prevent your IoT devices from being forced into botnet bondage". techcrunch.com. Retrieved 4 September 2016. 
15. Wendzel, Steffen (1 May 2016). "How to increase the security of smart buildings?". Communications of the ACM. 59 (5): 47-49.

doi:10.1145/2828636. Retrieved 4 September 2016.

16. Granzer, Wolfgang; Praus, Fritz; Kastner, Wolfgang (1 November 2010). "Security in Building Automation Systems". IEEE Transactions on Industrial Electronics. 57 (11): 3622-3630. doi:10.1109/TIE.2009.2036033. Retrieved 4 September 2016.

17. Buckman, A. H., Mayfield, M., \& B.M. Beck, S. (2014). What is a Smart Building? Smart and Sustainable Built Environment, 3(2), 92-109. https://doi.org/10.1108/S ASBE-01-2014-0003

18. DDC Online. (n.d.). An Overview of Direct Digital Controls. Retrieved November 14, 2016, from http://www.ddc-online.org/Digital-ControlSystems/Introduction-to-Direct-Digital-Control-Systems.aspx

19. IEA. (2013). Transition to sustainable buildings: strategies and opportunities to 2050. Paris: International Energy Agency. Retrieved from http://www.iea.org/publications/freepublications/publication/Building2013

20. Brambley, M. (2013, April). Small- and Medium-Size Building Automation and Control System Needs: Scoping Study. Retrie ved from http://energy.gov/sites/prod/files/2013/12/55/emrgtech05_brambley_040213.pdf

21. Granderson, J., Piette, M. A., Rosenblum, B., \& Hu, L. (2011). Energy Information Handbook: Applications for Energy-Efficient Building Operations. Lawrence Berkeley National Laboratory, LBNL5272E. Retrieved from http://eis.lbl.gov/downloads/energy-information-handbook.pdf

22. Navigant Research. (2014). Commercial Building Automation Systems. Retrieved from http://www.navigantresearch.com/research/commercial-buildingautomation-systems

23. The Ultimate Guide to Building Automation. (2015, January 22). Retrieved October 24, 2016, from http://controlyourbuilding.com/blog/entry/theultimate-guide-to-building-automation

24. U.S. EIA. (2012). Commercial Building Energy Consumption Survey (CBECS) 2012. Washington, D.C: U.S. Energy Information Administration. Retrieved from https://www.eia.gov/consumption/commercial/data/2012/bc/pdf/b7.pdf 